INSTITUTO DE PESQUISAS ENERGÉTICAS E NUCLEARES

Autarquia associada à Universidade de São Paulo

\title{
AVALIAÇÃo ECOTOXICOLÓGICA E CARACTERIZAÇÃo QUÍMICA EM ÁGUAS SUPERFICIAIS DO RIO CUBATÃO, SP
}

\author{
LETÍCIA CRISTINA ALVES MESQUITA
}

Dissertação apresentada como parte dos requisitos para obtenção do grau de Mestre em Ciências na Área de Tecnologia Nuclear - Aplicações.

Orientadora:

$\operatorname{Prof}^{\mathrm{a}} \mathrm{Dr}^{\mathrm{a}}$ Sueli Ivone Borrely

São Paulo 
Dedico este trabalho aos meus pais Ana e Carlos e ao meu irmão Vinícius pelo amor, carinho, atenção, apoio e incentivo. 


\section{O que fazer?}

$\mathrm{O}$ ar negro,

a água suja,

árvores derrubadas!

peixes mortos,

pássaros desabrigados!

e o Homem?

Prisão em domicílio.

A sombra sobre a cidade.

$\mathrm{O}$ ar sendo degradado!

Vida artificial!

Preferem o computador!

Cadê o Homem que pode sentir dor?

Sentado em casa

Vendo televisão.

Enquanto o mundo acaba em um lixão...

Mundo de pouca vida

que vai embora pelo ralo da pia!

Falta de ar: sinto!

Cadê o ar puro e limpo?

O céu azul sobre mim já não posso ver

No lugar, fumaça negra,que em nada me deixa crer!

Na completa escuridão

a humanidade caminha para seu fim

Sem solução!

Maria Isadora Fernandes Braga 


\section{Agradecimentos}

Ao IPEN - Instituto de Pesquisas Energéticas e Nucleares e em especial a parceria ao CEPEMA - Centro de Capacitação e Pesquisa em Meio Ambiente - POLI/USP, por possibilitarem a realização deste trabalho.

Aos Institutos Nacionais de Ciências e Tecnologia - INCT.

A Fundação de Apoio a Universidade de São Paulo (FUSP) pela concessão da bolsa.

À Dr ${ }^{\text {a }}$ Sueli Ivone Borrely, minha orientadora, pelas contribuições para minha vida profissional e pessoal.

Ao Coordenador do CEPEMA, Prof. Dr. Cláudio Augusto Oller do Nascimento, Poli/USP pelo total apoio ao Projeto.

Ao Dr Antônio Ésio Bresciani, ex-coordenador administrativo do CEPEMA.

Ao Secretario do Meio Ambiente do município de Cubatão e autor do livro: Cubatão - Caminhos da História, Cesar Cunha Ferreira.

Ao Gestor do Parque Estadual da Serra do Mar - Núcleo Itutinga Pilões, Biol. Lafaiete Alarcon.

Aos companheiros do LEBA: Dymes, Vanessa, Gabriel, Alessandro, Anna, Rebeca, Reginaldo, Marcela, Natalia, Renata e Neto.

Ao doutorando Alessandro Pinheiro por todas as colaborações técnicas e discussões que enriqueceram o trabalho.

Aos bolsistas do CTR: Carla, João, Renata, Diego, Beatriz, Rodrigo, Mara, Clécia, Robson e Larissa.

Aos companheiros do CEPEMA: Déborah, Patricia, Érick, Alex, Mirian, Amanda, Alexandre, Euder, Luciano, Marcela, Ricardo, Ingrid, Louise, Stanley, Matheus, Murilo, Ellen, Cleide, Juliana, Paula, Rafaela, Fabiana e Regina. 
Aos técnicos do CEPEMA Déborah Cristina de Assis Freitas e Erick Henrique de Almeida pela ajuda nas coletas e apoio no laboratório.

Aos meus companheiros do GP2 - EPUSP: Alex, Eduardo, Gil, Laércio, Luiz, Maritza, Pia, Rafael, Regina e Ricardo.

As minhas Amigas Déborah Freitas, Déborah dos Anjos, Thaís Lotfi (Dehletha), Anna Vilarrubia, Carla Daruich, Lidiane Andrade, Patricia Bailhão, Carina Pitwak por todo companheirismo e momentos de descontração e alegria.

Aos meus grandes incentivadores a pesquisa: Dr. Camilo Seabra, Dr. Augusto César, Ms Fernando Cortez e Dr. Aldo Ramos Santo - Laboratório de Ecotoxicologia UNISANTA.

Agradeço aos meus avós Elza e Manoel, as minhas tias Mariluce e Lucimar e aos outros familiares pelas boas vibrações, incentivo e amor doado.

Agradeço à minha mãe Ana Lucia, meu pai Carlos e meu irmão Vinícius por todo amor, carinho, compreensão e dedicação, no decorrer deste trabalho e durante toda minha vida.

Finalmente agradeço a Deus por todas as bênçãos em minha vida. 


\title{
AVALIAÇÃO ECOTOXICOLÓGICA E CARACTERIZAÇÃO QUÍMICA EM ÁGUAS SUPERFICIAIS DO RIO CUBATÃO, SP
}

\author{
Letícia Cristina Alves Mesquita
}

\begin{abstract}
RESUMO
Ambientes dulcícolas ocupam uma pequena parcela da superfície do planeta comparada aos ambientes marinhos e terrestres, porém são de suma importância para diversas atividades humanas e essenciais à manutenção da vida. Por estarem localizadas próximas a áreas urbanizadas passam a servir como corpos receptores de efluentes domésticos e até industriais. A cidade de Cubatão, SP, abriga um importante pólo industrial do país, sendo o rio Cubatão o corpo receptor principal de efluentes domésticos e industriais. O rio Cubatão é o principal da região e abastece quase toda a Baixada Santista juntamente com o rio Pilões. A intenção deste presente trabalho é evidenciar as fontes de contaminação do Rio Cubatão, por meio da literatura e de resultados de efeitos ecotoxicológicos (crônico e agudo) determinados em águas superficiais, utilizando os organismos Ceriodaphnia dubia e Vibro fischeri, respectivamente. Forte esforço foi aplicado a fim de quantificar os surfactantes (princípio ativo de detergentes) e outros contaminantes de interesse que permitam estabelecer a relação causa-efeito da toxicidade. Para as análises químicas e biológicas foram coletadas águas superficiais em cinco pontos do rio Cubatão, 2 pontos nos canais de Fuga da Usina Henry Borden e um ponto nos rios Pilões e Perequê. Os ensaios realizados com $V$. fischeri possibilitaram identificar toxicidade em todos os pontos amostrais, entre as cinco campanhas, cujos valores variaram entre $\mathrm{CE}(\mathrm{I}) 5025,98 \%$ e $61 \%$. Os resultados obtidos com C. dubia, tratados pelo Teste "t por bioequivalência", mostraram toxicidade nos pontos P0; P1; P3; P4; P5 e P6 na terceira campanha. Na segunda e terceira campanha, os valores médios para a reprodução de C.dubia variaram entre 2,9 a 12,6 neonatas, possível efeito observado para a espécie, já que estes valores estiveram abaixo de 15 organismos, número mínimo recomendado pela ABNT NBR 13373:2004 para C.dubia. Com relação à condutividade das águas, o valor médio de $774,18 \mu \mathrm{S} / \mathrm{cm}^{-1}$ foi determinado para o P5, sendo esta média significativamente maior em relação aos demais pontos, possivelmente associado a proximidade das salinas da Carbocloro S.A. Indústrias Químicas. O P5 apresentou valor médio de 74,68 mg/L para cloretos.Os valores de compostos fenólicos, na segunda e terceira campanha, variaram entre 0,05 e 3,62 mg/L, concentrações essas acima do estabelecido pelo CONAMA 357:2005, para rios de classe 1 e $2(0,003 \mathrm{mg} / \mathrm{L})$. Os valores médios de surfactantes aniônicos estiveram entre 0,01 e $0,04 \mathrm{mg} / \mathrm{L}$. Embora duas substâncias tenham sido empregadas na calibração do método (LAS) e (DSS), os resultados mostraram que não há diferença significativa na quantificação de surfactantes, pelo método (MBAS - methylene blue active substance - APHA, 2005) $\quad(p \leq 0,01)$. Em análise qualitativa foram identificados compostos aromáticos como tolueno, xileno, benzeno, etilbenzeno $\mathrm{e}$ diclorobenzeno, nos pontos amostrados em fevereiro de 2011.
\end{abstract}




\title{
ECOTOXICOLOGICAL ASSESSMENT AND CHEMICAL CHARACTERIZATION IN SURFACE WATERS OF CUBATÃO RIVER, SP
}

\author{
Letícia Cristina Alves Mesquita
}

\begin{abstract}
Freshwater environments occupy a small portion of the surface compared to marine and terrestrial environments, but are critical for many activities essential to maintaining human life. By being located close to urban areas they serve as receptors bodies and even industrial effluents. The city of Cubatão, SP, houses an important industrial center in the country. Cubatão river is an important receptor of sewage and industrial effluents. It is the principal river of the region and supplies almost all of Baixada Santista with the Pilões river. The intention of this paper is to highlight the sources of contamination for Cubatão, through literature and results of ecotoxicological effects (chronic and acute) to be determined in surface water bodies using Ceriodaphnia dubia and Vibro fischeri, respectively. Strong effort was applied to quantify surfactant (active ingredient of detergents) and other contaminants of interest for determining the cause-effect relationship of toxicity. For chemical and biological analysis surface waters of the Cubatão river were collected in five points, two points in the channels of Henry Borden Plant, one on the Pilões and Perequê river. Through tests using $V$. fischeri toxicity was identified in all nine sampling sites, whose values ranged from EC(I)50 25.98\% up to 60\%. The results obtained from $C$. dubia, using "t for bioequivalence" showed toxic effects at P0, P1, P3, P4, P5 and P6 , third campaign. Dring the second and third campaign, it was obtained 2.9 to 12.6 neonates of C.dubia, numbers interpreted as chronic effects once they were quite below 15 neonates, number recommended by Brazilian environmental agencies (ABNT NBR 13373:2004). Water conductivity was much higher at $\mathrm{P} 5,774.18 \mu \mathrm{S} / \mathrm{cm}^{-1}$, mean value, probably related to the salt source from Carbocloro SA Chemical Industries. Chlorides at P5 was $74.68 \mathrm{mg} / \mathrm{L}$, confirming the last statemente. Phenolic compounds varied from 0.05 to $3.62 \mathrm{mg} / \mathrm{L}$, which is above the recommended by CONAMA 357:2005 (0,003 $\mathrm{mg} / \mathrm{L})$. Anionic surfactants varied from 0,01 to $0,04 \mathrm{mg} / \mathrm{L}$. Although using two substances for internal method calibration (LAS) e (DSS), no statistically diference was obtained ( $p \leq$ 0,01) (MBAS - methylene blue active substance - APHA, 2005). Quantitative analysis reveled the following aromatic substances: toluene, xilene, benzene, ethylbenzene and dichlorobenzene, during February 2011 samplings.
\end{abstract}




\section{SUMÁRIO}

1. INTRODUÇÃ

1.1 Área de abrangência do projeto....................................................... 04

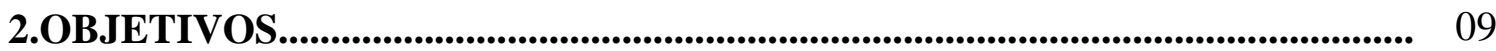

3. REVISÃO BIBLIOGRÁFICA............................................................................. 10

3.1 Cubatão uma cidade industrial......................................................... 10

3.2 Legislação para recursos hídricos...................................................... 19

3.3 Cubatão - Domínio Mata Atlântica..................................................... 20

3.4 Ecotoxicologia............................................................................... 23

3.5 Escolha do organismo-teste ............................................................ 25

3.6 Organismos-teste.......................................................................... 26

3.7 Qualidade das Águas e Índices relacionados...................................... 27

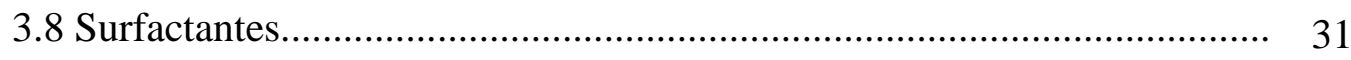

4. METODOLOGIA............................................................................................. 34

4.1 Procedimentos e locais da amostragem............................................. 34

4.2 Metodologias empregadas na determinação de parâmetros físico- 43 químicos em águas.

4.3 Determinação de surfactantes aniônicos................................................ 44

4.4 Determinação de cloretos em águas.................................................... 47

4.5 Determinação de fenol em águas.......................................................... 48

4.6 Determinação da Demanda Bioquímica de Oxigênio, $\operatorname{DBO}_{(5,20)}-49$ método respirométrico simplificado - OXITOP

4.9 Análise de compostos aromáticos......................................................... 50

4.10 Ensaios de toxicidade empregados no estudo................................... 50

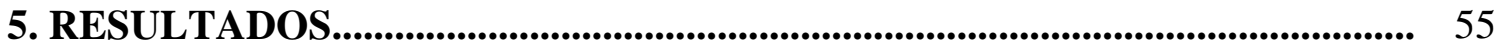

5.1 Resultados da caracterização química.................................................... 55

5.2 Avaliação ecotoxicológica................................................................ 68

5.3 Resultados de sensibilidade.............................................................. 73

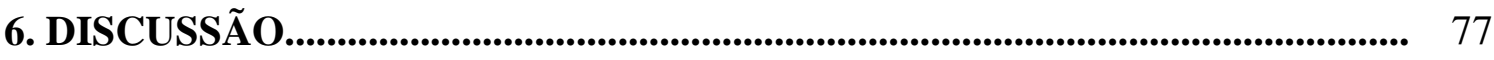

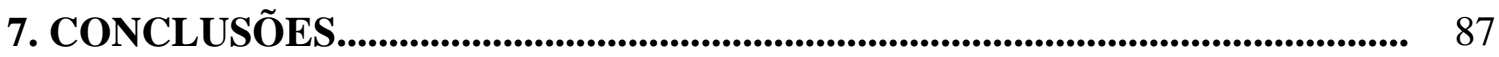

8. REFERÊNCIAS BIBLIOGRAFICAS................................................................. 88

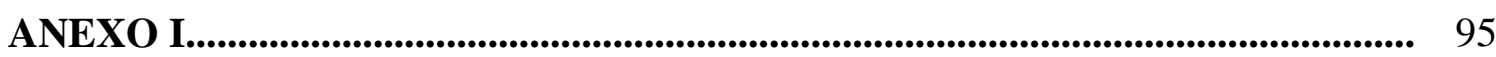




\section{LISTA DE FIGURAS}

FIGURA 1 - Intensidades de chuva mensais e anuais no Estado de São Paulo............ 05

FIGURA 2 - Mapa da Bacia Hidrográfica de Cubatão.............................................. 06

FIGURA 3 - Níveis de organização biológica e resposta aos efeitos de poluentes...... 25

FIGURA 4 - Porcentagem de efeitos tóxicos entre 2004 e 2009, no estado de São Paulo

FIGURA 5 - Valores percentuais para os ensaios ecotoxicológico com C. dubia....... 30

FIGURA 6 - Porcentagens de resultados não conformes com relação aos padrões estabelecidos para a Classe 2, em 2009.

FIGURA 7 - Modelos de agregados ...................................................................... 32

FIGURA 8 - Indicação dos pontos amostrados no Rio Cubatão (P0, P2, P4, P5 e P6); Canais de Fuga da UHB P1 e P3); no Rio Pilões (PI) e no Rio Perequê (PE)..... 37

FIGURA 9 - Rio Cubatão (P0), Ref. Estrada Caminho dos Pilões.............................. 38

FIGURA 10 - Canal de Fuga II - Usina Henry Borden (P1)................................. 38

FIGURA 11 - Rio Cubatão (P2) e ETA-3 - Estação de Tratamento de Água.............. 39

FIGURA 12 - Canal de Fuga I - Usina Henry Borden (P3).................................. 39

FIGURA 13 - Rio Cubatão (P4) - Ref. Hosp. Ana Costa e Cia Brás.de Estireno...... 40

FIGURA 14 - Rio Cubatão (P5) - Ref. salina da Carbocloro S.A. Ind. Quím............ 40

FIGURA 15 - Fotografia da salina da Carbocloro localizada em frente ao P5.......... 41

FIGURA 16 - Rio Cubatão (P6) - Refs. Ponte Rod. Côn. D. Rongoni e Barragem da Refinaria RPBC e da Fosfértil...............................................................................

FIGURA 17 - Rio Pilões (PI) - ref.Pq. Ecológico Itutinga Pilões - Antiga V. Itutinga....

FIGURA 18 - Rio Perequê (PE) - à jusante do Pq. Ecológico Perequê e da Ind. Petrocoque S.A

FIGURA 19 - Local onde esta localizado o ponto referência utilizado neste estudo, água utilizada para manutenção de cultivos e em ensaios de toxicidade com $C$. dubia.

FIGURA 20 - Separação da fase orgânica - método MBAS para surfactantes. aniônicos

FIGURA 21 - Curva de calibração do surfactante (LAS) em $625 \mathrm{~nm} . . . \ldots \ldots \ldots \ldots \ldots \ldots \ldots . . . . . . . . . .46$

FIGURA 22 - Curva de calibração do surfactante (DSS) em 652 nm....................... 46

FIGURA 23 - Fluxograma da análise de cloretos.................................................. 48

FIGURA 24 - Garrafas empregadas na determinação da DBO - OXITOP ${ }^{\circledR}$.............. 49 
FIGURA 25 - organismo-teste adulto de C.dubia

FIGURA 26 - células de V.fischeri evidenciando a bioluminescência.

FIGURA 27 - Sistema porta-amostra utilizado nos ensaios com C.dubia.

FIGURA 28 - Sistema Microtox utilizado na determinação de bioluminêscia da bactéria $V$. fischeri.

FIGURA 29 - variação de OD entre os pontos amostrados, por campanha................ 58

FIGURA 30 - variação dos valores de condutividade obtidos por campanha............ 58

FIGURA 31 - valores médios da condutividade por ponto...................................... 59

FIGURA 32 - variação do pH da água............................................................... 59

FIGURA 33 - variação da turbidez da água por campanha....................................... 60

FIGURA 34 - valores médios de turbidez da água por ponto de coleta...................... 60

FIGURA 35 - variação de valores de sólidos totais por campanha............................. 61

FIGURA 36 - valores médios obtidos para sólidos totais por ponto........................... 61

FIGURA 37 - variação dos valores obtidos para cloretos por campanha................... 63

FIGURA 38 - valores médios de cloretos por ponto amostrado................................ 63

FIGURA 39 - variação dos dados de $\mathrm{DBO}_{(5,20)}$ por campanha.................................. 64

FIGURA 40 - variação dos valores de carbono total por campanha........................... 64

FIGURA 41 - variação dos valores para carbono inorgânico total por campanha....... 65

FIGURA 42 - variação dos valores de carbono orgânico total por campanha.............. 65

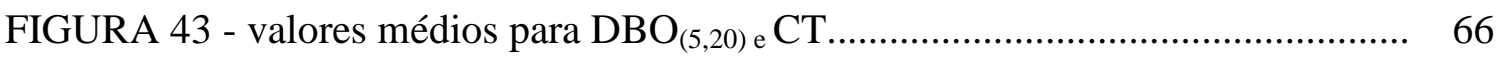

FIGURA 44 - variação da concentração de surfactantes, utilizando o (DSS) como substância de calibração do método analítico.

FIGURA 45 - variação da concentração de surfactantes, utilizando o (LAS) como substância de calibração do método analítico.

FIGURA 46 - valores médios da concentração de surfactantes, utilizando o (LAS) e o (DSS) como substância de calibração do método analítico $(p \leq 0,01)$.

FIGURA 47 - Média de neonatas obtidas durante exposição de C. dubia em 9 pontos amostrais (Rio Cubatão e seus contribuintes).

FIGURA 48 - Média de neonatas obtidas durante a exposição em sete dias (C.dubia) em todos as campanhas.

FIGURA 49 - Variação de $\mathrm{CE}\left(\mathrm{I}_{50}\right.$ em decorrência da exposição de $V$. fischeri às águas superficiais. 
FIGURA 50 - Médias obtidas durante exposição de $V$. fischeri às águas do Rio Cubatão e seus contribuintes (afluentes) 72

FIGURA 51 - Sensibilidade de $C$. dubia para substância referência - KCl................. 73

FIGURA 52 - Sensibilidade de V. fischeri para substância referência - Fenol............ 74

FIGURA 53 - Pátio de ônibus as margens do rio Cubatão (2352'33.00"S $\left.46^{\circ} 24 ' 47.86 " \mathrm{O}\right)$, localizado próximo ao P5 ............................................................... 76 


\section{LISTA DE TABELAS}

TABELA 1 - Produção dos principais segmentos industriais de Cubatão, em toneladas, para os anos 2004, 2008 e 2009.

TABELA 2 - Participação na produção nacional de 2009 em porcentagem de alguns produtos fabricados pelo pólo industrial de Cubatão.

TABELA 3 - Valores de classificação para fósforo total; clorofila-a e critérios para o IET.

TABELA 4 - Média Anual dos Índices de Qualidade das Águas - Relatórios de Qualidade das Águas Interiores (CETESB).

TABELA 5 - Posição geográfica dos locais amostrados com as principais referências utilizadas nas coletas de amostras de água.....

TABELA 6 - Metodologia empregada na realização dos ensaios de toxicidade.

TABELA 7 - Dados das análises físico-químicas para as campanhas do período de 2009 a 2011 e os valores referência estabelecidos pelo CONAMA 357/2005.

TABELA 8 - Faixa de valores determinados para oxigênio dissolvido, condutividade, $\mathrm{pH}$, turbidez e sólidos totais

TABELA 9 - Faixa de valores determinados para cloretos, $\operatorname{DBO}_{(5,20)}$, carbono total, carbono inorgânico total e carbono orgânico total....

TABELA 10 - Dados qualitativos das analises químicas realizadas com cromatografia gasosa em águas amostradas neste estudo

TABELA 11 - Resultados dos Testes Ecotoxicológicos utilizando Ceriodaphnia dubia em todas as campanhas

TABELA 12 - Valores de $\mathrm{CE}(\mathrm{I})_{50}$ obtidos para $V$. fischeri com intervalos de confiança

Tabela 13 - Análise estatística de correlação (r) entre os resultados obtidos das análises físico-químicas e dos ensaios de toxicidade

Tabela 14 - Variação de Hidrocarbonetos Policíclicos Aromáticos determinados em sedimentos do Rio Cubatão e contribuintes (afluentes). 


\section{INTRODUÇÃO}

A água é um bem de todos os povos e culturas e foi declarada pelas Organizações das Nações Unidas (ONU), como patrimônio do planeta, devendo ser plenamente assegurada por cada povo, nação, continente, cidade ou cidadão, garantindo seu uso para a presente e para as futuras gerações (SMA /CEA, 2010).

Segundo a Secretaria do Meio Ambiente (SMA), e a Coordenadoria de Educação Ambiental (CEA), a água ocupa 75\% da superfície da Terra. Cerca de 97,3\% é constituído de água salgada e apenas $2,7 \%$ de água doce. Estima-se que apenas $0,01 \%$ da água existente no planeta esteja disponível para consumo humano. O Brasil tem $12 \%$ aproximadamente de toda água doce do planeta. Porém a Região Norte do Brasil, com menor concentração populacional, possui $68,5 \%$ deste total, enquanto regiões mais habitadas possuem menor quantidade de água doce: Região Nordeste (3,3\%); Região Centro-Oeste (3,3\%); Região Sul (6,5\%); Região Sudeste (6,0\%), onde vivem $42 \%$ da população brasileira (SMA /CEA, 2008).

O termo água refere-se ao elemento natural, desvinculado de qualquer utilização. Por sua vez, o termo recurso hídrico é a consideração da água como bem econômico, passível de utilização com tal fim. Essas águas apresentam características de qualidade muito variadas, que lhes são conferidas pelos ambientes de origem, por onde circulam, percolam ou onde são armazenadas. Considerando a importância crescente da influência dos fatores antrópicos na qualidade das águas - formas de uso e ocupação do meio físico e das atividades sócio-econômicas o que torna necessário distinguir suas características naturais daquelas geradas pela ação do homem (REBOUÇAS et al, 2002).

Os Ambientes dulcícolas apesar de ocuparem uma pequena parcela da superfície do Planeta são de suma importância para as diversas atividades humanas essenciais a manutenção da vida. Alguns mananciais por estarem localizados próximos a áreas urbanizadas passam a servir como corpos receptores de efluentes domésticos e até industriais. Mananciais são corpos d'água, superficiais ou subterrâneos utilizados para abastecimento: nascentes, aquúferos, rios, lagos, córregos, riachos, reservatórios e represas são alguns exemplos de potenciais mananciais (SMA /CEA, 2010). 
Inúmeros problemas ambientais são enfrentados devido às modificações ambientais provocadas pela industrialização e aumento demográfico. Constantes cargas de efluentes, contendo uma variedade de substâncias tóxicas, são lançadas em recursos hídricos diariamente, provocando impactos substanciais e, conseqüentemente, colocando em risco a biodiversidade aquática e a saúde pública. O estudo dos efeitos adversos de agentes exógenos sobre sistemas biológicos ou organismos vivos, incluindo o homem, tem crescido e ganhado importância tanto no meio científico como no meio político, sobretudo devido aos possíveis riscos ambientais para os diferentes tipos de ecossistemas aquáticos (ALVES et al., 2004).

Segundo Rebouças (2002), os efeitos adversos podem ser causados pela presença de pequenas doses de compostos químicos na água: tóxicos (causa distúrbios em quaisquer sistemas biológicos, ou mortalidade); neurotóxicos (efeito destrutivo ou tóxico ao sistema nervoso); carcinogênicos (causa crescimento descontrolado de células anômalas); mutagênicos (causa alterações hereditárias no material genético das células) e teratogênicos (deformações congênitas não hereditárias (má formação) em organismos vivos.

Segundo a Organização Mundial de Saúde - OMS (2008) águas contaminadas são a principal causa de mortalidade mundial, sendo que a melhoria da água, saneamento, higiene e gerenciamento de recursos, tem o potencial de prevenir cerca de $9,1 \%$ das doenças ou $6,3 \%$ do total de óbitos. O total de $20 \%$ da mortalidade de crianças com até 14 anos em particular de países em desenvolvimento pode ser atribuída a falta de água potável e saneamento básicos. A diarréia é consequiência da morte de 1,4 milhões de crianças por ano; ocasionada principalmente pela ingestão de patógenos, por meio de alimentos contaminados, falta de água potável e higiene com as mãos. (PRÜSS- ÜSTÜN, 2008).

No Brasil, 28.700 pessoas morrem por ano de doenças decorrentes de problemas relacionados a água, saneamento e higiene. Número que corresponde a 2,3\% do total de mortes no país (SMA/CEA, 2010).

Em grandes cidades os investimentos para tornar a água própria para consumo serão cada vez mais altos e os mananciais utilizados cada vez mais raros. São necessários a racionalização do consumo de água, investimentos em tratamento de efluentes, o controle 
da ocupação populacional em áreas de mananciais, fiscalização e punição de indústrias poluidoras, novas ações para a conservação dos corpos hídricos, além do reuso da água (ROMANELLLI, 2004).

No Estado de São Paulo estão concentradas as principais atividades industriais do país. De acordo com o Relatório de Qualidade de Águas Interiores do Estado de São Paulo (CETESB) em 2009, a qualidade da água de abastecimento público é imprópria em $28 \%$ das amostras podendo estar associada aos agentes químicos de origem antrópica (industrial ou doméstica) ou à presença de algas. Em 2009, o percentual de tratamento dos esgotos domésticos, atingiu 49\%, porém não se constatou, por meio dos índices de qualidade de água, uma tendência de melhora na qualidade dessas águas (CETESB, 2009).

A cidade de Cubatão abriga um importante pólo industrial do Brasil, que é responsável por grande parte da poluição na Baixada Santista. O crescimento econômico promovido no local, com a instalação de inúmeras indústrias, sem qualquer preocupação com o aspecto ambiental e social, acabou gerando um contexto de degradação ambiental extremamente grave (LUIZ-SILVA, 2002). A ocupação dessa região ocorreu de forma inadequada, com a instalação descontrolada de fontes múltiplas de contaminação, gerando problemas sócio-econômicos, diminuição da balneabilidade das praias, desvalorização imobiliária, contaminação do pescado, entre outros (ABESSA \& SOUZA, 2005).

A intenção deste presente trabalho foi evidenciar as fontes de contaminação do Rio Cubatão, por meio da literatura e de resultados de efeitos ecotoxicológicos, determinados em águas superficiais. Forte esforço foi aplicado a fim de quantificar surfactantes (princípio ativo de detergentes) e outros contaminantes de interesse que permitam estabelecer a relação causa-efeito da toxicidade.

Visando à preservação da biodiversidade e a melhoria da qualidade das águas dos rios, a Legislação CONAMA 357/05, prevê a avaliação ecotoxicológica para o lançamento de efluentes em rios e avaliação da qualidade dos ambientes aquáticos (águas e sedimentos), permitindo, ainda, a classificação dos corpos d'água conforme o uso de suas águas.

Os ensaios ecotoxicológicos têm se consolidado como importante ferramenta para a compreensão dos impactos provocados por agentes químicos nas comunidades biológicas. 
Estes testes têm sido empregados no gerenciamento ambiental, manejo e monitoração de ambientes aquáticos, planejamento de política ambiental, criação de legislação referente a emissões de efluentes, cálculo de riscos ambientais e geração de informações vitais para o setor de vigilância da saúde pública (OLIVEIRA-NETO \& BOTTA-PASCHOAL, 2000). Além disso, fornecem informações adicionais sobre o perigo potencial de substâncias tóxicas ou das interações entre essas substâncias químicas sobre a biota aquática no ambiente impactado, pois acusam a biodisponibilidade (NUNES \& FONSECA, 2002; CETESB, 2009).

\section{1 Área de abrangência do projeto}

Cubatão situa-se na latitude $23^{\circ} 50^{\prime}$ a $23^{\circ} 55^{\prime}$ sul e na longitude $46^{\circ} 30^{\prime}$ oeste de Greenwich. Ocupa uma área de $148 \mathrm{~km}^{2}$ e situa-se a $57 \mathrm{~km}$ da capital paulista e a $16 \mathrm{~km}$ de Santos ou São Vicente. A distância entre os municípios de São Bernardo do Campo e Santo André é de aproximadamente $25 \mathrm{~km}$ (tendo como ponto de referência os limites municipais). Limita-se com os municípios de São Bernardo do Campo, Santo André, Santos e São Vicente. A cidade apresenta clima tropical atlântico (quente e muito úmido) o que potencializa extrema umidade. A umidade relativa do ar é superior a $80 \%$, o que se coaduna com a alta taxa pluviométrica: média anual de $2.541 \mathrm{~mm}$. A temperatura é variável com médias de $36^{\circ} \mathrm{C}$ máxima e $12^{\circ} \mathrm{C}$ mínimas (www.cubatao.sp.gov.br).

A região de Cubatão apresenta índice pluviométrico superior à média registrada em no Estado de São Paulo (1443 mm). O período de estiagem do Estado vai de abril a setembro, destacando-se o mês de agosto como mais seco (precipitações mensais inferiores a $100 \mathrm{~mm}$ ). O período úmido inicia de outubro a março, sendo janeiro o mês mais chuvoso, com média aproxima de $300 \mathrm{~mm}$. Em 2009 o índice pluviométrico esteve $26 \%$ maior do que a média histórica dos 14 anos anteriores $(1817 \mathrm{~mm}$ ) (Figura 1). No estado de São Paulo o período de seca corresponde de abril a setembro, enquanto o chuvoso situa-se entre março a setembro (CETESB, 2009). 


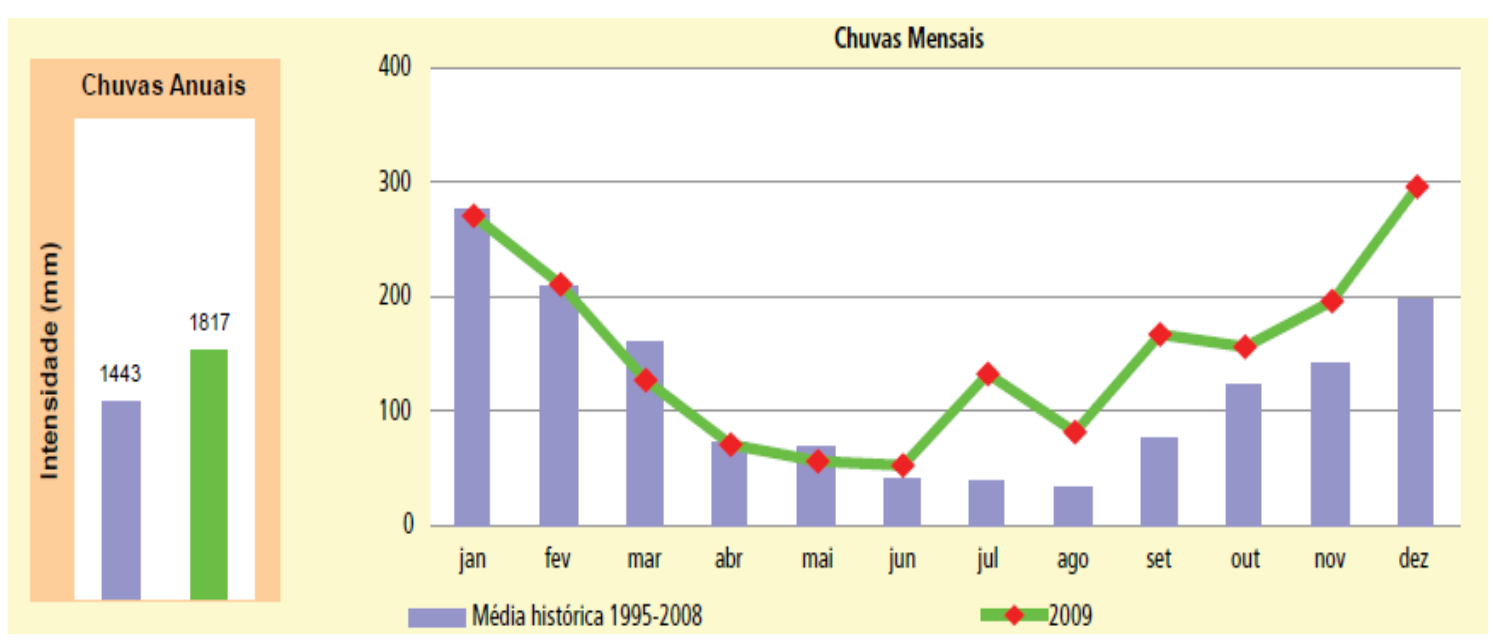

FIGURA 1 - Intensidades de chuva mensais e anuais no Estado de São Paulo (CETESB, 2009).

A cidade de Cubatão tem cerca de $62 \%$ de seu território de áreas protegidas (mata atlântica e manguezais) e conta com pouco mais de $28 \%$ para área urbana. De forma geral, a zona industrial estabeleceu-se entre o rio e a serra, enquanto a zona habitacional ficou entre o rio e estuário (CUBATÃO, 2006).

Devido à proximidade da Serra do Mar, os rios que banham Cubatão, podem ser definidos dois tipos de rios: em primeiro lugar, os que têm em comum o fato de suas nascentes serem na Serra do Mar e de possuírem vales que são sulcos importantes a separarem esporões. São rios que nascem torrenciais e se tornam, vencida a escarpa, rios de planície, responsáveis pela grande sedimentação fluvial que dificulta o escoamento das águas, dando então a formação de meandros, furados e dos manguezais. Exemplos desse tipo de rio são os rios Cubatão e Mogi. O segundo tipo compreende os rios de pequeno curso, praticamente de planície. Exemplos: rios Casqueiro, Cascalho, Mourão, Onça e outros. Esses rios percorrem trechos montanhosos, recebendo chuvas violentas, e, duas vezes por dia (em decorrência da maré), suas partes mais baixas entram em contato direto com a água salobra. Todos os rios com exceção do Mãe Maria, pertencem à bacia do Rio Cubatão, destacando-se os Rios Cubatão, Perequê, Perdido, Cascalho, Mãe Maria, Pilões, Rios das Pedras. Há ainda três braços do Mar; Casqueiro, Sant'Ana e Paranhos (Figura 2) (www.cubatao.sp.gov.br; FERREIRA et al, 2008; FERREIRA \& PASSERANI, 2005). 


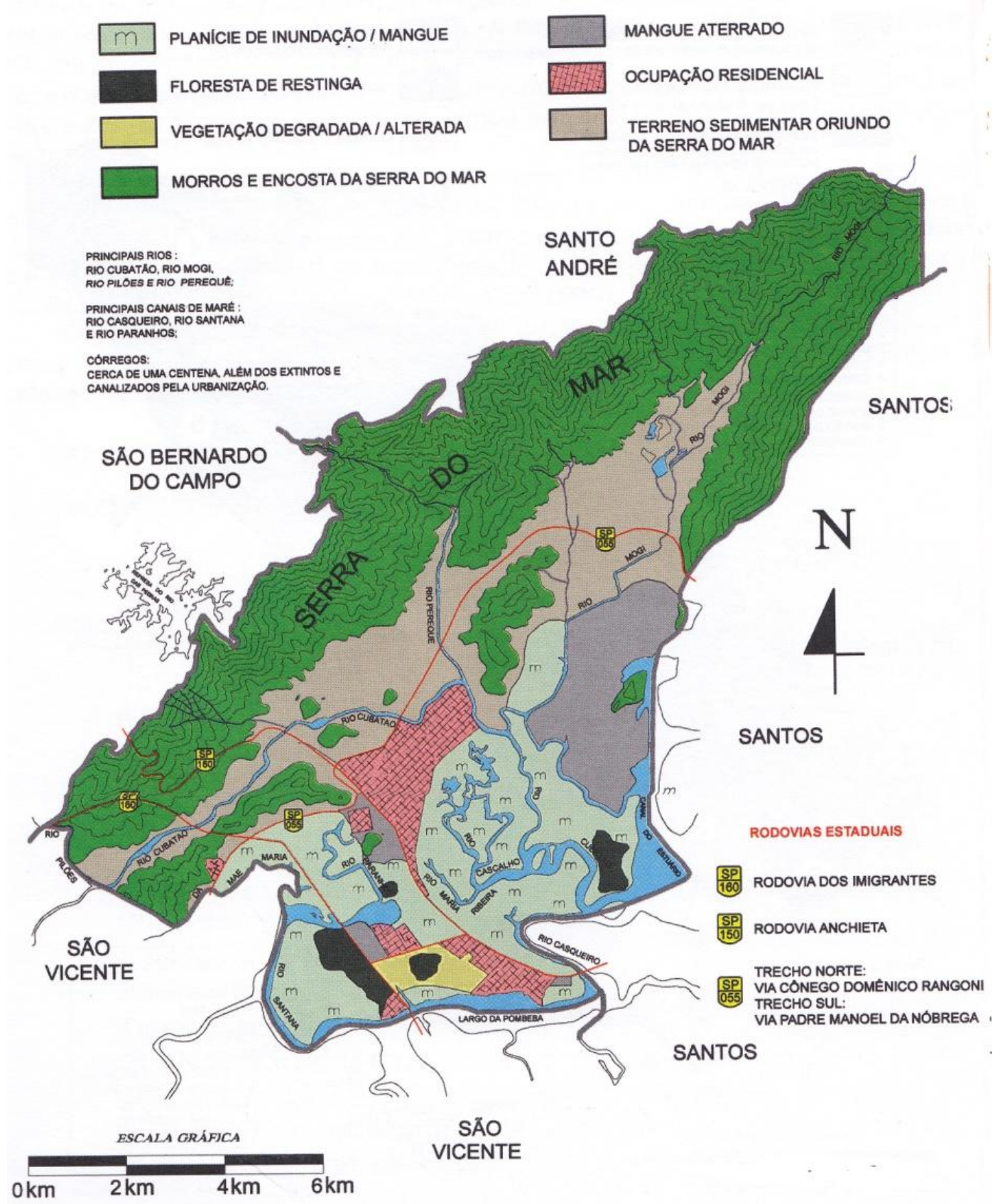

FIGURA 2 - Mapa da Bacia Hidrográfica de Cubatão (FERREIRA et al, 2008).

O Rio Cubatão é o mais importante da região, cuja bacia se situa parte na grande São Paulo e quase sua totalidade na Baixada Santista. Compõe uns dos rios dos estuários de santos. A bacia hidrográfica do rio Cubatão tem uma área de aproximada de $177 \mathrm{~km}^{2}$. O rio Cubatão nasce em São Bernardo, onde é conhecido por Cubatão de cima. Atravessa um pequeno trecho do município de São Vicente, pelo vale Itutinga-Pilões, e passa a banhar o município de Cubatão após receber, á margem esquerda, o rio Pilões. Descendo 
o rio, na mesma margem recebe o Rio das Pedras e o Rio Perequê, todos afluentes da margem esquerda descem a Serra do Mar.

Devido às freqüentes enchentes que ocorreram no município, na década de 60 , o rio foi retificado no trecho urbano e dragado com o intuito de aumentar a profundidade da calha natural e escoamento. A obra foi executada pelo DAEE (Departamento de Água e Energia Elétrica) em 1970. Sendo que o rio Capivari, foi o principal afluente da margem direita, hoje está canalizado (FERREIRA et al, 2008; FERREIRA \& PASSERANI 2005).

O Rio Cubatão juntamente com Rio Pilões abastecem as cidades de Cubatão, Santos, São Vicente e parte de dos municípios de Praia Grande e Guarujá, responsáveis por cerca de $80 \%$ do abastecimento da Baixada Santista. Há duas estações de tratamento: ETA-3, com capacidade de 4500 litros por segundo, e ETA-Pilões, com capacidade de 600 litros por segundo (CUBATÃO, 2006). Essa água retirada do Rio Cubatão com o auxilio de uma barragem sub-álvea localizada a 1100 metros a montante dos Canais de Fuga da Usina Henry Borden (FERREIRA \& PASSERANI, 2005).

Nesta área de estudo estão localizados alguns bairros de Cubatão que estão inseridos no programa de desocupação da Serra do Mar e no Projeto Onda Limpa, que visa aumentar a rede de tratamento de esgoto para aproximadamente 95\%. Muitos trabalhos realizados na Baía de Santos apontam o Rio Cubatão como sendo uma das principais fontes de poluição. Sua bacia de drenagem cobre uma área de aproximadamente 27.000 $\mathrm{km}^{2}$ e recebe grande carga de efluentes industriais e domésticos, além de uma contribuição de parte do esgoto de São Paulo através da Usina Henry Borden (CUBATÃO, 2006).

Cubatão tem população total de 129.582 e $36 \%$ de esgoto coletado e tratado com $70 \%$ de eficiência, sendo que o Rio Cubatão é seu corpo receptor. Seu ICTEM - Indicador de Coleta e Tratabilidade de Esgoto da População Urbana de Município é de $(3,9)$. Este índice calculado segundo Resolução SMA-070 (2009) almeja retratar uma medida além da efetiva remoção da carga orgânica, em relação à carga orgânica potencial, gerada pela população urbana, sem deixar de levar em consideração, a coleta, o afastamento e o tratamento dos esgotos, bem como o atendimento à legislação quanto à eficiência de remoção (superior a $80 \%$ da carga orgânica) e respeito aos padrões de qualidade do corpo receptor dos efluentes (CETESB, 2009). 
A maioria dos bairros periféricos de Cubatão não possuem tratamento de esgoto, colocando em risco a saúde pública onde a incidência de verminoses, hepatite e leptospirose. Existem muitas áreas de invasão em pleno crescimento no município, como exemplo os bairros Cota, Água Fria e Pilões com mais de 20 mil habitantes, sem rede de esgoto e despejando o material in natura no Rio Cubatão, antes da captação de água da Cia de Saneamento Básico do Estado de São Paulo (SABESP). Desde 1950 a cidade apresenta um elevado crescimento demográfico, com média de crescimento de 2,7\% entre 1996 a 2000 (FERREIRA et al, 2008). 


\section{OBJETIVOS}

Este trabalho tem como objetivos:

Determinar parâmetros físico-químicos como oxigênio dissolvido, $\mathrm{pH}$, condutividade, turbidez; surfactantes aniônicos, cloretos, fenóis totais, demanda bioquímica de oxigênio, carbono total, carbono inorgânico total e carbono orgânico total e alguns compostos aromáticos nas águas superficiais do rio Cubatão e seus contribuintes (afluentes);

Avaliar a toxicidade aguda e crônica em águas superficiais do Rio Cubatão e seus contribuintes (afluentes), utilizando os ensaios com Vibrio fischeri e Ceriodaphnia dubia, respectivamente;

Correlacionar causa-efeito de toxicidade e evidenciar fontes de contaminação do rio Cubatão (fontes pontuais e difusas);

Analisar possíveis interferências na toxicidade do rio Cubatão por seus contribuintes (afluentes); rio Pilões; rio Perequê e canais de fuga da Usina Henry Borden. 


\section{REVISÃO BIBLIOGRÁFICA}

\subsection{Cubatão uma cidade industrial}

Durante o auge da Era Industrial, Cubatão chegou a ser considerada a cidade mais poluída do mundo, segundo Organização mundial da saúde, sendo conhecida como Vale da Morte (FERREIRA \& PASSERANI, 2005).

A escolha da região de Cubatão para o estabelecimento de indústrias se deu pela sua posição geográfica privilegiada e a proximidade com o porto de Santos e a capital, obtenção de energia abundante e barata, além das condições favoráveis do sistema rodoviário e ferroviário (FERREIRA et al, 2008).

Os primitivos engenhos de açúcar, característicos da economia colonial, registram a primeira atividade industrial do município. Muito depois, os curtumes ganharam importância, representando a fase primária da industrialização na região, utilizando o tanino, extraído das folhas dos mangues e, mesmo, vendendo a lenha (FERREIRA et al, 2008). Entre 1951 e 1977, deu-se a consolidação do pólo industrial, neste período entram em operação 24 empresas de ramos industriais variados (FERREIRA \& PASSERANI, 2005).

A Cia. Curtidora Max teve suas atividades iniciadas em 1912; maior estabelecimento desse tipo no Brasil, mais tarde adquirida pela Costa Muniz, que variou seu ramo de produção para a confecção de cintos de couro, mangueiras, fios para tecido, correias e corda de couro curtido para exportação. Em 1981, a Costa Muniz teve sua falência decretada (FERREIRA et al, 2008).

Construída a antiga Química em 1915 e começando a funcionar em 1916, teve como fundador J.B. Duarte, com o nome específico de Fábrica de Anilinas e Produtos Químicos do Brasil. Em 1941, porém, passa a chamar-se Companhia de Anilinas, Produtos Químicos e Material Técnico. Entra em falência em 1965 (FERREIRA et al, 2008).

Em 1903 A CIA. Santista de Papel foi à terceira indústria a se instalar na cidade. A proximidade do Porto de Santos, a grande quantidade de água de boa qualidade (essencial para a fabricação de papel) proveniente do rio Cubatão e o potencial hidrelétrico do mesmo (quedas d'águas e vale encaixado propício para represamento) contribuíram na escolha da 
localização. A fábrica localiza-se na entrada do vale do rio Cubatão, na margem esquerda. Em 1919, a empresa construiu sua própria usina hidrelétrica, na margem direita do rio, situada no extremo oposto do vale (próximo à nascente). A usina possuía a capacidade de 2300 volts (FERREIRA et al, 2008).

Devido à distância de 14 quilômetros entre a hidrelétrica e a Fábrica de Papel, foi implantada uma pequena ferrovia. Utilizavam também uma linha férrea existente da Cia. City de Santos (entre a região de Itutinga ou Cubatão de Cima e a estação ferroviária de Cubatão). Por essa linha chegava a matéria-prima importada diretamente do Porto de Santos e era escoada parte da produção da fábrica. As pontes ferroviárias que atravessavam mais de uma vez o rio Cubatão, serpenteando o vale, foram destruídas pelo tempo e pela força fluvial. A única que se mantém conservada é a Ponte Preta. A linha serviu também para o escoamento da produção de banana vinda dos Pilões e Vale Verde, atividade bastante significativa na época (FERREIRA et al, 2008).

Em razão do racionamento de combustível no Brasil, causado pela Segunda Guerra, a empresa iniciou um grande desmatamento das encostas da Serra situadas entre a hidrelétrica e a fábrica, usando a lenha como combustível para suas caldeiras. Devido à interrupção da importação de celulose, a Cia. Santista de Papel, em 1947, decidiu produzir sua própria celulose, plantando um milhão de pés de eucaliptos nas áreas desmatadas. Entretanto o projeto de auto-suficiência de matéria-prima não vingou, os eucaliptos introduzidos são encontrados até hoje em grande quantidade na região do vale (FERREIRA et al, 2008).

Em 1967, o grupo Ripasa S/A - Celulose e Papel comprou a Cia. Santista de Papel. Em 2004, a Companhia foi comprada pelo Grupo Votorantim. Em 2007, foi adquirida pela empresa MD Papéis. Atualmente, sua capacidade de produção é de 55.000 toneladas/ano (papéis para impressão e escrita, papéis especiais e cartolinas (FERREIRA et al, 2008).

Cronologia Industrial de acordo com Ferreira et al, (2008):

- Em 1953, instituiu-se o monopólio do petróleo no Brasil, e a consequente criação da Petrobras. Com o início de suas operações em 1955, a Refinaria Presidente Bernardes de Cubatão (RPBC) representou um impacto considerável, desencadeando o processo industrial na cidade por atrair as indústrias de derivados de petróleo - as petroquímicas. 
- Em 1956, a primeira transnacional petroquímica a entrar em operação foi a Alba S/A Indústrias Químicas que até o seu fechamento em 1992, supriu de uma vasta linha de produtos como metanol, formol e resinas;

- Em 1957, às margens do rio Cubatão, entrou em funcionamento a Companhia Brasileira de Estireno (CBE), primeira fábrica de estireno do hemisfério sul, e que utiliza matériaprima (benzeno e eteno) da RPBC.

- Em 1958, foi a inaugurada a Fábrica de Fertilizantes de Cubatão (Fafer). Em 1969 foi transferida para a Petroquisa S/A. Em 1977 foi incorporada à Ultrafértil, também pertencente à Petroquisa. Foi privatizada em 1993 e no ano de 2004 passou a ser denominada Fosfértil;

- Em 1958, é criada a Companhia Petroquímica Brasileira - Copebrás. Pioneira na produção de "negro de fumo" (também chamado de pó de asfalto), utilizado na confecção de pneus, artefatos de borracha e tintas;

- Em 1958, a Fibrastec - Comércio, Indústria e Importação Ltda. iniciou suas atividades, produzindo mantas de sisal para estofamento em geral, complementando as necessidades industriais de Cubatão;

- Em 1958, a Union Carbide do Brasil S/A Indústria e Comércio, adquirida pela Dow Química, entrou em funcionamento, sendo a primeira unidade a produzir polietileno na América Latina, utilizando como matéria prima o etileno da Petrobras.

- Em 1963, houve a consolidação do processo industrial com o início das operações da Cia. Siderúrgica Paulista (Cosipa). A empresa estatal foi vendida para a iniciativa privada em agosto de 1993. Em 2005, a Cosipa deu início a um processo de expansão da capacidade produtiva com a inauguração de outra unidade da Aciaria (fabricação de aço), chegando à marca de 4,5 milhões de toneladas de aço por ano. O Plano de Expansão anunciado pelo Sistema USIMINAS (grupo ao qual pertence a Cosipa) indica a implantação de uma nova linha de Laminação a Quente, modernização da Máquina de Lingotamento Contínuo 3 e reforma do Alto Forno 1;

- Em 1964, a Carbocloro S/A Indústrias Químicas iniciou suas atividades. Atualmente, a empresa é líder no fornecimento de cloro para o tratamento de água no Brasil. É controlada pela empresa brasileira Unipar e pela norte-americana Occidental Chemical Corporation (Oxychem). Seus produtos: cloro, soda, ácido clorídrico, hipoclorito de sódio e dicloretano são componentes fundamentais para fabricação de papel, sabões, medicamentos, plásticos, alumínio, alimentos, bebidas, tecidos entre outros; 
- Em 1966, a Clorogil S/A iniciou suas atividades no município e em 1976 foi incorporada à Rodhia Indústrias Químicas e Têxteis S/A. Produzia solventes, clorados e pentaclorofenato;

- Em 1968, a antiga fábrica de Cimento Santa Rita, hoje pertencente às Indústrias Votorantin S/A, começou sua produção;

- Fundada em 1968 e inaugurada em 1970, a Ultrafértil S/A Indústria e Comércio de Fertilizantes é considerada uma das maiores indústrias de fertilizantes da América Latina, hoje pertencente ao grupo Fosfértil.

- Em 1970, a empresa Liquid Carbonic Indústrias S/A se instalou na cidade para produzir gás carbônico;

- Em 1971, a Oxiteno S/A - Indústria foi instalada no pólo cubatense para produzir Cloreto de Amônia utilizado em eletrólitos de pilhas secas, como agente de fixação para revestimento com zinco, fluxo de solda (para remover camada de óxido dos metais a soldar), fertilizantes para arroz, em colas para compensados de madeira entre outros;

- Em 1972, a Liquid Química S/A se instalou em Cubatão para produzir ácido benzóico e ácido benzóico farmacêutico;

- Ainda em 1972, a Solorrico S/A - Indústria e Comércio teve suas atividades iniciadas para a produção de fertilizantes. Posteriormente, foi incorporada pela Cargill;

- Em 1973, a Engebasa - Mecânica e Usinagem S/A iniciou suas atividades, produzindo peças metálicas sob encomenda (caldeiraria), além de serviços de manutenção de equipamentos industriais, soldas e revestimentos, alívio de tensões e montagem industrial;

- Em 1974, a Hidromar Produtos Químicos Ltda. foi instalada para produzir hipoclorito de sódio e cloro gás;

- Em 1975, a Petrocoque iniciou suas atividades, a partir da decisão da Petrobras de produzir coque verde, a Petrocoque S/A começou sua construção em 1972 para transformar este coque em coque de petróleo calcinado;

- Também em 1975, a I.A.P. S/A Indústria Agro-Pecuária iniciou produção de fertilizantes químicos para a lavoura. Foi vendida nos anos 90 para a norte-americana Bunge Fertilizantes S/A;

- Em 1976, a Gespa - Gesso Paulista Ltda. Começou a produzir gesso retardante e gesso fertilizante;

- Em 1977, a Manah S/A Indústria e Comércio, começou a produzir fertilizantes, posteriormente foi incorporada também à Bunge. 
- Em 1989, AGA S/A instalou-se e passou a produzir oxigênio, nitrogênio e argônio.

- Em 1997, a antiga Adubos Trevo foi incorporada à IFC - Indústrias de Fertilizantes de Cubatão.

Atualmente os principais segmentos industriais de Cubatão conforme os Relatórios Anuais do Pólo Industrial de Cubatão estão descritos na Tabela 1.

TABELA 1 - Produção dos principais segmentos industriais de Cubatão, em toneladas, para os anos 2004, 2008 e 2009.

\begin{tabular}{c|c|c|c}
\hline Segmentos & $\mathbf{2 0 0 4}$ & $\mathbf{2 0 0 8}$ & $\mathbf{2 0 0 9}$ \\
\hline Petroquímica & 6254 & 8664 & 8747 \\
Fertilizantes & 4295 & 4468 & 3991 \\
Siderúrgica & 3767 & 3388 & 2760 \\
Química & 1560 & 1175 & 1219 \\
\hline
\end{tabular}

Anual Segundo o Relatório do Pólo Industrial de Cubatão (2009), a participação na produção nacional das industrias de Cubatão, para grupos de produtos, estão apresentadas na Tabela 2.

TABELA 2 - Participação na produção nacional de 2009 em porcentagem de alguns produtos fabricados pelo pólo industrial de Cubatão.

\begin{tabular}{c|c}
\hline DAP - Fosfato Di Amônio & $100 \%$ \\
Gasolina de Aviação & $100 \%$ \\
Monômero de Estireno & $100 \%$ \\
Nitrato de Amônio & $100 \%$ \\
Nitrato de Amônio de Baixa Densidade (Ultrapril) & $100 \%$ \\
Solventes Aromáticos & $100 \%$ \\
Hexano & $85 \%$ \\
Ácido Clorídrico & $80 \%$ \\
Cloreto de Amônio & $77 \%$ \\
Ácido Nítrico & $76 \%$ \\
Coque de Petróleo Calcinado & $75 \%$ \\
Hipoclorito de Sódio & $60 \%$ \\
Aços Planos & $47 \%$ \\
Coque de Petróleo & $40 \%$ \\
Oleum & $28 \%$ \\
MAP - Fosfato Mono-Amônio & $25 \%$ \\
Aço Bruto & $24 \%$ \\
\hline
\end{tabular}


No município de Cubatão, tal como ocorreu com a qualidade do ar, as águas superficiais sofreram sérios danos durante as décadas de 60 a 80, com períodos críticos de 70 a 80. A contaminação das águas superficiais produziu acentuada redução de oxigênio dissolvido nas águas dos principais rios da região, impedindo a sobrevivência dos peixes e outros organismos aquáticos (CUBATÃO, 2006).

A partir de 1985 um esforço conjunto feito pela comunidade, administração municipal e Governo do Estado, e também da CETESB, em dez anos foi possível reduzir 92\% das 320 fontes da poluição do ar com a implantação de um rigoroso programa de despoluição (FERREIRA \& PASSERANI, 2005). Durante a década de 90, deu-se continuidade à implantação e aperfeiçoamento dos sistemas de controle da poluição das águas e do solo na região (LAMPARELLI, 2001; CUBATÃO, 2006).

Com relação aos dados de saúde pública, em 1985 foram divulgadas as primeiras mortes diretas pelo ambiente nocivo de Cubatão. O pentaclorohexabenzeno conhecido como pó-da-china, produzida pela indústria Rhodia, mata dois trabalhadores e contamina 149 pessoas dos 150 funcionários, muitos dos quais faleceram mais tarde. Além da contaminação dos empregados, houve a contaminação do solo e das águas subterrâneas, pois foram encontrados lixões clandestinos da empresa carregados de organoclorados, datados de 1976 a 1984, nos municípios de Cubatão, São Vicente e Itanhaém. Há suspeita de outros depósitos, ainda desconhecidos, pois essa prática não era tão incomum como se acredita (FERREIRA \& PASSERANI, 2005).

Em 2002, o número de óbitos atribuídos a doenças do aparelho circulatório foi de $22,21 \%$, de causas externas (violência) $21,65 \%$ e neoplasias $13,41 \%$. Devido à falta de Serviço de Verificação de Óbitos na região, o coeficiente de mortalidade por causa mal definida, em 2001, foi de 80,98 por 100 mil habitantes, valor duas vezes maior que a média do Estado de São Paulo (CUBATÃO, 2006).

Recentemente, a mortalidade infantil apresentou uma queda significativa, com tendência de estabilidade e coeficiente em torno de 20 por mil nascidos vivos, sendo 19,98 em 2004, enquanto a Baixada Santista teve coeficiente de 18,17 e o Estado de São Paulo 14,25, segundo a Fundação Seade. O coeficiente de mortalidade materna, em 2000, foi de 40,24 por 100 mil nascidos vivos, sendo observada, também, uma queda progressiva na 
mortalidade por doenças infecciosas e parasitológicas. O município apresenta muitos casos de esquistossomose por ano, com o coeficiente de incidência de 84,3 por 100 mil habitantes, sendo alguns casos classificados como autóctones (CUBATÃO, 2006).

Com relação a acidentes de trabalho e doenças ocupacionais, verifica-se que no Pólo Industrial há uma diminuição crescente e progressiva dos registros de acidentes de trabalho. Por outro lado, há no mercado informal do município atividades de micro e pequenas indústrias que não efetuam registros de acidentes de trabalho, os quais, no entanto, são identificados no sistema municipal de saúde. Como este sistema ainda não está informatizado, é difícil uma análise comparativa para este item (CUBATÃO, 2006).

A Lei municipal de 1991 inclui o câncer como agravo de notificação compulsória. Anualmente é realizado relatório simples com o número total de casos notificados. Entretanto, muitos casos de neoplasia de moradores em Cubatão são tratados e notificados em outros municípios da região (CUBATÃO, 2006).

As áreas com solos contaminados na Baixada Santista constituem fontes de alto risco para o ambiente estuarino e marinho devido, sobretudo, à alta toxicidade, persistência e potencial de bioacumulação de alguns dos resíduos industriais depositados de forma irregular em diversos pontos da região. Destacam-se como áreas mais críticas os depósitos de organoclorados da indústria Rhodia, nos municípios de Cubatão e São Vicente, e o lixão de Pilões, utilizado indevidamente para disposição de resíduos industriais contendo organoclorados e metais pesados, além de outros poluentes. O lixão de Pilões, por estar localizado no rio Cubatão, a montante da principal captação de água da Baixada Santista, aumenta significativamente seu potencial de risco para a região. Devem ser ressaltadas, ainda, aquelas fontes relacionadas à contaminação do solo em áreas industriais e que vem sendo alvo de pesquisa e remediação por parte das respectivas indústrias. Neste sentido destacam-se as áreas da Rhodia, CBE, Carbocloro, Cosipa e PETROBRÁS-DTCS, contaminadas com compostos orgânicos e/ou metais pesados de alto potencial de impacto no ambiente (LAMPARELLI, 2001).

Outro risco eminente aos mananciais são os acidentes com caminhões transportadores de produtos tóxicos, que circulam pelo sistema Anchieta-Imigrantes, resultando em derramamento de produtos, que escoam, podendo atingir nascentes da bacia 
hidrográfica do Rio Cubatão. Isto coloca em risco o abastecimento de água da Baixada Santista (FERREIRA et al, 2008). Embora tenha ocorrido o retorno de peixes e outros organismos aquáticos à bacia do Rio Cubatão isso não garante a recuperação total do ecossistema, uma vez que alguns compostos químicos, entre eles os metais, podem residir no ambiente por longos períodos de tempo. Entretanto, um dos aspectos mais graves da introdução de substâncias químicas nesses compartimentos é a sua bioacumulação na cadeia alimentar (VIRGA et al, 2007).

Existe, ainda, o problema das águas das chuvas arrastarem resíduos para os corpos de água, razão que tem levado a CETESB a exigir segregação e controle de águas pluviais, notadamente pelas indústrias de fertilizantes (CUBATÃO, 2006).

Cubatão (2006) aponta dentre os principais pontos fracos referentes à qualidade das águas:

- Coleta e tratamento de esgotos insuficientes.

- Impossibilidade de uso, em curto prazo, dos recursos hídricos do sistema Billings, ficando a utilização desses recursos atrelada ao controle da poluição das águas no Alto Tietê e do bombeamento para a represa.

- Existência de focos de contaminação de águas subterrâneas.

- Lançamento de efluentes podendo apresentar reflexos nos ecossistemas aquáticos.

- Divulgação insuficiente de informação sobre a qualidade das águas para a comunidade, ficando restrita apenas à sinalização sobre a balneabilidade em praias de rio usadas pela comunidade.

- Ausência de instrumentos legais do município para gerenciamento do uso e conservação dos recursos hídricos.

- Ocupações desordenadas em áreas estuarinas e de mananciais.

- Constante assoreamento de cursos d'água, provocando enchentes e prejuízos aos usos e conservação dos recursos hídricos.

A sucessão de acidentes com reflexos negativos para o ambiente e o nível de risco da atividade industrial e de transporte de produtos perigosos levaram as autoridades ambientais a criar o Programa de Gerenciamento de Riscos, contendo ações preventivas e planos de ação de emergência, organizando os diversos atores e recursos disponíveis para 
atender às emergências ambientais e conter a poluição em casos de acidente. Este programa hoje tornou-se uma ação de rotina das indústrias e representou uma sensível redução das ocorrências e de sua gravidade ou nível de impacto ao meio ambiente (CUBATÃO, 2006).

Os fatores principais associados aos acidentes ambientais, que podem estar relacionados à contaminação ambiental, são: a susceptibilidade do Rio Cubatão e outros mananciais em caso de acidente e derramamento; a intensa movimentação e armazenamento de grandes quantidades de produtos químicos; a grande concentração de dutos para transporte de produtos químicos; ausência de instrumentos legais do município para gerenciamento dos riscos de atividades urbanas (oficinas mecânicas, pintura, entre outras); maior potencial de acidentes ambientais devido ao elevado inventário de produtos químicos e inflamáveis; falta de mecanismos e sistema viário adequado para controle do tráfego de cargas perigosas.

Outra importante fonte de água para a região é o Sistema Billings, que desvia uma parte das águas do Alto Tietê para gerar energia elétrica na Usina Henry Borden. Esta fonte, no entanto, apresenta restrições de vazão, sendo uma importante via de importação de poluentes do planalto para a Baixada Santista, contribuindo negativamente para a qualidade das águas e dos sedimentos em Cubatão (CUBATÃO, 2006; LAMPARELLI, 2001).

A Usina Henry Borden, juntamente com a represa Billings, construídas pela Companhia Light (canadense), foram responsáveis pela geração de energia elétrica para Cubatão e seu pólo petroquímico, que teve como objetivo inicial abastecer aos trens elétricos que rodavam na capital e, também, atender à demanda da expansão industrial. Entre os anos de 1952 e 1955, ocorreu a ampliação da capacidade geradora da usina que poderia atingir até $889.000 \mathrm{kw}$ de potência. Em 1926 gerava apenas $44.347 \mathrm{kw}$ (FERREIRA et al, 2008).

Desde outubro de 1992, a usina opera com até $25 \%$ de sua capacidade, devido a um dispositivo constitucional (Resolução Conjunta SMA/SES 03/92, de 04/10/92, atualizada pela Resolução SEE-SMA-SRHSO-I, de 13/03/96), que permite o bombeamento das águas do rio Pinheiros para o Reservatório Billings somente para controle de cheias. Devido à 
poluição da água, o bombeamento foi limitado a $10 \%$ da vazão média do Rio Tietê afluente ao reservatório Edgard de Souza ao longo do ano. Para adequação do processo operacional foi publicada (Resolução Conjunta SMA/ SSE-002 DE 19 de fevereiro de 2010) que trata de procedimentos a serem adotados em casos de emergência na operação do sistema hídrico da Bacia do Alto Tietê e Bacias a ela interligadas.

Com a redução do volume de água em direção à Baixada Santista, o avanço de água marinha, sobretudo ao longo do rio Cubatão, ocasionou problemas operacionais em

algumas indústrias que captavam água deste rio. Como a água era insuficiente para “empurrar” água salobra durante a maré cheia, esta era captada pelas indústrias causando danos, como corrosão nos equipamentos. Algumas delas tiveram que modificar o sistema de captação, construindo, por exemplo, barragens em outros locais como o rio Perequê, para se prover de água doce. Atualmente, a Usina é administrada pela Empresa Metropolitana de Águas e Energia (Emae) (FERREIRA et al, 2008).

\subsection{Legislação para recursos hídricos}

O Decreto n 27.576, de 11 de novembro de 1987 de São Paulo - Criou o Conselho Estadual dos Recursos Hídricos (CRH), antecipando-se ao Governo Federal. Dispõe sobre diretrizes para elaboração do Plano Estadual e a estruturação do sistema de Gerenciamento dos Recursos Hídricos do Estado, definido, em 1989, no Capítulo IV da Constituição Estadual.

A Lei Estadual N 7.633 de 30 de dezembro de 1991 - que estabelece a Política Estadual de Recursos Hídricos e define como princípios: a gestão descentralizada, participativa e integrada em relação aos demais recursos naturais e a cobrança pelo uso da água.

A Lei Federal n ${ }^{\circ}$ 9.433, de 8 de janeiro de 1997 - Institui a Política Nacional de Recursos Hídricos, cria o Sistema Nacional de Gerenciamento de Recursos Hídricos, regulamenta o inciso XIX do art. 21 da Constituição Federal. A água passa a ser um bem de domínio público e reconhecida como um recurso natural limitado, dotado de valor econômico, além da criação da Agência Nacional de Águas - ANA em 2000.

A Lei Federal $n^{\circ}$ 9.433, de 8 de janeiro de 1997 e a Lei Estadual $N^{\circ} 7.633$ de 30 de dezembro de 1991 - com a criação dos Comitês de Bacias Hidrográficas, que deram início 
ao processo de descentralização da gestão dos recursos hídricos, com a participação do poder público, dos usuários e das comunidades.

A Lei Estadual n 9.866, de 28 de novembro de 1997 - Dispõe sobre diretrizes e normas para a proteção e recuperação das bacias hidrográficas dos mananciais de interesse regional do Estado de São Paulo, e dá outras providencias.

A Portaria $\mathrm{n}^{\circ} 518$ em 25 de março de 2004. Estabelece os procedimentos e responsabilidades relativos ao controle e vigilância da qualidade da água para consumo humano e seu padrão de potabilidade, e dá outras providências. Entre outras legislações relativas à proteção aquática.

A Resolução CONAMA $n^{\circ}$ 357, de 17 de março de 2005. Dispõe sobre a classificação dos corpos de água e diretrizes ambientais para o seu enquadramento, bem como estabelece as condições e padrões de lançamento de efluentes, e da outras providencias.

\subsection{Cubatão - Domínio Mata Atlântica}

A cidade Cubatão apesar de ser um grande Pólo Industrial; está inteiramente inserida no Domínio da Mata Atlântica, sendo município integrante da Reserva de Biosfera. O município ocupa desde os cumes da Serra do Mar aos meandros estuarinos, destacando-se em sua paisagem três elementos básicos: a floresta atlântica nas escarpas; as matas de restingas ou florestas de terras baixas nas planícies; e os mangues nas áreas alagadas (CUBATÃO, 2006).

A definição Domínio Mata Atlântica foi reconhecida pelo CONAMA (Conselho Nacional de Meio Ambiente) em 1992 como as áreas que formavam uma cobertura florestal contínua. Passou também a ser um instrumento para definição de políticas e ações concernentes à proteção, à recuperação e ao uso sustentável de todo o bioma (MONTEIRO et al, 2003).

A biodiversidade da Mata Atlântica possui cerca de 20 mil espécies de plantas e no conjunto a floresta abriga cerca de 1,6 milhão de espécies animais incluindo insetos, sendo espécies endêmicas, na sua maioria (www.sosmatatlantica.org.br). 
O bioma Mata Atlântica é responsável por grande parte da água disponível à medida que protege as nascentes de diversos rios e regula o fluxo das fontes de água, superficiais e subterrâneas, utilizadas para abastecimento humano e manutenção de atividades econômicas. Os mananciais existentes em seus domínios são responsáveis, segundo Companhia de Saneamento Básico do Estado de São Paulo (SABESP), pelo abastecimento de cerca de 8,8 milhões de pessoas da Região Metropolitana de São Paulo, que corresponde a 55\% do abastecimento total desta metrópole (MAGALHÃES et al, 2009).

Vale destacar, ainda, a existência de 7 das 9 maiores bacias hidrográficas brasileiras neste bioma. A Mata Atlântica também é responsáveis pela quantidade e qualidade da água potável para cerca de 3,4 mil municípios, e para os mais diversos setores da economia nacional como a agricultura, a pesca, a indústria, o turismo e a geração de energia (MAGALHÃES et al, 2009). Os rios e lagos do Domínio Mata Atlântica abrigam ricos ecossistemas aquáticos, grande parte deles ameaçados pelo desmatamento das matas ciliares e consequentemente assoreamento dos mananciais, pela poluição da água, e pela construção de represas sem os devidos cuidados ambientais. Cerca de 93\% de sua formação original já foi devastada (www.sosmatatlantica.org.br).

Cerca de $60 \%$ da população vivem no Domínio Mata Atlântica, correspondendo $62 \%$ da população brasileira (110 milhões de pessoas). A maior ameaça ao equilíbrio da biodiversidade é a ação humana provocada pela pressão da sua ocupação e os impactos de suas atividades (www.sosmatatlantica.org.br; MONTEIRO et al, 2003).

O atual Plano Diretor Municipal de Cubatão reservou extensa área para preservação ambiental, equivalente a 62,6\% do município, ou 92,63 $\mathrm{km}^{2}$ e nas áreas urbanizadas, mais $2,4 \%$, ou 3,62 $\mathrm{km}^{2}$, para praças e parques urbanos. Todavia, diversos fatores de pressão sobre as áreas de preservação no município de Cubatão, destacam-se os núcleos de ocupação desordenada e áreas de invasão. Em Cubatão, o mangue tem sido prejudicado por meio de desmatamentos, drenagens e aterros, e também por ser usado como local de despejo de esgoto e materiais poluentes. Atualmente, restam apenas $20,5 \mathrm{~km}^{2}$, dos quais $1,3 \mathrm{~km}^{2}(6 \%)$ apresentam-se afetados pela ação do homem (CUBATÃO, 2006). 
Segundo a CETESB/Cubatão, a cidade é detentora de uma boa parcela do manguezal da Baixada Santista, com a crescente invasão dos manguezais, acredita-se que existam 24\% de áreas coluvionares, aluvionares e aterradas contra $18 \%$ de mangue remanescente. As Unidades de Conservação são áreas de relevante interesse. Criadas pelo poder público com objetivo de conservação da natureza e definição de limites, destacam-se em Cubatão o Parque Estadual da Serra do Mar e dois dos parques administrados pela Secretaria Municipal de Meio-Ambiente, que são o Parque Municipal do Perequê e o Parque Municipal Cotia-Pará (CUBATÃO, 2006).

O Parque Estadual da Serra do Mar é o maior parque estadual paulista; com área de $300 \mathrm{~km}$, detendo a maior parte das nascentes dos rios que vertem para o Atlântico. É responsável por cerca de $80 \%$ de toda a água que abastece a região da Baixada Santista. É também a Unidade de Conservação com maior área de florestas de Mata Atlântica, além de vários ecossistemas a ela associados, contribuindo para a manutenção da diversidade biológica. É um dos últimos bancos genéticos da flora e da fauna do Estado de São Paulo e compõe a lista dos ecossistemas mais ricos e ameaçados do mundo (CUBATÃO, 2006).

O Parque é administrado pelo Instituto Florestal, órgão subordinado à Secretaria do Meio-Ambiente do Estado de São Paulo, através de oito núcleos administrativos. O Núcleo Itutinga-Pilões, cuja sede está localizada no município de Cubatão, é o de maior área, contendo aproximadamente 116.000 hectares. Este núcleo é uma Unidade de Conservação de Proteção Integral definida em lei. É de domínio público, não sendo permitido o uso direto dos recursos naturais (CUBATÃO, 2006).

O maciço florestal do Parque Estadual da Serra do Mar próximo aos limites de uma área extremamente urbanizada, como a região metropolitana de São Paulo, e mesmo da Baixada Santista e do Distrito Industrial de Cubatão, contribui para a melhoria da qualidade do ar, aumenta a umidade relativa do ar e melhora as condições climáticas de maneira geral, prestando assim um serviço ambiental às populações humanas vizinhas. A mata colabora ainda para a formação de um revestimento natural das encostas da serra, reduzindo o risco de deslizamentos do solo (CUBATÃO, 2006).

O Núcleo Itutinga-Pilões possui em seus limites algumas áreas de ocupação irregular - os três Bairros-Cota, Água Fria e Sítio dos Queirozes - que se encontram em 
processo de expansão gradativa. O controle desta expansão exigiria fiscalizações contínuas, inviáveis frente às limitações do contingente atual de guarda-parques na Unidade. Como consequiência, agravam-se os problemas de desmatamentos, deslizamentos, contaminação de águas superficiais, caça e extrativismo ilegal, entre outros (CUBATÃO, 2006).

A lei de criação do Parque Municipal Perequê estabelece critérios de uso e manejo, dividindo-o em três zonas. A primeira é a Zona Primitiva, destinada à preservação do ambiente natural, às atividades de pesquisa científica, de educação ambiental e, também, de recreação. A segunda é a Zona de Recuperação - compreendida entre as cotas 40 e 15 metros da Serra do Mar, que se destina a conter a degradação e promover a restauração dos recursos naturais daquela área. A terceira é a Zona de Usos Intensivos e Especial (áreas em cotas inferiores a 15 metros) destinada à recreação e à educação ambiental em harmonia com o meio, podendo ser implantadas no local estruturas de administração, manutenção e serviços de apoio aos usuários (CUBATÃO, 2006).

O Parque Municipal Cotia-Pará destina-se a objetivos educacionais, científicos e recreativos. Com 840 mil metros quadrados, abriga um zoológico com algumas espécies de animais, viveiro de pássaros, viveiro de plantas, lago com ilhas, áreas de lazer com quiosques, pesque-pague ou pesque-solte, um mini-teleférico, imagem do Cristo Redentor e um Núcleo de Educação Ambiental. Localiza-se ao lado da Via Anchieta, a dois quilômetros da cidade (CUBATÃO, 2006).

\subsection{Ecotoxicologia}

A degradação dos recursos aquáticos tem sido motivo de preocupação do homem nas últimas décadas. Por esta razão existe um crescente interesse por conhecer e proteger os ecossistemas fluviais e estudar suas trocas com o meio, desenvolvendo critérios físicos, químicos e biológicos que possibilitem diagnosticar o efeito e a magnitude das intervenções humanas (NORRIS \& HAKWINS, 2000).

A Legislação CONAMA 357/2005, que substituiu a CONAMA 20/1986, prevê a avaliação ecotoxicológica para o lançamento de efluentes e avaliação do ambiente aquático, para a preservação da biodiversidade e pela melhoria da qualidade das águas dos rios. O controle ecotoxicológico de efluentes líquidos deve ser exercido nos corpos de água 
doce pertencentes às classes $1,2,3$, e nas classes 1 e 2 de águas marinhas ou salobras. São aplicados recursos da ecotoxicologia, ciência que estuda os efeitos dos poluentes aos organismos e como esses interagem em seus habitats (Blasei, 1984 apud ZAGATTO, 2006).

A utilização de testes de toxicidade aquática para a caracterização da qualidade da água e de efluentes reduz limitações encontradas na caracterização físicas e químicas, pois fornecem informações adicionais sobre o perigo potencial de uma substância tóxica sobre a biota aquática ou da mistura quando no ambiente impactado (NUNES \& FONSECA, 2002).

Atualmente, vários ensaios de toxicidade já estão bem estabelecidos, sendo alguns padronizados nacional e internacionalmente por associações ou organizações de normalização, como Associação Brasileira de Normas Técnicas (ABNT), Association Française de Normalisation (AFNOR), American Society for Testing and Materials (ASTM), American Water Work Association (AWWA), Deutsches Institut fur Normung (DIN), International Organization for Standardization (ISO) e Organization for Economic Co-Operation and Development (OECD) (KNIE \& LOPES, 2004).

A aplicação dos testes de toxicidade na analise ambiental é bastante abrangente e sua importância aumenta na proporção que cresce a complexidade das transformações químicas no meio ambiente. A determinação de substâncias isoladas através de análises químicas tradicionais, além de não detectarem os efeitos nos organismos, não dão resposta sobre que tipo de agente químico esta sendo responsável pela toxicidade e informações sobre as possíveis interações entre substâncias (aditivas, antagônicas ou sinergéticas), como também da biodisponibilidade das mesmas (Figura 3) (MAGALHÃES \& FERRÃO FILHO, 2008). 


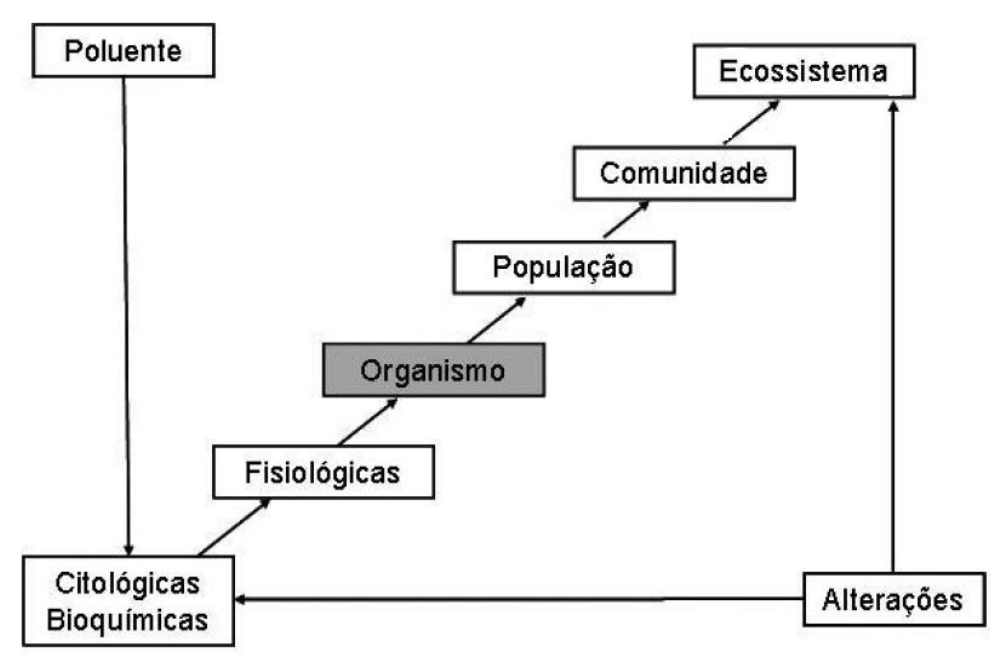

FIGURA 3 - Níveis de organização biológica e resposta aos efeitos de poluentes (MAGALHÃES \& FERRÃO FILHO, 2008).

Todas as substâncias químicas têm um potencial tóxico de ação que depende não somente da sua concentração. Dependendo da composição e da estrutura química das substâncias, existem vários mecanismos de ação no organismo, influenciando-o de formas mais variadas: DNA (ex.:genotoxicidade, mutagenidade, fertilidade); transporte de elétrons (ex.: luminescência, fotossíntese); sistemas enzimáticos (ex.: metabolismo, digestão); compartimentos celulares (ex.: respiração celular); formações celulares (ex.: tumores celulares, hematomas) (KNIE \& LOPES, 2004). Além disso, muitos trabalhos demonstram efeitos sinérgicos, antagônicos, de potenciação e de adição de contaminantes orgânicos e inorgânicos sobre muitas comunidades da biota. A exposição da biota a mistura de contaminantes pode levar a interações toxicológicas resultantes da exposição a dois ou mais contaminantes, acarretando uma resposta biológica (MOZETO \& ZAGATTO, 2008).

\subsection{Escolha do organismo-teste}

Os organismos-teste utilizados nos ensaios ecotoxicológicos são escolhidos e padronizados de acordo com algumas características, entre elas a ampla distribuição geográfica, a alta sensibilidade a diversas classes de contaminantes, a baixa variabilidade genética, a sua disponibilidade em abundância e, de preferência, ser autóctone e representativo do ambiente em estudo (RAND, 1995; KNIE \& LOPES, 2004).

A utilização de cladóceros como organismo-teste em ensaios biológicos fundamenta-se principalmente nos seguintes critérios: seus descendentes são 
geneticamente idênticos (uniformidade de respostas nos ensaios); cultivar estes organismos em laboratório sob condições controladas é fácil e sem grandes dispêndios; os organismos reagem sensivelmente a uma ampla gama de reagentes nocivos, além disso, são adequados para testes estáticos, semi-estáticos ou de fluxo contínuo; o ciclo de vida e de reprodução são curtos, o que permite usá-los em testes crônicos (KNIE \& LOPES, 2004).

Por serem utilizados em testes ecotoxicológicos os organismos teste devem ter uma determinada faixa de sensibilidade constante ao longo do tempo. As condições laboratoriais influenciam diretamente no ciclo de vida desses organismos, podendo aumentar ou diminuir a sensibilidade dos organismos teste (KALINKA et al, 2004).

\subsection{Organismos-teste}

As pulgas d' água (subordem Cladocera) constituem metade dos branquiópodos e incluem muitas espécies largamente disseminadas e comuns, tais como aquelas que pertencem ao gênero Daphnia. Possuem apenas poucos milímetros de comprimento, possuindo cor pálida ou transparente, podendo ser encontradas cores rosadas ou vermelhas devido à presença de hemoglobina. Os cladóceros habitam correntes de águas, grandes lagoas e lagos (RUPPERT \& BARNES, 1996).

Os cladóceros apresentam 2 tipos de reprodução: uma partenogenética ou assexuada e outra sexuada. A reprodução partenogenética é a mais comum em condições ambientais favoráveis, provocando um crescimento explosivo da população devido ao alto número de embriões formados por cada fêmea. A reprodução sexuada se manifesta quando o ambiente se altera negativamente (BUCKUP \& BOND-BUCKUP, 1999). Quando as condições ambientais se tornam novamente favoráveis, os ovos do efípio eclodem, liberando fêmeas que irão se reproduzir partenogeneticamente. (BARNES, 1984 apud BUCKUP \& BOND-BUCKUP, 1999).

Os cladóceros, iguais a outros grupos de crustáceos planctônicos, realizam movimentos verticais e horizontais estimulados principalmente pela luz. Outros fatores, como alimento, temperatura, predação, podem desencadear o fenômeno de migração. (BUCKUP \& BOND-BUCKUP, 1999). São organismos filtradores; suas pernas torácicas, compostas por cerdas, agem como peneiras, que retêm algas, bactérias e pequenas 
partículas de material orgânico da água. (BUIKEMA \& SHERBERGER, 1977 apud DOMINGUES \& BERTOLETTI, 2006).

Os ensaios de toxicidade aguda são realizados a bactéria marinha bioluminescente Vibrio fischeri. A bioluminescência produzida pela bactéria é decorrente do processo enzimático de seu metabolismo. Este processo enzimático pode ser modificado ou sofrer danos por exposição a substâncias tóxicas, culminando na diminuição da bioluminescência. Esse decréscimo da quantidade da luz é proporcional à toxicidade da amostra (RONENELLI, 2004). O ensaio se baseia na diferença entre a emissão de luz da bactéria antes e depois de sua exposição a uma amostra por um período de 15 minutos. A intensidade de luz emitida é comparada a um controle.

O ensaio realizado com a bactéria bioluminescente apresenta diversas vantagens como rapidez na obtenção dos resultados, alta sensibilidade a diferentes grupos de contaminantes, pois detecta substâncias tóxicas em baixas em concentrações, boa reprodutibilidade, simplicidade e custo relativamente baixo, além de necessitar pequeno volume de amostra $(<10 \mathrm{~mL})$ (SANCHES \& SATO, 2002; ROMANELLI, 2004).

\subsection{Qualidade das Águas e Índices relacionados}

Com o intuito de facilitar a interpretação das informações de qualidade de água, a CETESB, a partir de um estudo realizado em 1970 pela "National Sanitation Foundation" dos Estados Unidos, adaptou e desenvolveu o Índice de Qualidade das Águas - IQA. No entanto, o IQA apresenta algumas limitações como à possibilidade de superestimar a qualidade da condição real do recurso hídrico (tendo em vista que contempla somente 9 parâmetros) e restringir-se a uma avaliação limitada somente à utilização das mesmas para o abastecimento público.

Para o cálculo do IQA, são consideradas variáveis de qualidade que indicam o lançamento de efluentes sanitários para o corpo d'água (temperatura, $\mathrm{pH}$, oxigênio dissolvido, demanda bioquímica de oxigênio, coliformes termotolerantes, nitrogênio total, fósforo total, resíduos totais e turbidez) (CETESB, 2009).

Outro indicador importante é o IAP (Índice de Qualidade das Águas para fins de Abastecimento Público) - avalia, além das variáveis consideradas no IQA, que indicam o 
lançamento de esgotos sem tratamento nos corpos d'água, as substâncias tóxicas e as variáveis que afetam a qualidade organoléptica da água, advindas, principalmente, de fontes difusas. Variáveis de Qualidade (IAP): temperatura, $\mathrm{pH}$, oxigênio dissolvido, demanda bioquímica de oxigênio, coliformes termotolerantes, nitrogênio total, fósforo total, resíduos totais e turbidez, ferro dissolvido, manganês, alumínio dissolvido, cobre dissolvido, zinco, potencial de formação de trihalometanos, número de células de cianobactérias, cádmio, chumbo, cromo total, mercúrio e níquel (CETESB, 2009).

No cálculo do IVA (Índice de Qualidade das Águas para Proteção da Vida Aquática), além das variáveis do IET, incluem-se também as variáveis essenciais para a vida aquática como o oxigênio dissolvido, $\mathrm{pH}$ e toxicidade, assim como as substâncias tóxicas, complementado pelos índices de comunidades aquáticas (CETESB, 2009).

O índice do estado trófico, IET, tem por finalidade classificar os corpos d'água em diferentes graus de trofia, ou seja, avalia a qualidade da água quanto ao enriquecimento por nutrientes e seu efeito relacionado ao crescimento excessivo das algas ou ao aumento da infestação de macrófitas aquáticas. Variáveis de Qualidade (IET) - clorofila a e fósforo total (CETESB, 2009).

Na tabela 3 esta descrita a classificação de um corpo de água, quanto ao estado trófico, associada aos níveis de fósforo total; clorofila-a e critérios para o IET, segundo CETESB, 2009.

TABELA 3 - Valores de classificação para fósforo total; clorofila-a e critérios para o IET (CETESB, 2009).

\begin{tabular}{l|l|l|l|l|}
\hline RIOS & Critério & Secchi - S & P-Total - P & Clorofila a \\
\hline Estado Trófico & IET $\leq 47$ & & $\mathrm{P} \leq 13$ & $\mathrm{CL} \leq 0,74$ \\
\hline Ultraoligotrófico & $47<\mathrm{IET} \leq 52$ & & $13<\mathrm{P} \leq 35$ & $0,74<\mathrm{CL} \leq 1,31$ \\
\hline Oligotrófico & $52<\mathrm{IET} \leq 59$ & $35<\mathrm{P} \leq 137$ & $1,31<\mathrm{CL} \leq 2,96$ \\
\hline Mesotrófico & $59<\mathrm{IET} \leq 63$ & $137<\mathrm{P} \leq 296$ & $2,96<\mathrm{CL} \leq 4,70$ \\
\hline Eutrófico & $63<\mathrm{IET} \leq 67$ & & $296<\mathrm{P} \leq 640$ & $4,70<\mathrm{Cl} \leq 7,46$ \\
\hline Supereutrófico & $\mathrm{IET}>67$ & $\mathrm{P}>640$ & $\mathrm{CL}>7,46$ \\
\hline Hipereutröfico & & &
\end{tabular}

Na tabela 4 foram apresentados os dados referentes ao Índice de Qualidade das Águas, segundo os Relatórios de Águas Interiores no período de 2002 a 2009, dos pontos 
CUBA 02700; CUBA 03900; CFUG 02900 e PERE 02900, pontos estes próximos ou em comum aos pontos de coleta do presente estudo.

TABELA 4 - Média Anual dos Índices de Qualidade das Águas - Relatórios de Qualidade das Águas Interiores (CETESB)

\begin{tabular}{|c|c|c|c|c|c|c|c|c|c|}
\hline Pontos & Índice & 2002 & 2003 & 2004 & 2005 & 2006 & 2007 & 2008 & 2009 \\
\hline \multirow{4}{*}{ 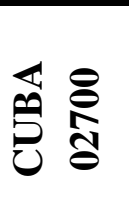 } & IAP* & 51 & 45 & 51 & 57 & 39 & 43 & $\overline{52}$ & 63 \\
\hline & IQA* & 65 & 64 & 69 & 62 & 65 & 62 & 65 & 63 \\
\hline & IVA* & 3,8 & 3,9 & 3,7 & 4,4 & 3,6 & 3,1 & 2,6 & 5,0 \\
\hline & IET** & 44 & 41,75 & 22,27 & 50 & 50 & 52,80 & 49,60 & 56,76 \\
\hline \multirow{4}{*}{ 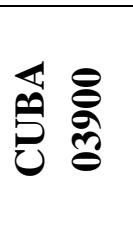 } & IAP* & 43 & 64 & 57 & 54 & 54 & 59 & --- & --- \\
\hline & IQA* & 55 & 49 & 58 & 55 & 56 & 59 & 56 & 58 \\
\hline & IVA* & 61 & 5,2 & --- & --- & --- & --- & --- & --- \\
\hline & IET** & 44 & 54,13 & 49,08 & 62 & 55 & 54,04 & 54,59 & 54,90 \\
\hline \multirow{4}{*}{ 它 } & IAP* & 54 & 77 & 67 & 60 & 45 & 29 & 42 & 28 \\
\hline & IQA* & 80 & 76 & 80 & 68 & 77 & 70 & 73 & 78 \\
\hline & IVA* & 3,7 & 5,4 & 4,8 & 6,7 & 6,7 & 5,6 & 6,1 & 8,2 \\
\hline & IET** & 52 & 64,31 & 52,86 & 67 & 65 & 64,96 & 57,38 & 61,71 \\
\hline \multirow{4}{*}{ 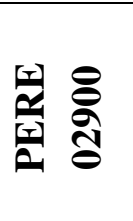 } & IAP* & --- & --- & --- & 65 & 55 & 67 & --- & --- \\
\hline & IQA* & --- & --- & --- & 67 & 67 & 65 & 62 & 69 \\
\hline & IVA* & --- & --- & --- & 4,6 & 3,8 & 3,1 & 3,3 & --- \\
\hline & IET** & --- & --- & --- & 56 & 52 & 52,14 & 49,19 & 54,26 \\
\hline
\end{tabular}

Legenda de Classificação

Ótima

$* *$

Ultraoligotrófico Oligotrófico Mesotrófico

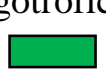

Boa

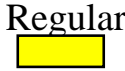

Eutrófico

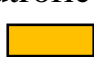

Supereutrófico Hipereutrófico

--- coleta não realizada

Na figura 4 demonstra-se a distribuição percentual de cada efeito observado nos ensaios ecotoxicológicos realizados com Ceriodaphnia dubia para o total de amostras analisadas (757) em 2009, no Estado de São Paulo comparada com o período 2004 a 2008. Podemos observar que houve um aumento do efeito crônico e agudo em amostras coletas em 2009, segundo os dados apresentados no relatório de águas superficiais (CETESB, 2009). 


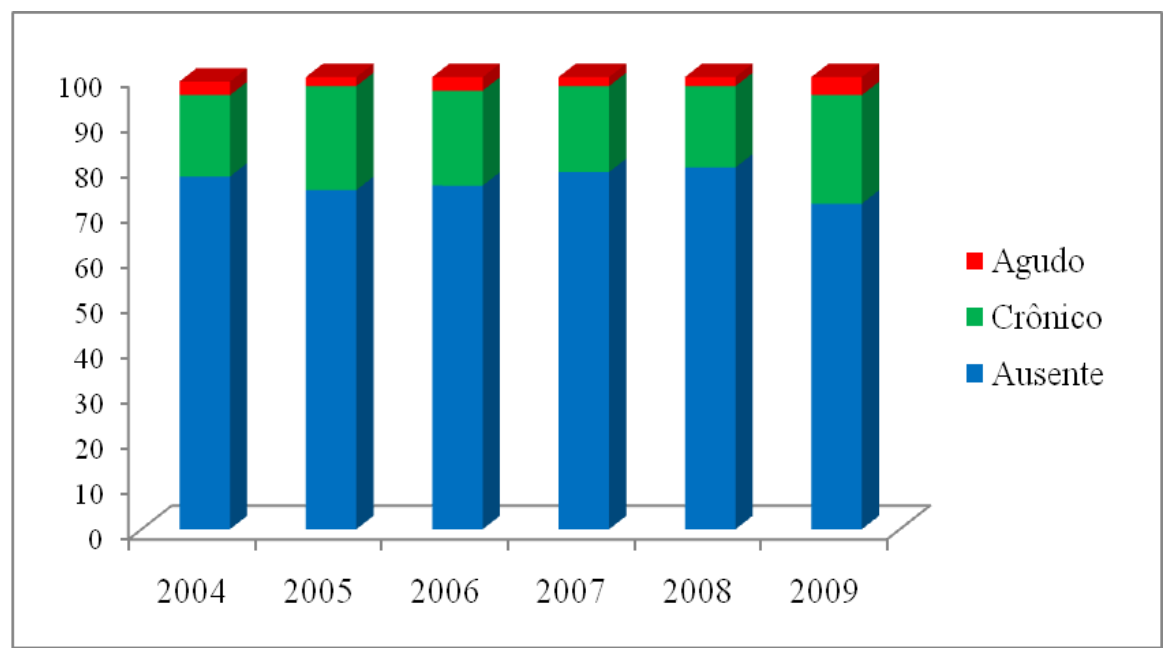

FIGURA 4 - Porcentagem de efeitos tóxicos entre 2004 e 2009, no estado de São Paulo (CETESB, 2009).

A Figura 5 representa os valores percentuais para os ensaios ecotoxicológicos com o organismo Ceriodaphnia dubia realizados por CETESB (2009) para avaliar efeito tóxico (crônico ou agudo) observado nos ensaios aplicados para a UGRHI 7 - Unidades de Gerenciamento de Recursos Hídricos (Baixada Santista).

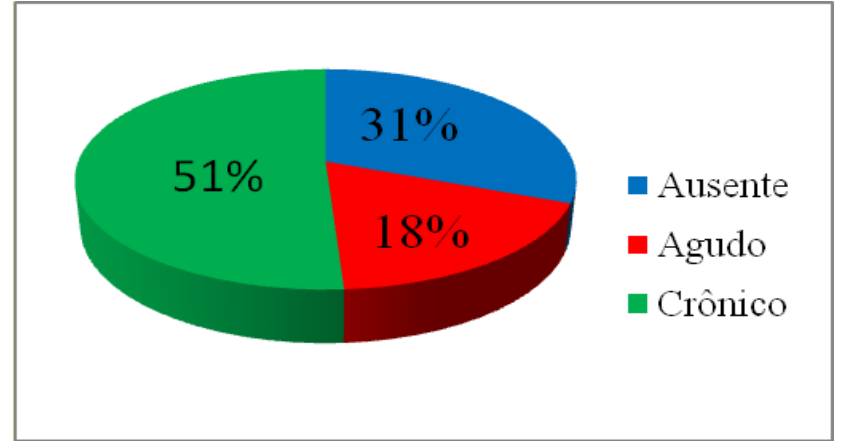

FIGURA 5 - Valores percentuais para os ensaios ecotoxicológicos com C. dubia (CETESB, 2009).

A figura 6 representa as porcentagens de resultados não conformes com os padrões de qualidade para corpos d'água classe 2, estabelecidos pela Resolução Conama 357/05. Adotaram-se, nesta análise, os padrões da Classe 2, uma vez que 75\% dos corpos d'água monitorados pela CETESB, no Estado de São Paulo, estão classificados dessa forma 
(CETESB,2009).

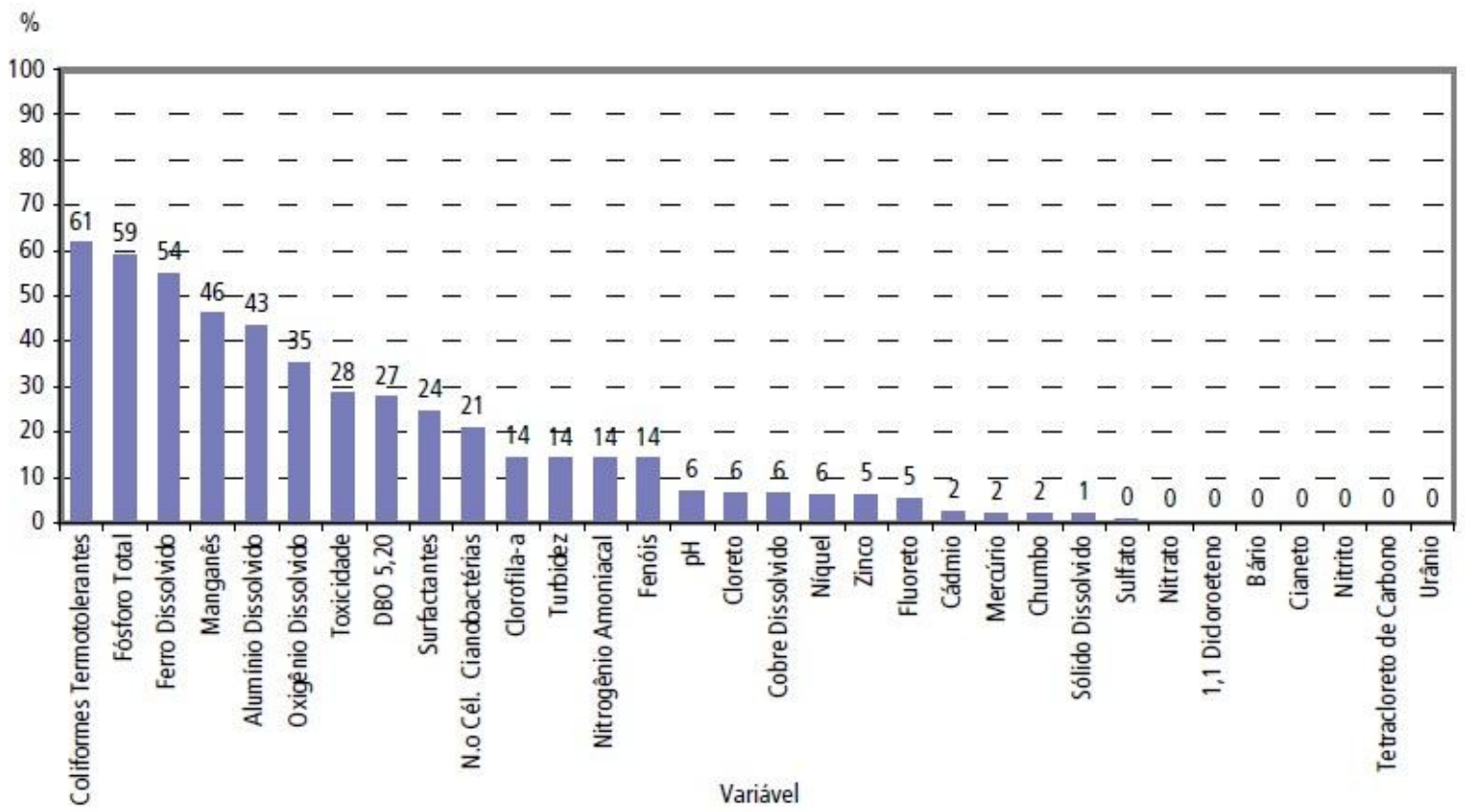

FIGURA 6 - Porcentagens de resultados não conformes com relação aos padrões estabelecidos para a Classe 2, em 2009 (CETESB, 2009).

Segundo CETESB (2009), podemos observar que a porcentagem de resultados com toxicidade Crônica ou Aguda atingiu 28 \% das amostras de 2009, podendo estar associada aos agentes químicos de origem antrópica (industrial ou doméstica) ou à presença de algas.

Os resultados com efeitos adversos à vida aquática nos corpos d'água do Estado de São Paulo, em 2009, foram causados pela presença de agentes químicos, carreados, provavelmente, pelo maior aporte do escoamento superficial decorrente das chuvas (CETESB, 2009).

\subsection{Surfactantes}

O termo "Agente de Atividade Superficial" originou-se a palavra surfactante. Esta propriedade cabe aos surfactantes devido à sua estrutura química, que possui duas partes distintas, a primeira delas é uma parte hidrofílica, usualmente chamada de cabeça e a segunda parte é uma cadeia lipofílica, chamada de cauda (CAROLEI, 2005).

Uma das principais características dos surfactantes é a concentração micelar crítica (CMC). A partir desta concentração as moléculas de surfactantes formam agregados moleculares denominados micelas e a tensão superficial da solução não é mais reduzida, permanecendo constante (CUNHA et al, 2000). Os tipos de agregados dependem das 
estruturas dos tensoativos (cabeça e cauda), sua concentração, presença de aditivos, $\mathrm{pH}$ do meio e outros (Figura 7) (CAROLEI, 2005).
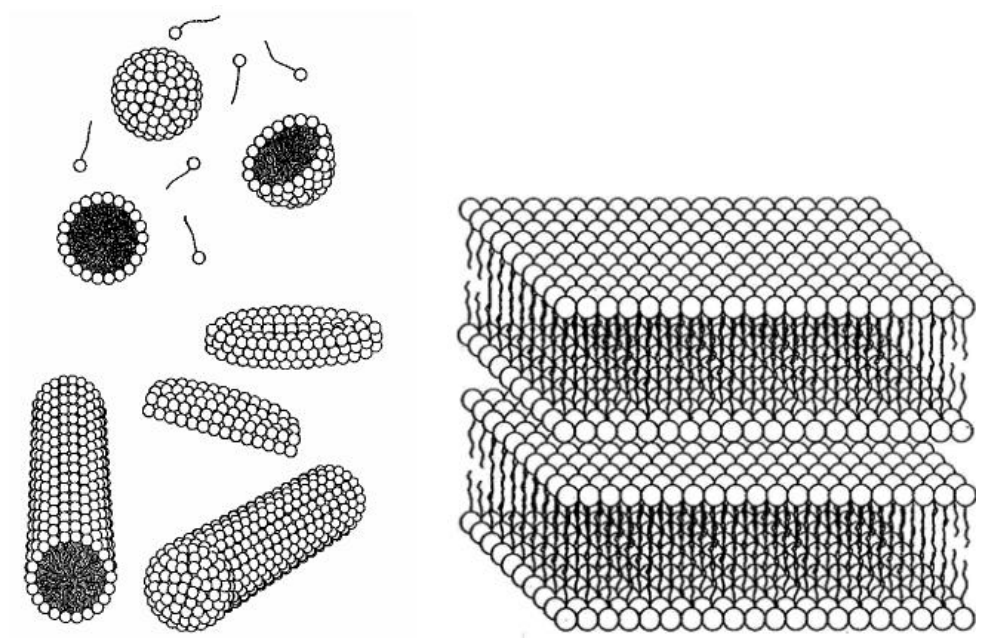

FIGURA 7 - Modelos de agregados (CAROLEI, 2005).

Os surfactantes aniônicos, conforme o próprio nome diz, são surfactantes que possuem a cabeça polar com carga negativa. Alguns dos principais exemplos são os surfactantes que possuem os seguintes grupos: (CAROLEI, 2005).

\section{Sulfato $\left(\mathrm{R}-\mathrm{OSO}^{3-}\right)$ \\ Sulfonato $\left(\mathrm{R}^{-\mathrm{SO}^{3-}}\right)$ \\ Carboxilato $\left(\mathrm{R}-\mathrm{CO}^{2-}\right)$}

Os surfactantes aniônicos são os mais utilizados para aplicações em produtos de higiene pessoal e limpeza doméstica, e apresentam uma grande variedade de produtos onde são utilizados. Estes surfactantes estão presentes em shampoos, sabonetes líquidos, detergentes em pó, detergentes líquidos e outros, e geralmente são os que estão presentes em maiores concentrações (CAROLEI, 2005).

Os surfactantes, princípio ativo dos detergentes, são importantes produtos causadores de poluição do ambiente aquáticos, freqüentemente encontrados em efluentes industriais e domésticos. A presença de surfactantes pode causar sérios distúrbios ecológicos, afetando organismos aquáticos, inclusive peixes (ROMANELLI et al, 2006). Antigamente muitos detergentes possuíam grandes quantidades de tripolifosfatos de sódio (TPF), $\mathrm{Na}_{5} \mathrm{PO}_{3} \mathrm{O}_{3}$, como agente sequestrante. Quando em contato com os cursos d'água 
após serem descartados, o excesso de tripolifosfato reage lentamente com a água, sendo transformada em íons fosfato $\left(\mathrm{PO}_{4}{ }^{3-}\right)$, que pode ocasionar um efeito devastador no equilíbrio aquático, pois sua presença causa a eutrofização (ROMANELLI, 2004).

Segundo Piveli e Kato, (2006), os esgotos sanitários possuem de 3 a $6 \mathrm{mg} / \mathrm{L}$ de detergentes que podem provocar prejuízos de ordem estética pela formação de espumas, além de exercerem efeitos tóxicos sobre os ecossistemas aquáticos. Conforme esses autores citados anteriormente os surfactantes têm sido responsabilizados pela aceleração da eutrofização, pois a maioria dos detergentes comerciais empregados são ricos em fósforo, além de exercerem efeito tóxico sobre zooplânctons, predadores naturais das algas. Além disso, inibem processos de depuração dos corpos receptores e nas Estações de Tratamento de Esgotos (ETEs), podem interagir com os principais componentes da membrana celular, as proteínas e os lipídeos, alterando os sistemas de membrana, enfraquecendo estruturas de proteção dos organismos, além de provocar outras modificações estruturais celulares (ROMANELLI et al, 2006 ; BOSQUILHA, 2002). 


\section{METODOLOGIA}

\subsection{Procedimentos e locais da amostragem}

Para este estudo foram realizadas cinco campanhas de amostragem de águas no período de julho/2009 a fevereiro/2011. As águas superficiais foram coletadas em cinco pontos amostrais do rio Cubatão, dois pontos nos canais de fuga da Usina Henry Borden, um ponto no rio Pilões e um ponto no rio Perequê, (contribuintes) afluentes com influência nesses locais amostrados no rio Cubatão, conforme as coordenadas geográficas apresentadas na Tabela 5. Os pontos foram demarcados com o auxílio de um Sistema de Posicionamento Global, de modo a abranger locais de menor impacto bem como aqueles próximos ao Pólo Industrial de Cubatão.

Outro fator importante na seleção dos pontos de coleta para este estudo foram as suas proximidades com aqueles comumente adotados e publicados nos Relatórios de Qualidade das Águas Interiores do Estado de São Paulo pela CETESB e outros pontos foram definidos por estarem próximos a possíveis fontes de contaminação por meio de efluentes domésticos e industriais mesmo que em áreas mais preservadas, aparentemente.

Na primeira campanha foram coletadas amostras em quatro pontos do rio Cubatão e dois pontos nos canais de Fuga da Usina Henry Borden (contribuintes). No entanto, o ponto $\mathrm{P} 0$, inicialmente programado para ser o local de controle, foi incluído como ponto de coleta, a partir da terceira campanha, pois apesar de estar em uma região mais preservada de Cubatão, por apresentar toxicidade foi descartado como ponto controle e mantido como ponto de coleta. Os pontos PI (rio Pilões) e PE (rio Perequê) foram adicionados, a partir da quarta campanha, a fim de investigar suas possíveis contribuições para a toxicidade do rio Cubatão. Na primeira campanha não foi possível coletar amostras de águas, em volumes suficientes para realizar ensaios de toxicidade crônica (C. dubia).

As amostras de águas de superficiais foram coletadas a profundidade entre 40 a 50 $\mathrm{cm}$ da superfície com o auxílio de um balde e uma corda que foram lavados a cada ponto de coleta, com a própria amostra que era usada para enxaguar o coletor e depois descartada. Durante a coleta de água foram determinados os valores de condutividade e oxigênio dissolvido na água, com uso de eletrodos. Após a determinação desses parâmetros, as amostras foram fracionadas e acondionadas em frascos de polietileno que 
foram mantidas sob refrigeração em caixas de isopor com gelo, durante o período da coleta. Quando encerrada a amostragem, as amostras seguiram para os laboratórios participantes do projeto. As amostras foram resfriadas, com o auxílio de caixas de isopor e gelo, assim que coletadas. Após serem transportadas até seu destino foram congeladas ($10^{\circ} \mathrm{C}$ ), por até 30 dias. Os ensaios realizados para as analises físico-químicas, utilizaram amostras com até $48 \mathrm{~h}$ de armazenamento e os ensaios para avaliar toxicidade crônica e aguda, as amostras foram congeladas em até 30 dias. . Os procedimentos de coleta e preservação das amostras de águas para os ensaios de toxicidade foram realizados de acordo com a norma de preparo e preservação de amostras ABNT NBR 15469:2007

Os volumes de água coletados em cada ponto amostrado para as análises físicoquímicas foram: três frascos de $500 \mathrm{~mL}$ (surfactante e $\mathrm{DBO}_{(5,20)}$ ); três frascos de $300 \mathrm{~mL}$ (cloretos); $50 \mathrm{~mL}$ em tubo falcon (para turbidez, sólidos totais, $\mathrm{pH}$, fenóis, carbono total, outros compostos orgânicos. Para as análises biológicas foram coletadas três frascos de $300 \mathrm{~mL}$ para as análises com C.dubia e um falcon de $50 \mathrm{~mL}$ para as análises com V.fischeri. Assim, cada ponto amostrado originou 18 subamostras por ponto coletado.

Terminada a coleta, parte das amostras foi transportada ao LEBA (Lab. Ensaios Biológicos Ambientais), no Centro de Tecnologia das Radiações (CTR/IPEN) para realização dos ensaios de toxicidade com $V$. fischeri. Outra parte das amostras foi encaminhada ao CEPEMA (Centro de Capacitação e Pesquisa em Meio Ambiente) para as análises biológicas com $C$. dubia e para todas as análises físico-químicas.

A salinidade da água foi monitorada durante as coletas de águas do rio Cubatão e de seus contribuintes, utilizando-se o Refratômetro Quimis (Q-767-3). Todas as medidas resultaram em zero de salinidade para as amostras de água. 
TABELA 5 - Posição geográfica dos locais amostrados com as principais referências utilizadas nas coletas de amostras de água

\begin{tabular}{|c|c|c|c|}
\hline Pontos & Latitude & Longitude & Descrição do local de amostragem \\
\hline 0 & $\mathrm{~S} 23^{\circ} 54^{\prime} 53,3^{\prime \prime}$ & WO 46²9`43.8” & $\begin{array}{l}\text { Ponte suspensa sobre o rio Cubatão - } \\
\text { Caminhos dos Pilões, nos limites do } \\
\text { Pq. Ecológico Itutinga Pilões. }\end{array}$ \\
\hline 1 & $\mathrm{~S} 23^{\circ} 52^{\prime} 46,9^{\prime \prime}$ & WO 46²6 48.6” & $\begin{array}{l}\text { Ponte Canal de Fuga II da UHE (Usina } \\
\text { Hidroel. Henry Borden), saída da } \\
\text { turbina da Usina Externa. }\end{array}$ \\
\hline 2 & $\mathrm{~S} 23^{\circ} 52^{\prime} 50,3^{\prime \prime}$ & WO $46^{\circ} 26^{`} 48.1^{\prime \prime}$ & $\begin{array}{l}\text { Ponte de Ferro - ETA-3 (Estação de } \\
\text { Tratamento de Água - Cubatão). }\end{array}$ \\
\hline 3 & $\mathrm{~S} 23^{\circ} 52^{\prime} 47,2^{\prime \prime}$ & WO $46^{\circ} 26 ` 54,5^{\prime \prime}$ & $\begin{array}{l}\text { Ponte do Canal de Fuga I da UHE e } \\
\text { (Emae - Empresa Metropolitana de } \\
\text { Águas e Energia S.A.) }\end{array}$ \\
\hline 4 & $\mathrm{~S} 23^{\circ} 52^{\prime} 45,8^{\prime \prime}$ & WO 46²5`19,2” & $\begin{array}{l}\text { Ponte rio Cubatão - Centro do } \\
\text { município e próximo ao Hosp. Ana } \\
\text { Costa - jusante da CBE }- \text { Cia Brasileira } \\
\text { de Estireno. }\end{array}$ \\
\hline 5 & $\mathrm{~S} 23^{\circ} 52^{\prime} 39,5^{\prime \prime}$ & WO $46^{\circ} 244^{`} 43,1^{\prime \prime}$ & $\begin{array}{l}\text { Margem do rio Cubatão em frente da } \\
\text { salina da Carbocloro S.A. Ind. Quím. }\end{array}$ \\
\hline 6 & $\mathrm{~S} 23^{\circ} 52^{\prime} 49,4^{\prime \prime}$ & WO $46^{\circ} 25^{`} 36,7^{\prime}$ & $\begin{array}{l}\text { Ponte-Rod. Cônego Domênico Rongo- } \\
\text { ni (km 265); jusante RBPC (Refinaria } \\
\text { Pres. Rodrigues Bernardes) e da } \\
\text { Fosfértil - Fertilizantes Fosfatados S.A }\end{array}$ \\
\hline PI & $\mathrm{S} 23^{\circ} 54^{\prime} 27,1^{\prime \prime}$ & WO 46²9`31,6”' & $\begin{array}{l}\text { Ponto rio Pilões }- \text { Pq. Itutinga Pilões, } \\
\text { antiga Vila Itutinga. }\end{array}$ \\
\hline $\mathrm{PE}$ & $\mathrm{S} 23^{\circ} 52^{\prime} 00,7^{\prime \prime}$ & WO $46^{\circ} 25^{`} 05,8^{\prime \prime}$ & $\begin{array}{l}\text { Ponto rio Perequê - jusante do Pq. } \\
\text { Ecológico Perequê e Ind. e Com. } \\
\text { Petrocoque S.A.; captação de água da } \\
\text { Carbocloro S.A. Ind. Quím. }\end{array}$ \\
\hline
\end{tabular}

Na figura 8 estão representados todos os locais selecionados para a coleta de águas deste estudo. Os locais incluem amostras de águas superficiais do rio Cubatão, rio Pilões e Perequê. Sendo o rio Cubatão o foco do estudo, foram selecionados os locais com possibilidade de maior impacto associado à ocupação do solo na atualidade. Para isso foram incluídos locais de coleta próximos aos canais de fuga da Usina Henry Borden (P1 e P3) e dos rios afluentes do Cubatão, rio Pilões e Perequê, além de locais mais próximos ao centro do município de Cubatão, São Paulo. A fotografia permite observar os locais de maior concentração humana e de atividades produtivas. 


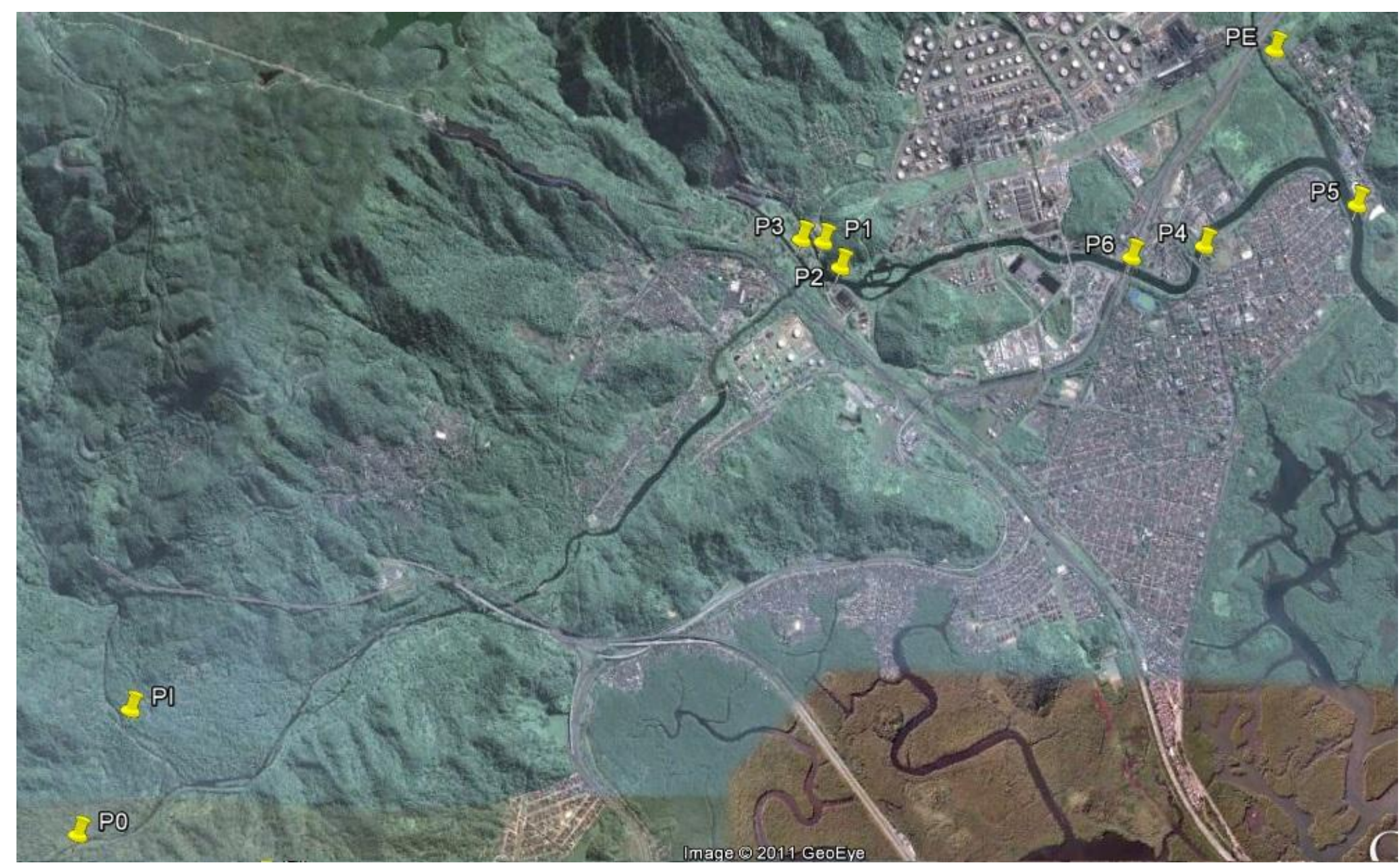

FIGURA 8 - Indicação dos pontos amostrados no rio Cubatão (P0, P2, P4, P5 e P6); canais de fuga da UHB (P1 e P3); no rio Pilões (PI) e no rio Perequê (PE). 
As fotografias obtidas onde foram realizadas as coletas do presente estudo, durante as amostragens, constam entre as Figuras 9 até 18, sendo a Figura 15, referente às salinas da Carbocloro.

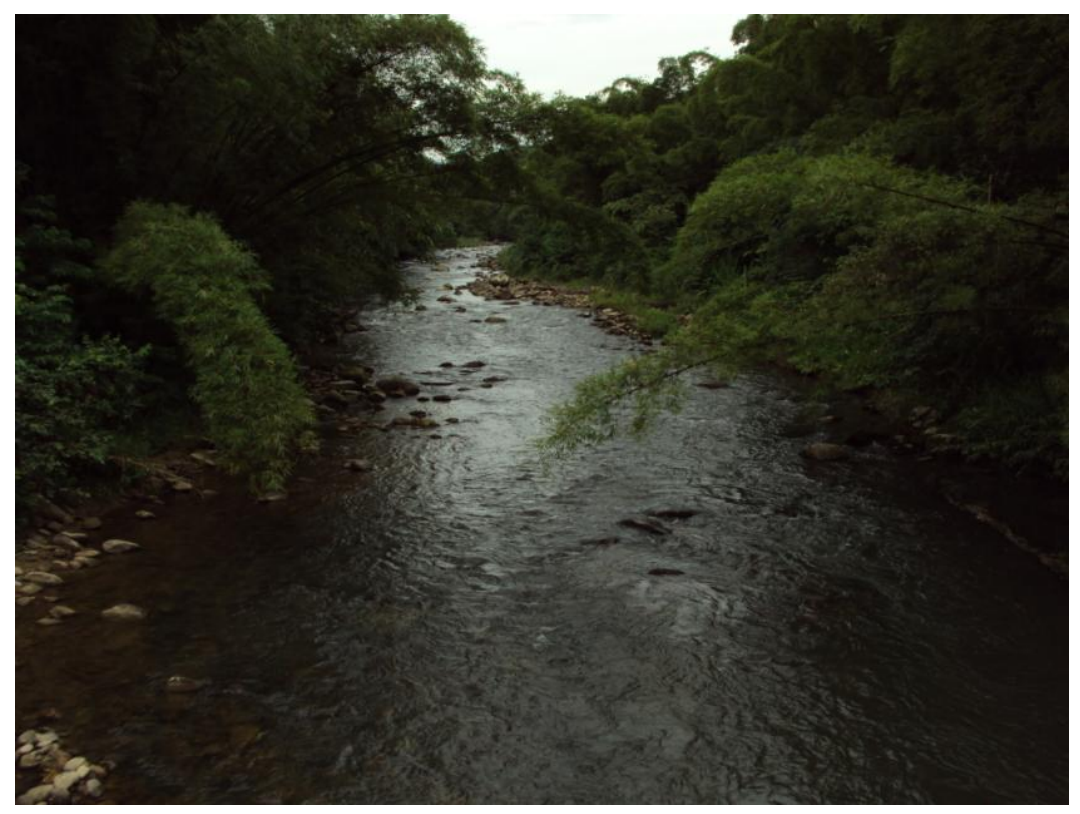

FIGURA 9 - Rio Cubatão (P0), Ref. Estrada Caminho dos Pilões

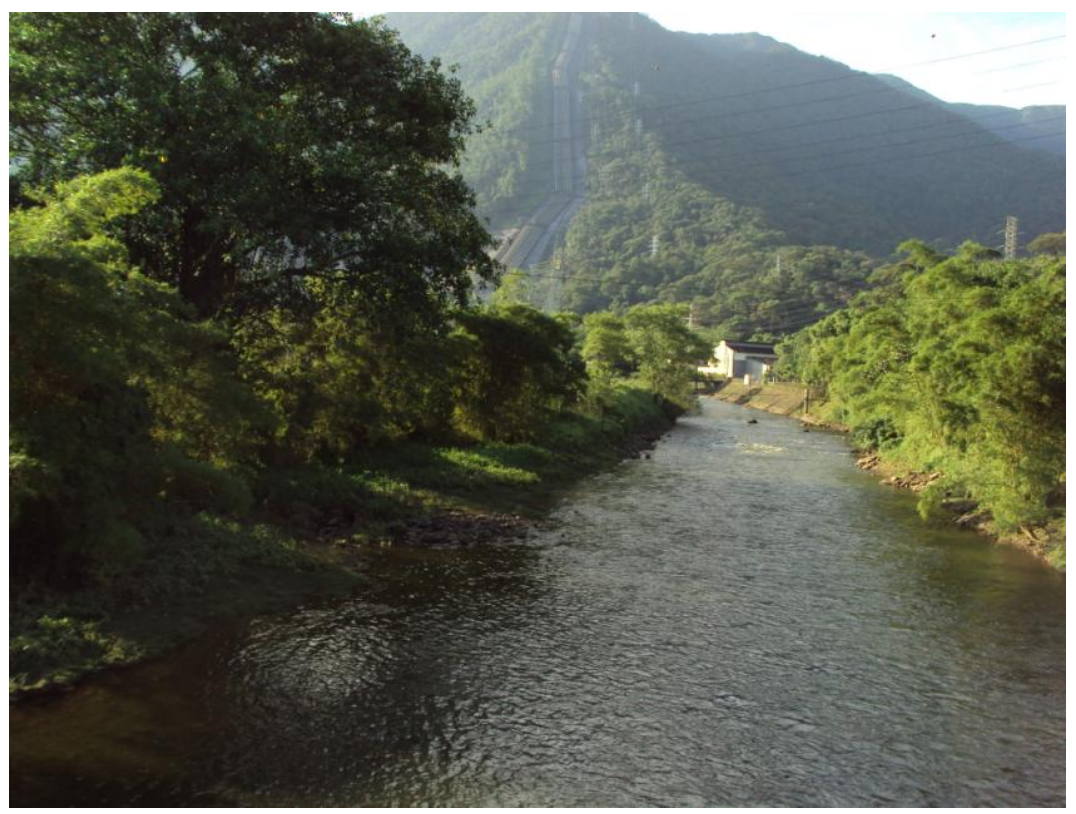

FIGURA 10 - Canal de Fuga II - Usina Henry Borden (P1). 


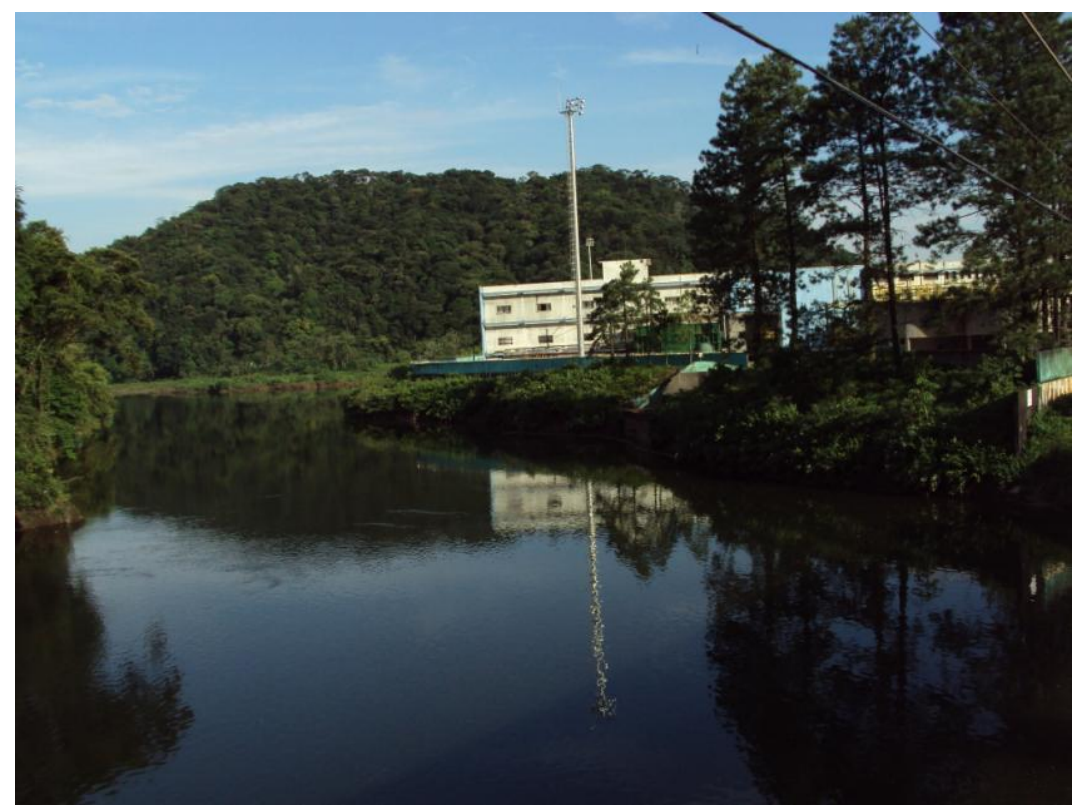

FIGURA 11 - Rio Cubatão (P2) e ETA-3 - Estação de Tratamento de Água

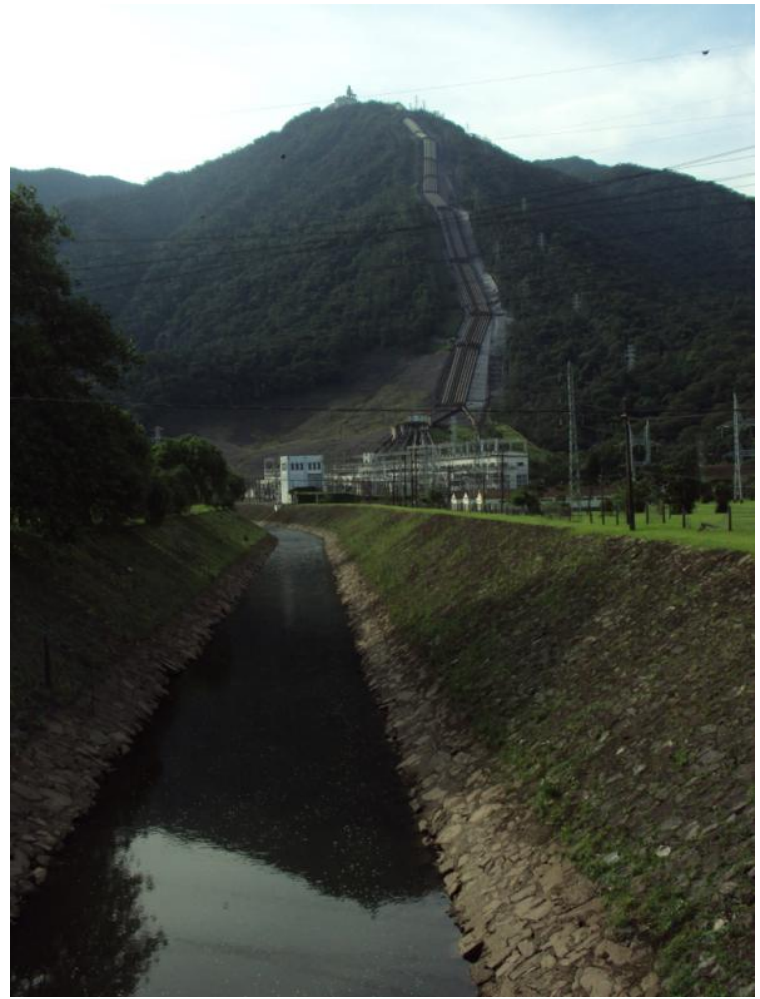

FIGURA 12 - Canal de Fuga I - Usina Henry Borden (P3). 


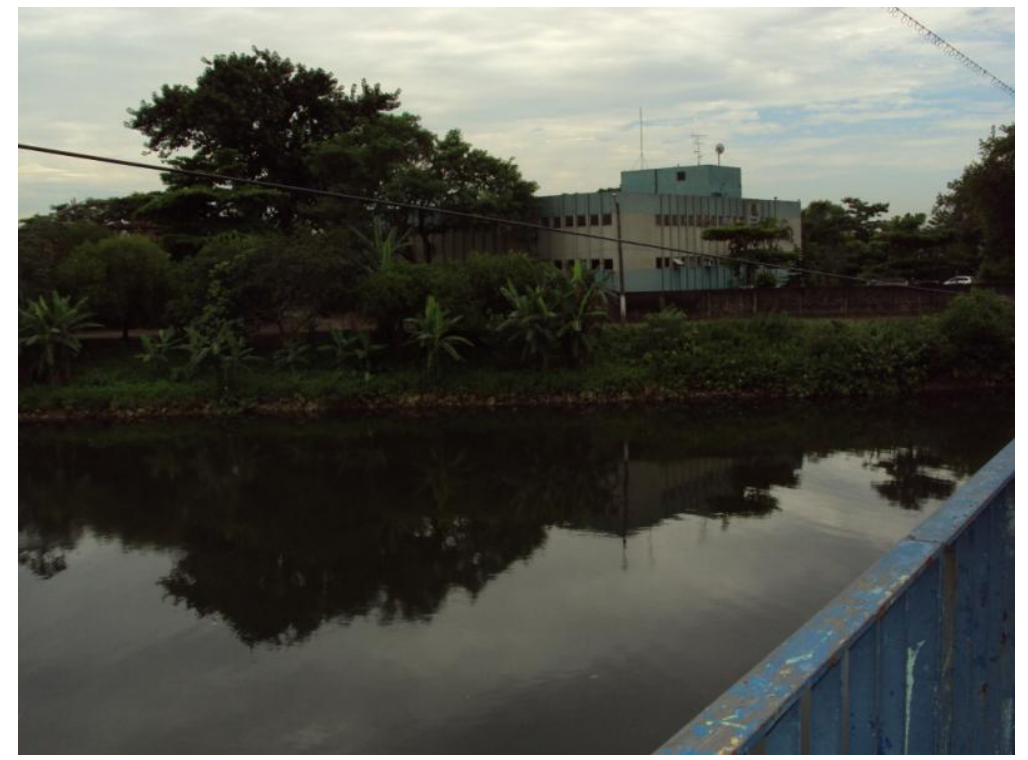

FIGURA 13 - Rio Cubatão (P4) - Ref. Hosp. Ana Costa e Cia Bras.de Estireno

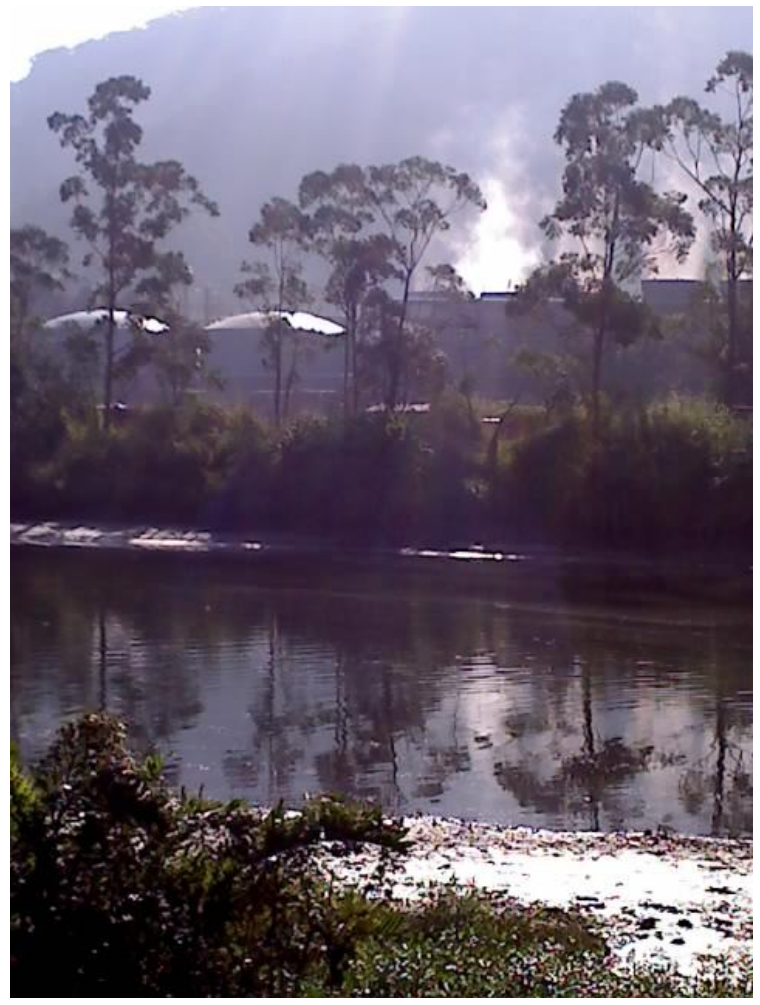

FIGURA 14 - Rio Cubatão (P5) - Ref. salina da Carbocloro S.A. Ind. Quím. 


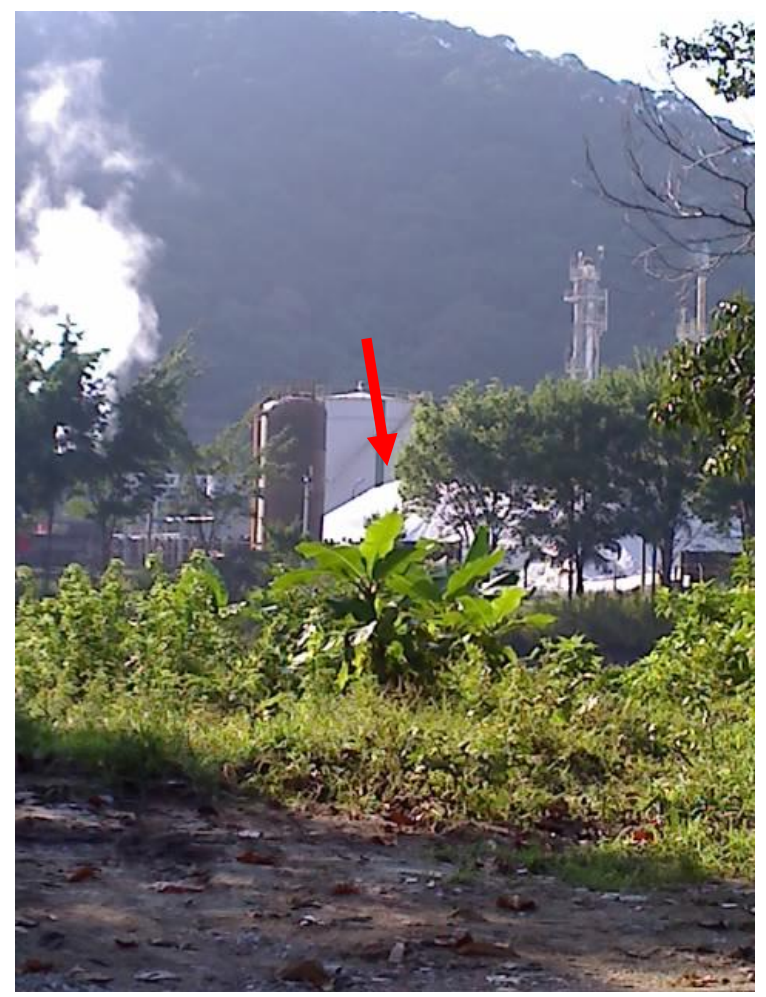

FIGURA 15 - Fotografia da salina da Carbocloro localizada em frente ao P5.

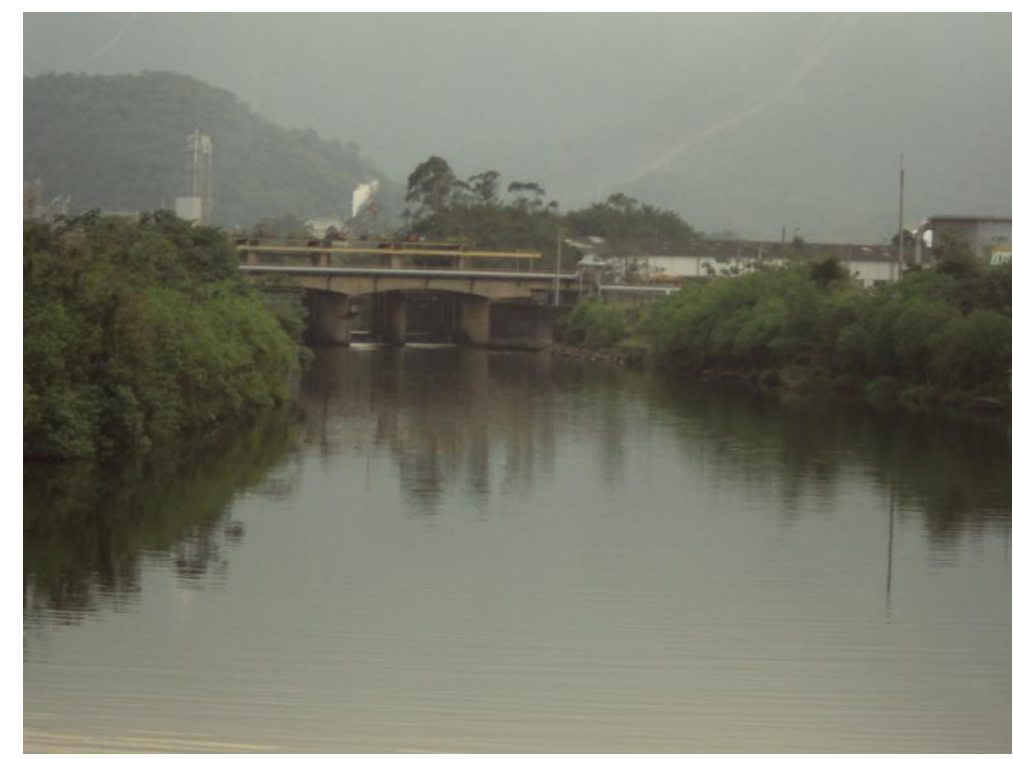

FIGURA 16 - Rio Cubatão (P6) - Refs. Ponte Rod. Côn. D. Rongoni e Barragem da Refinaria RPBC e da Fosfértil 


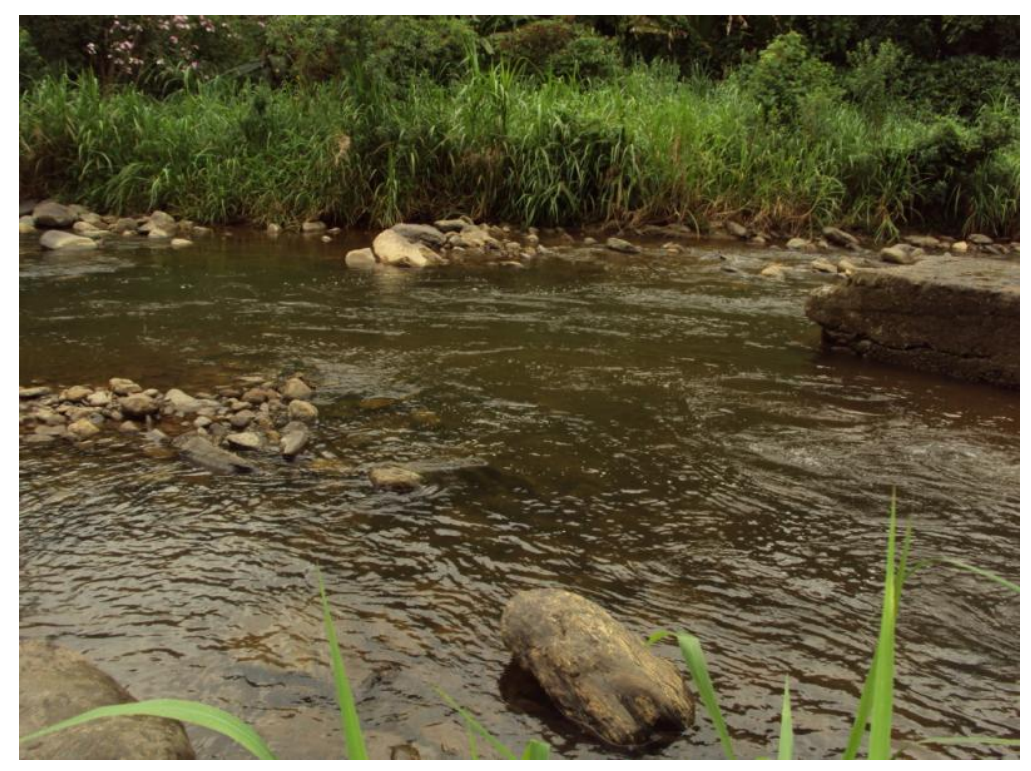

FIGURA 17 - Rio Pilões (PI) - ref.Pq. Ecológico Itutinga Pilões - Antiga V. Itutinga

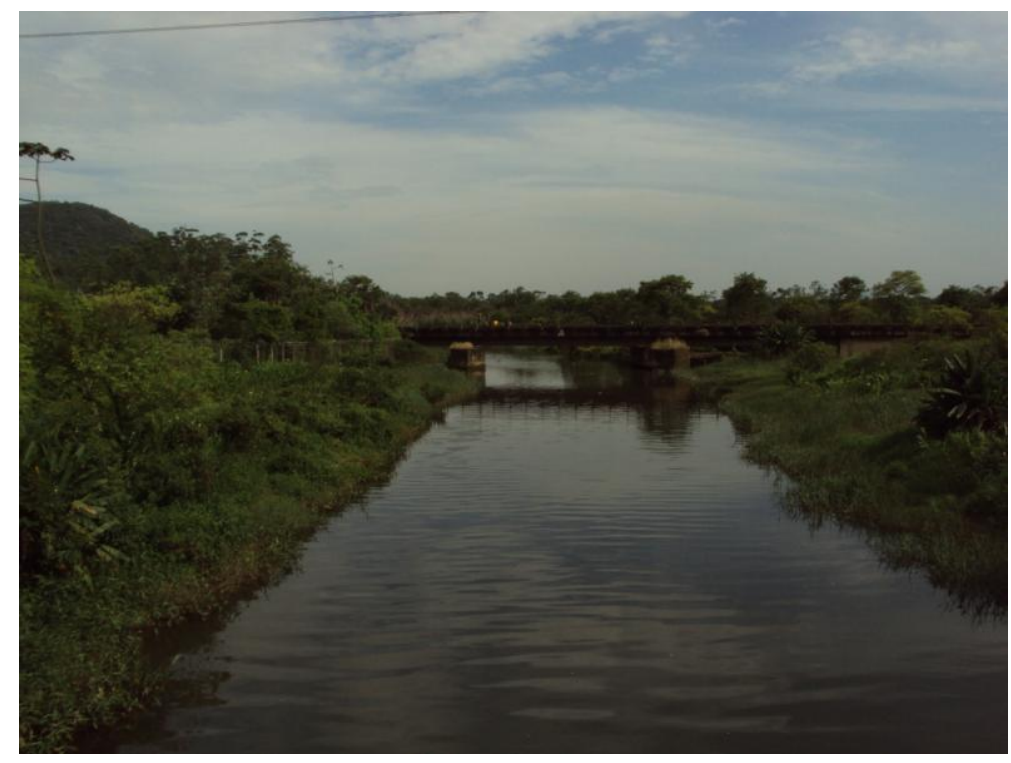

FIGURA 18 - Rio Perequê (PE) - à jusante do Pq. Ecológico Perequê e da Ind.

Petrocoque S.A.

A Figura 19 ilustra o local cuja água foi coletada para a manutenção e cultivo dos organismos aquáticos (Ceriodaphnia dubia) em laboratório e também utilizada como água referência nos ensaios. Esta água foi utilizada como ponto referência devido a dificuldade de encontrar um ponto isento de fontes de contaminação no rio Cubatão. Este ponto referência esta localizado próximo a uma nascente, localizada do Parque Ecológico da Serra do Mar (Caminhos do Mar); estrada velha. 


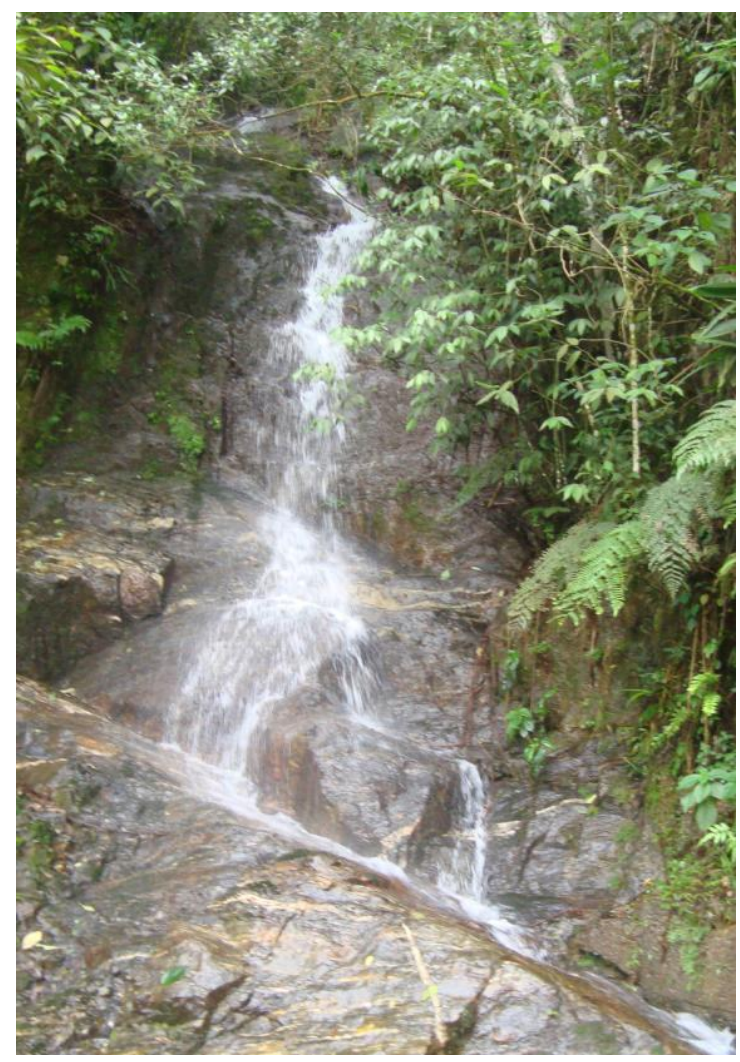

FIGURA 19 - Local onde esta localizado o ponto referência utilizado neste estudo, água utilizada para manutenção de cultivos e em ensaios de toxicidade com $C$. dubia.

\subsection{Metodologias empregadas na determinação de parâmetros físico-químicos em águas}

Os valores para oxigênio dissolvido na água, condutividade e $\mathrm{pH}$ foram obtidos com uso de eletrodos específicos tanto no momento da coleta como em laboratório. Durante as coletas foi utilizado um analisador multiparâmetros (HQ 40d multi - HACH).

No laboratório a concentração de oxigênio dissolvido na água (OD) foi medida com um oxímetro da Digmed DM-4P; medidas de condutividade em amostras de água foram obtidas com o condutivímetro TEC-4MP, da TECNAL, enquanto que os valores de $\mathrm{pH}$ foram medidos no phmetro (TEC - 3MP - TECNAL), sempre precedidos das respectivas calibrações .

A turbidez da água foi obtida com o turbidímetro (modelo FTV color - Hayonik), com as seguintes concentrações padrões $(0,1 ; 0,8 ; 8 ; 80$ e 1000 UNT), soluções estas 
usadas calibração do equipamento, sendo os resultados expressos por Unidade Nefelométrica de Turbidez, UNT.

Os resíduos sólidos foram determinados por pesagem, em cápsulas de porcelanas recomendadas pelo método. A diferença de peso da amostra úmida e seca foi reportada como a concentração de sólidos totais (em ppm) e medidos a partir dos resíduos secos que restaram na cápsula. $\mathrm{O}$ procedimento de secagem durou $24 \mathrm{~h}$, durante os quais as amostras foram mantidas em estufa a $105^{\circ} \mathrm{C}$ com circulação (Estufa - Nova Ética) sendo o cálculo de sólidos totais foi realizado a partir da diferença entre peso inicial e o peso final da cápsula, seguido da transformação g/L para mg/L.

\subsection{Determinação de surfactantes aniônicos}

A determinação de surfactantes aniônicos foi realizada por método de extração por solvente, seguido de leitura de absorbância em espectrofotômetro, segundo método recomendado por APHA, 2005. Utilizando o azul de metileno durante a extração com solvente (clorofórmio) o método também é conhecido como MBAS - methylene blue active substance, uma vez que a extração forma um complexo que apreende o surfactante de interesse para a determinação.

O método compreendeu três extrações sucessivas do surfactante da água para a fase orgânica com clorofórmio, em um meio ácido contendo o Azul de Metileno. Em seguida três sequências de lavagem da solução usando solução adequada foram realizadas a fim de retirar da água possíveis frações residuais do surfactante, sendo juntados todos os volumes da extração e submetidos à determinação da absorbância no comprimento de onda ideal. A partir dos valores de absorbância foram construídas as curvas de calibração, então utilizadas na determinação dos surfactantes contidos nas amostras de água coletadas para este trabalho.

A separação do complexo MBAS foi obtida com uso de funil de separação, como é possível observar pela Figura 20. 


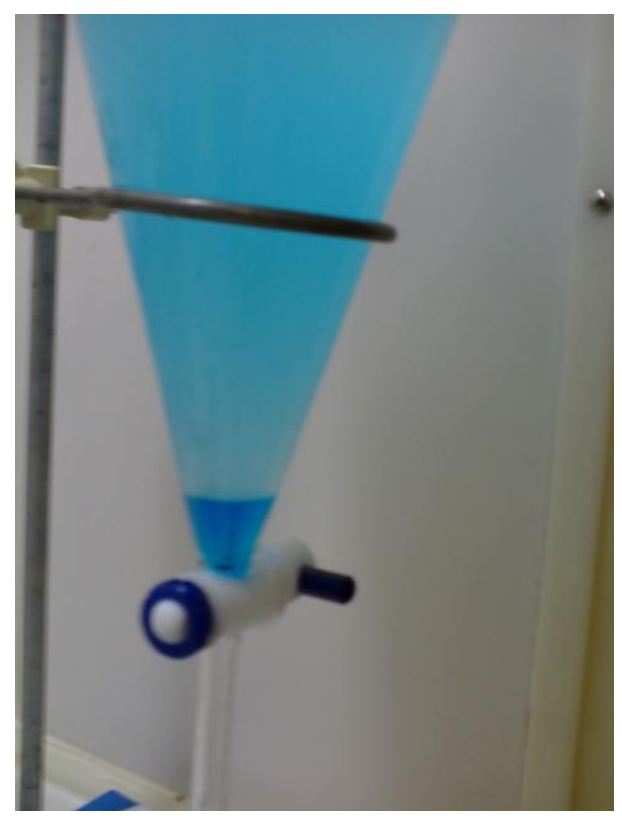

FIGURA 20 - Separação da fase orgânica - método MBAS para surfactantes aniônicos

Visando otimizar a técnica para a determinação de surfactantes aniônicos foram construídas duas curvas de calibração, uma para o dodecilsulfonato de sódio (DSS) e a segunda para o aquilbenzeno linear sulfonado de sódio (LAS). Primeiramente foram preparadas as soluções estoque a partir de $1 \mathrm{~g} / \mathrm{L}$ para preparação da curva de calibração com as seguintes concentrações (0,04; 0,1;0,2;0,4 e 1 mg/L de LAS e DSS) (Figura 21 e 22).

Juntamente com as soluções estoque foram preparadas a solução indicadora de fenolftaleína; a solução de hidróxido de sódio $(\mathrm{NaOH}-1 \mathrm{~N})$; a solução de ácido sulfúrico $\left(\mathrm{H}_{2} \mathrm{SO}_{4}-1 \mathrm{~N}\right)$; a solução de azul de metileno (100 mg de azul de metileno, diluído em água destilada e avolumado a $1000 \mathrm{~mL}$ em balão volumétrico). Finalmente foi preparada a solução de lavagem: $6,8 \mathrm{~mL}$ de ácido sulfúrico concentrado, $50 \mathrm{~g}$ de fosfato monobásico de sódio monohidratado em balão volumétrico, totalizando 1 litro de solução.

A curva colorimétrica para quantificação do surfactante (DSS) foi feita a partir da mesma metodologia descrita anteriormente para (LAS). As análises com o surfactante (DSS) foram feitas para verificar se a uma diferença significativa na determinação de surfactantes em águas superficiais em comparação com o (LAS), dada a dificuldade se quantificar estes compostos em águas naturais. 
Após finalizado o procedimento de extração as leituras foram realizadas no espectrofotômetro UV - VIS ( modelo 2450 - SHIMADZU).

As curvas de calibração de cada um dos surfactantes foram obtidas pelos valores de absorbância em função da concentração do surfactante, sendo que as leituras de absorbância utilizaram diferentes comprimentos de onda: $625 \mathrm{~nm}$ para o LAS e $652 \mathrm{~nm}$ para o DSS.

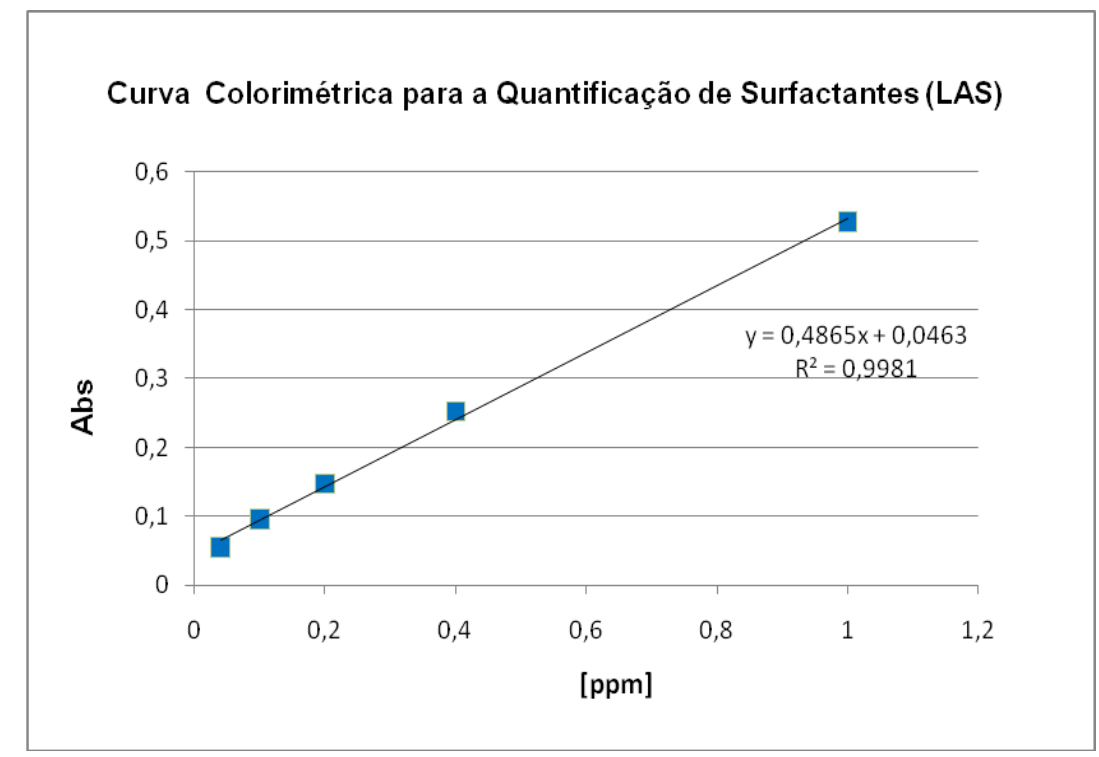

FIGURA 21 - Curva de calibração do surfactante (LAS) em 625 nm.

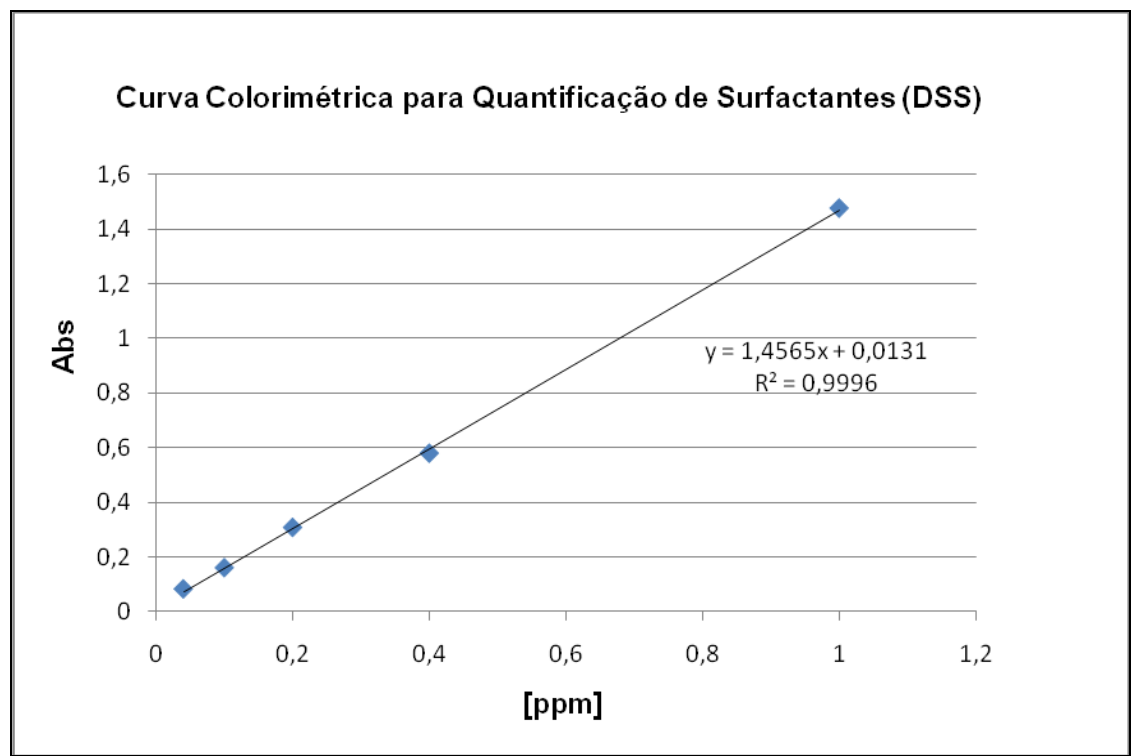

FIGURA 22 - Curva de calibração do surfactante (DSS) em 652 nm. 


\subsection{Determinação de cloretos em águas}

Para a determinação de cloretos foi utilizado o método argentométrico, segundo APHA, 2005. Uma solução neutra de cromato de potássio $\left(\mathrm{K}_{2} \mathrm{CrO}_{4}\right)$ foi utilizada como indicador do ponto final de uma titulação de nitrato de prata $\left(\mathrm{AgNO}_{3}\right)$ em amostra contendo cloretos.

A reação entre o $\mathrm{AgNO}_{3}$ e o $\mathrm{K}_{2} \mathrm{CrO}_{4}$ resulta num precipitado de cor vermelho tijolo, devido a formação do $\mathrm{Ag}_{2} \mathrm{CrO}_{4}$ (cromato de prata), e a reação entre o $\mathrm{AgNO}_{3}$ e o íon $\mathrm{Cl}^{-}$ resulta num precipitado branco, devido a formação do $\mathrm{AgCl}$ (Figura 23).

Soluções utilizadas para a titulação:

- $\quad$ solução padrão de nitrato de prata $0,0141 \mathrm{~N}$;

- solução indicadora de cromato de potássio $\mathrm{K}_{2} \mathrm{CrO}_{4}$;

- hidróxido de sódio $1 \mathrm{~N}$;

- ácido sulfúrico $1 \mathrm{~N}$;

- cloreto de sódio $0,0141 \mathrm{~N}$.

Foram utilizadas titulação em triplicata em todas as amostras a fim de expressar um resultado que represente a média de três valores na obtenção da concentração total de cloretos presentes nas águas. Estes resultados foram obtidos a partir da fórmula a seguir:

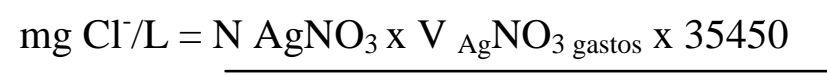

Volume da amostra

Um esquema que mostra a sequência de procedimentos seguidos durante o método é apresentado na figura 23 (FUNASA, 2006). 

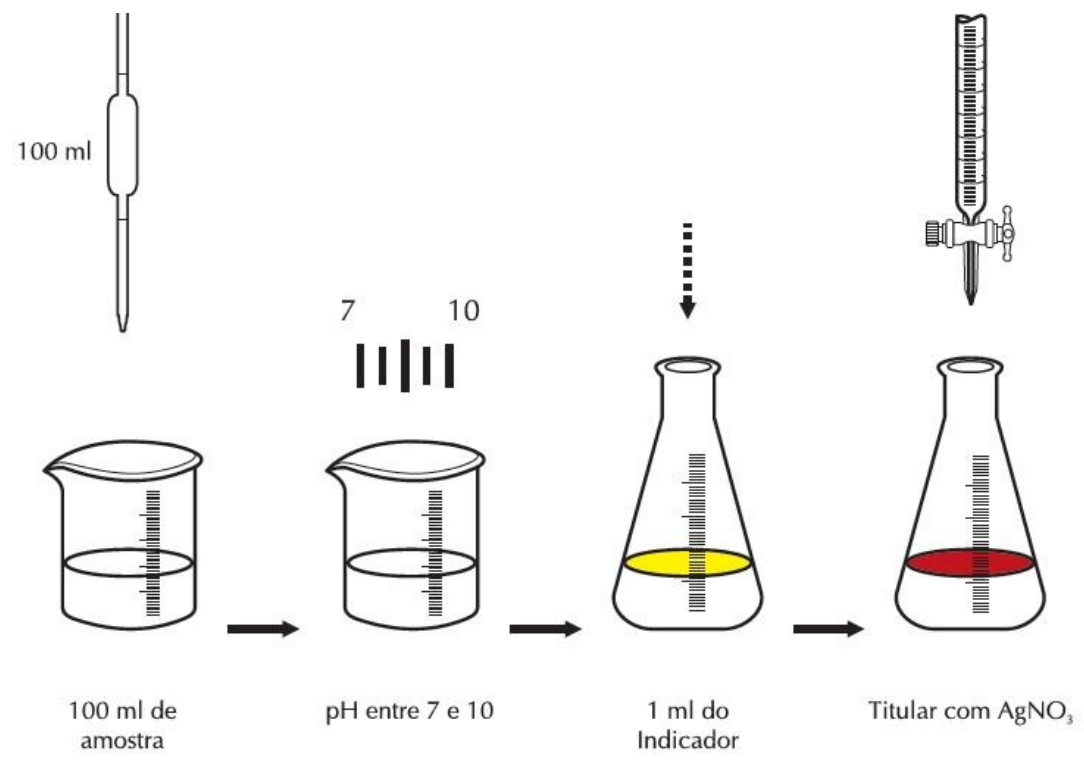

FIGURA 23 - Fluxograma da análise de cloretos (Funasa, 2006)

\subsection{Determinação de fenol em águas}

As análises de compostos fenólicos empregaram extração com solvente, segundo APHA, 2005, sendo o clorofórmio o solvente empregado. As medidas de absorbância foram realizadas no comprimento de onda de $460 \mathrm{~nm}$, no espectofotômetro UV - 50 Bio, VARIAN. Um controle do método empregado (branco com água MiliQ) foi utilizado com a mesma metodologia, para correção final das leituras.

$\mathrm{O}$ fenol contido na água pode reagir com 4-aminoantipirina em um $\mathrm{pH}$ na faixa de $7,9 \pm 0,1$, em presença de ferricianeto de potássio, originando um pigmento colorido de tintura de antipirina. Este pigmento pode ser extraído da fase aquosa com clorofórmio $\left(\mathrm{CHCl}_{3}\right)$ e sua absorbância medida no comprimento de onda de $460 \mathrm{~nm}$.

Este método é indicado para amostras cuja concentração de fenol variem entre 0,1 a $250 \mathrm{mg} / \mathrm{L}$. 


\subsection{Determinação da Demanda Bioquímica de Oxigênio, $\operatorname{DBO}_{(5,20)}$ - método respirométrico simplificado - OXITOP}

A Demanda Bioquímica de Oxigênio (DBO) foi obtida com emprego do método manométrico simplificado, OXITOP ${ }^{\circledR}$, a partir da depuração da matéria orgânica pelas bactérias.

O sistema manométrico OXITOP ${ }^{\circledR}$ é constituído por um microprocessador sem mercúrio, que permite a determinação de DBO de acordo com a pressão exercida dentro do frasco. Os microrganismos ao degradarem a matéria orgânica consomem oxigênio da amostra, ocorrendo uma redução de pressão no interior do frasco (garrafa âmbar, Figura 24). Essa redução é identificada pelo sensor, sendo diretamente proporcional à matéria orgânica presente na amostra de água. $\mathrm{O}$ ensaio ocorre em câmara de germinação mantida a $20^{\circ} \mathrm{C} \pm 1$ (Thermostatic Cabinets - LS LOGEN Scientific) (APHA, 2005; Santos, 2003).

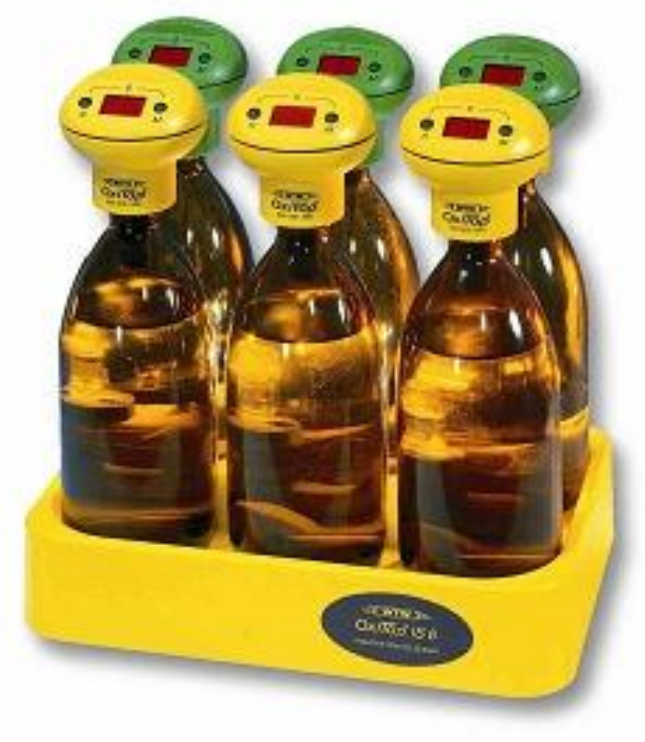

FIGURA 24 - Garrafas empregadas na determinação da DBO - OXITOP ${ }^{\circledR}$

\subsection{Determinação de Carbono Total (CT), Carbono Orgânico Total (COT), e Carbono Inorgânico Total (CIT)}

Esta metodologia empregou a oxidação térmica na presença de ácido. A partir da obtenção do carbono total e do carbono inorgânico, são determinados os valores de carbono orgânico total. O equipamento compreende - detector específico onde é efetuada a 
leitura. Thermo Scientific Hiper TOC. (CLEMENTINO et al, (2008); BISUTTI et al, 2004).

Procedeu-se a obtenção de médias de três determinações para cada um dos parâmetros, sendo apresentados os valores com respectivos desvios padrão (DP) e dados reportados em função da variação entre valores obtidos para cada um dos locais amostrados.

\subsection{Análise de compostos aromáticos}

As análises qualitativas dos compostos aromáticos foram feitas a partir de cromatografia gasosa com injeção líquida, utilizando as seguintes metodologias EPA (1996) e EPA (2007).

Para estas análises foi utilizada a coluna DVB35 Varian factor four (constituição: $5 \%$ diphenyl dimethyl polysilosane $-95 \%$ apolar), sendo esta coluna capilar VF-5ms, com $30 \mathrm{~m}$ x 0,25 mm, com espessura de filme de 0,50 $\mu \mathrm{m}$ (Split 100/Injeção $150{ }^{0} \mathrm{C}$ ).

\subsection{Ensaios de toxicidade empregados no estudo}

Os ensaios ecotoxicológicos foram realizados com Ceriodaphnia dubia (Fig. 25) e Vibrio Fischeri (Fig. 26), seguindo metodologia padronizada pela Associação Brasileira de Normas Técnicas referente a cada espécie (Tabela 6).

TABELA 6 - Metodologia empregada na realização dos ensaios de toxicidade.

\begin{tabular}{ccc}
\hline Método/Norma & Organismo-teste & Resultados \\
\hline ABNT NBR 13373 (2005) & microcrustaceo & Média de neonatos nascidos \\
Ecotoxicologia aquática & Ceriodaphnia dubia & no decorrer da exposição. \\
\hline ABNT NBR 15411-1 & Bactéria & Efeito inibitório da \\
(2006) Ecotoxicologia & luminescente. & bioluminescência, após 15 \\
aquática & Vibrio fischeri & amostra. de exposição à \\
\hline
\end{tabular}




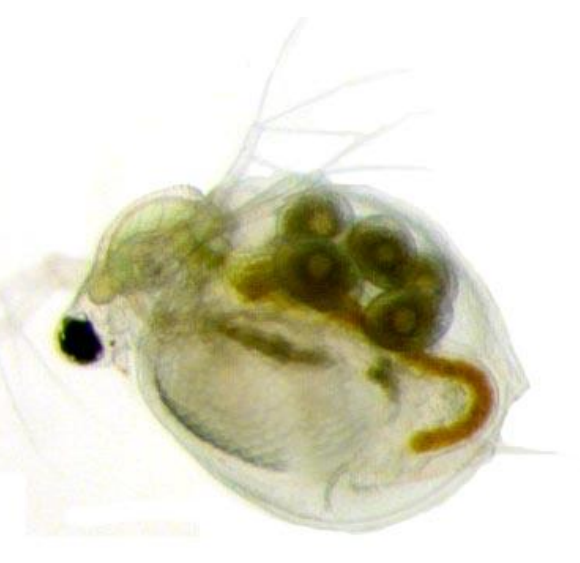

FIGURA 25 - organismo-teste adulto de C.dubia (ROMANELLI, 2004).

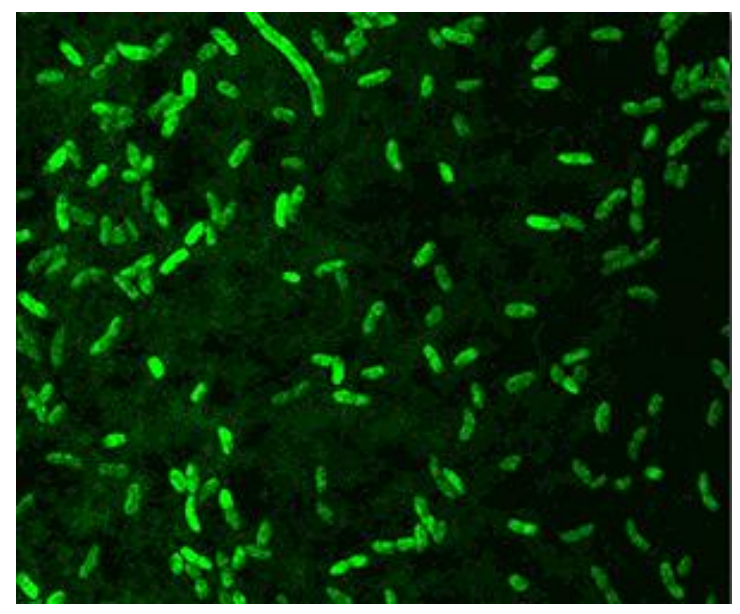

FIGURA 26 - células de $V$.fischeri evidenciando a bioluminescência

(SLONCZEWSKI \& FOSTER, 2010).

Ensaios com Ceriodaphnia dubia: os organismos-teste foram mantidos em cultivos no CEPEMA, em água natural e o alimento desses microcrustáceo foi a microalga verde Pseudokirchneriella subcapitata fornecidas a quantidade de 1 a $5 \times 10^{6}$ células por organismo, complementada por alimento composto a base de ração de truta fermentada e leveduras, com teores de sólidos-totais entre 2,5 g/L a 3,1 g/L; nestas condições é suficiente a adição de $0,02 \mathrm{ml}$ de alimento por organismo.

Antes do início dos ensaios, as amostras foram descongeladas e aclimatadas à uma temperatura de $25^{\circ} \mathrm{C}$. Posteriormente, foram adicionadas $25 \mathrm{~mL}$ das amostras em recipientes de plástico transparente e descartável, onde foram dispostos dez organismos, 
um organismo neonato em cada recipiente (10 replicatas). $\mathrm{O}$ mesmo alimento utilizado no cultivo foi empregado durante os ensaios.

As culturas de C.dubia e os ensaios ecotoxicológicos foram mantidos em câmara de germinação (modelo TE-40I -TECNAL) - a uma temperatura de $25^{\circ} \mathrm{C} \pm 1$ e fotoperíodo de 16 horas luz e 8 horas escuro. Durante a execução dos ensaios de toxicidade com este organismo foram medidos os parâmetros de oxigênio dissolvido na água e pH (inicial e final).

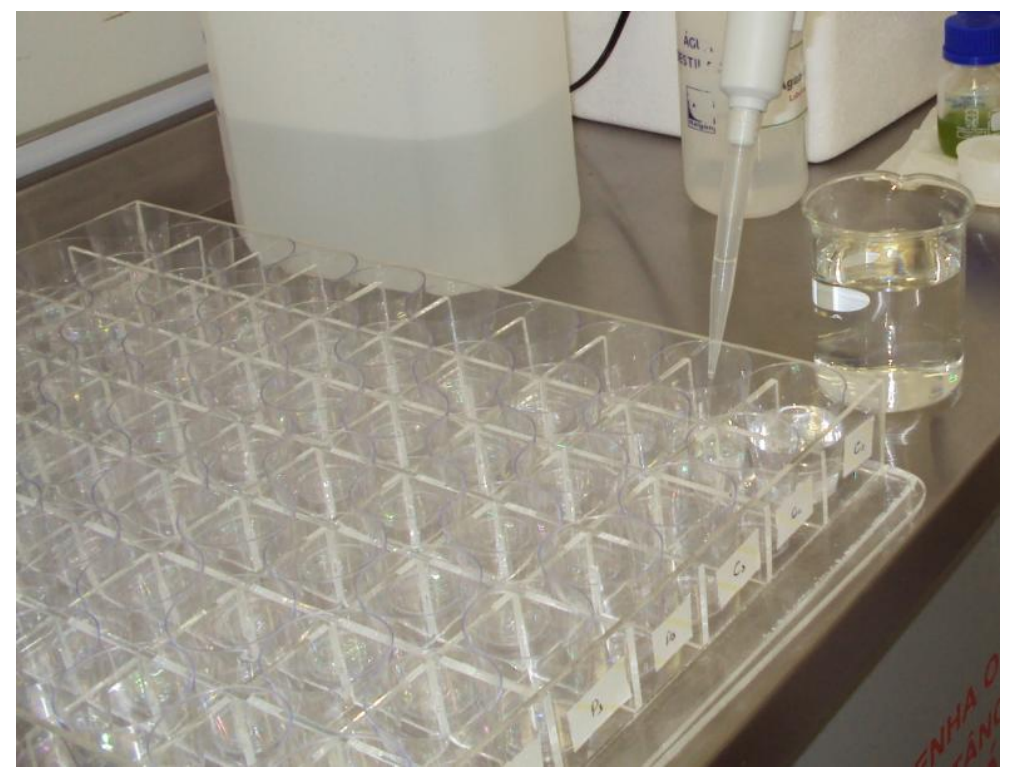

FIGURA 27 - Sistema porta-amostra utilizado nos ensaios com C.dubia.

Os ensaios tiveram duração de sete dias, com alimentação diária e troca da amostra a cada dois dias (teste semi-estático) (Figura 27). A cada troca de amostra durante os ensaios, os neonatos nascidos em cada replicata foram contados e retirados do ensaio. Finalizada a exposição, obteve-se a média de neonatos nascidos para cada amostra, para permitir a comparação com a média de neonatos nascidos nas águas coletadas no ponto referência (PR).

Todos os ensaios com C.dubia foram validados quando o número médio de neonatos obtidos no controle foi igual ou superior a 15, após sete dias de exposição. Valor médio sugerido pela Norma ABNT NBR 13373:2005.

A sensibilidade dos organismos foi avaliada segundo metodologia descrita pela Norma Técnica ABNT NBR 13373:2004, utilizando o cloreto de potássio ( $\mathrm{KCl}$ ) como 
substância de referência. As concentrações utilizadas foram 70;125;250; $300 \mathrm{mg} / \mathrm{L}$ e controle. Os ensaios de sensibilidade foram realizados paralelamente aos ensaios de toxicidade.

De acordo com as Normas Técnicas da ABNT 12713:2004; 13373, o valor obtido do ensaio de sensibilidade deve estar compreendido num intervalo de \pm 2 desvios padrão em relação aos valores médios anteriormente obtidos para a mesma espécie, podendo constituir a carta-controle do laboratório para aquele ensaio.

A análise estatística empregou o Teste "T" e Teste "t por bioequivalênica". De acordo com Buratini e Bertoletti (2008), o Teste "t por bioequivalênica" reduz a incidência de resultados falsos positivos (os efeitos são significativos estatisticamente, mais não são importantes sob o aspecto biológico). Estes testes têm sido empregados de forma qualitativa, onde amostra é caracterizada como tóxica e não tóxica. Para sua aplicação é necessária a definição do nível de efeito biologicamente significativo é incorporado ao cálculo pela constante de proporcionalidade "B” (PRÓSPERI et al, 2008).

Segundo Bertoletti et al (2007), a constante de Bioequivalência (B) calculada para Ceriodaphnia dubia foi $(\mathrm{B}=0,79)$. Os testes estatísticos foram realizados com o programa TOXSTAT, Versão 3.5 (GULLEY, 1996). Os Testes “T” e Testes "t por bioequivalência", empregados permitiram classificar as amostras em tóxicas ou não tóxicas, a partir da comparação com os resultados obtidos no ponto de referência.

Ensaios com Vibrio fischeri: $\mathrm{O}$ ensaio $V$. fischeri consistiu em expor a bactéria à amostra por 15 minutos, sendo registrada a quantidade de luminescência inicial $\left(\mathrm{I}_{0}\right)$ e aquela obtida após a exposição $\left(\mathrm{I}_{15}\right)$, seguindo metodologia descrita na Norma ABNT NBR 15411-2/2006. Como forma de avaliar quantativamente a qualidade das águas superficiais do rio Cubatão e seus contribuintes (afluentes), as amostras coletadas foram diluídas, a fim de calcular a $\mathrm{CE}_{50}$ (concentração efetiva da amostra que causa efeito em $50 \%$ dos organismos), já que as amostras se mostraram tóxicas em todos os pontos amostrados. As concentrações utilizadas nos ensaios realizados com as amostras de todos os pontos foram $13,8 \% ; 20,7 \% ; 31,1 \% ; 46,6 \%, 70 \%$ e controle, em sua maioria. O equipamento utilizado para medir a bioluminescência foi Toxicity Analyser M500, Microbics® (Figura 28). 


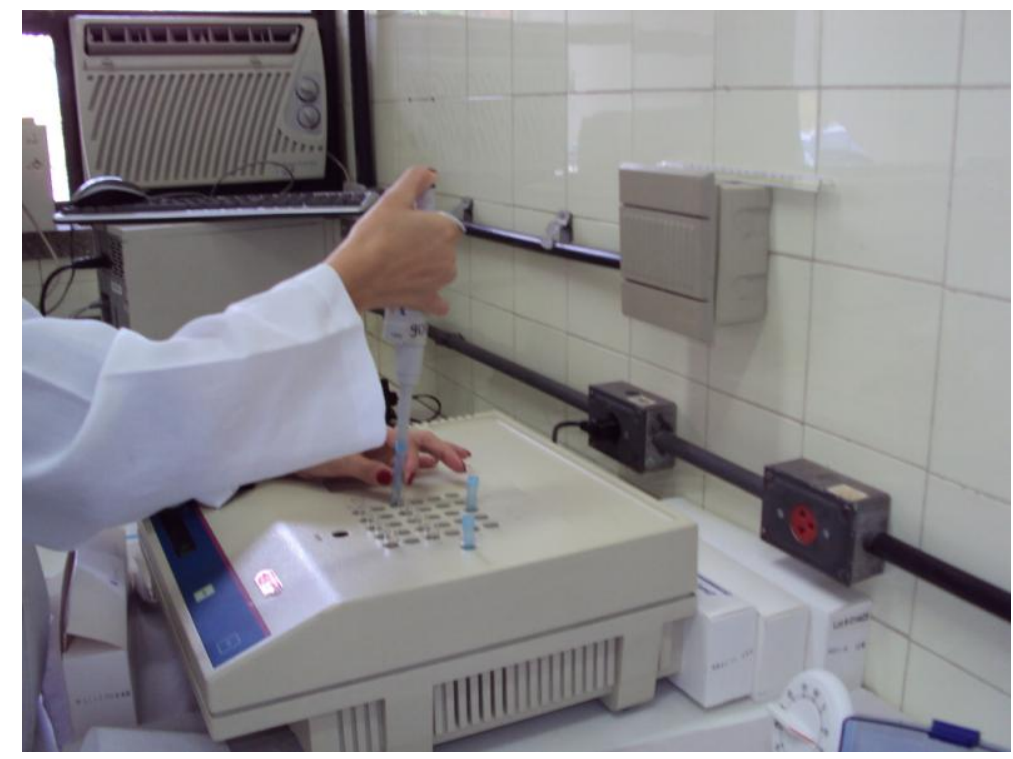

FIGURA 28 - Sistema Microtox utilizado na determinação de bioluminêscia da bactéria $V$. fischeri.

O ensaio se inicia com o acondicionamento da temperatura do ambiente (ideal próximo a $16{ }^{\circ} \mathrm{C}$ ) e do equipamento. Em seguida foi realizada a hidratação da bactéria, adquirida na forma liofilizada. A solução Biolux foi utilizada nesse procedimento, seguindo de transferência da bactéria para algumas cubetas para leitura e verificação da estabilização do sinal (unidades de luz).

No preparo das amostras foram utilizadas a solução diluente e a solução de ajuste osmótico (esta somente na maior concentração da amostra). Assim que o ensaio empregou cubetas de vidro neutro, especiais e descartáveis, para o preparo da série de diluição da amostra bem como para as leituras da bioluminescência. As soluções Biolux, solução de ajuste osmótico, solução de diluição também foram compradas juntamente com o kit de organismo-teste.

Atualmente esses reagentes são adquiridos de laboratório no país. Para a validação dos ensaios foi comparada a sensibilidade dos organismo-teste utilizando fenol como substância de referência. O ensaio foi realizado segundo Norma Técnica ABNT 154112/2006, seguindo o mesmo procedimento utilizado para as amostras de água do rio.

Os resultados obtidos para a $\mathrm{CE}_{(50)}$ foram gerados a partir de uma curva de regressão linear, com os valores de gama (relação entre luz perdida e luz remanescente) e da concentração da amostra, utilizada na série de diluição, empregando o programa estatístico específico da Microbics®. 


\section{RESULTADOS}

Os resultados do estudo visando à determinação de efeitos ecotoxicológicos em águas superficiais do rio Cubatão e seus contribuintes (afluentes) foram obtidos a partir de cinco campanhas. Na primeira campanha foram coletadas amostras em 4 pontos do rio Cubatão e 2 pontos nos canais de fuga da Usina Henry Borden (contribuintes). O ponto P0 foi incluído na terceira campanha e os pontos PI (rio Pilões) e PE (rio Perequê) a partir da quarta campanha. O ponto referência (PR), utilizado neste estudo foi empregado como água controle nos ensaios de toxicidade crônica realizados com C. dubia e na manutenção dos cultivos desses microrganismos, pois o ponto (P0), localizado em uma área mais preservada do rio Cubatão, apresentou indícios de toxicidade, inviabilizando a utilização deste ponto como ponto referência deste estudo.

\subsection{Resultados da caracterização química}

Os resultados das análises físico-químicas referentes às coletas realizadas de julho de 2009 a fevereiro de 2011 em todos os pontos amostrados do rio Cubatão e seus contribuintes (afluentes), são apresentados na Tabela 7, juntamente aos valores de referência estabelecidos na legislação CONAMA 357/2005 para esses parâmetros. Os valores em destaque na tabela encontram-se acima do valor pré-estabelecido na legislação para rios classe 1 e 2 .

TABELA 7 - Dados das análises físico-químicas para as campanhas do período de 2009 a 2011 e os valores referência estabelecidos pelo CONAMA 357/2005. 


\begin{tabular}{|c|c|c|c|c|c|c|c|c|c|c|c|c|c|c|}
\hline & $\stackrel{o}{\stackrel{0}{0}}$ & 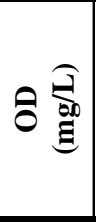 & 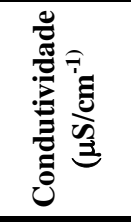 & $\mathbb{2}$ & 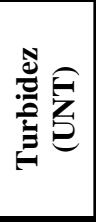 & 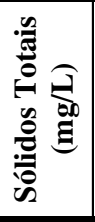 & 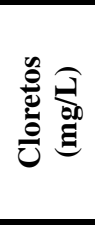 & 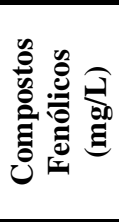 & 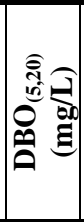 & 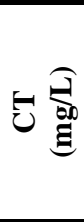 & 卢 & 气઼ & 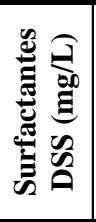 & 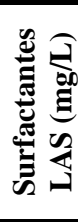 \\
\hline \multicolumn{2}{|c|}{$\begin{array}{c}\text { Conama } \\
\text { 357/classe } 1\end{array}$} & 6,0 & --- & 6 a 9 & 40 & 500 & 250 & 0,003 & 3 & --- & --- & --- & 0,5 & 0,5 \\
\hline \multicolumn{2}{|c|}{$\begin{array}{c}\text { Conama } \\
\text { 357/classe 2 } \\
\end{array}$} & 6,0 & --- & 6 a 9 & 100 & 500 & 250 & 0,003 & 5 & --- & --- & --- & 0,5 & 0,5 \\
\hline \multirow{9}{*}{ 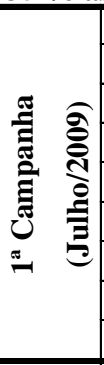 } & P0 & --- & --- & --- & --- & --- & --- & --- & --- & --- & $\overline{---}$ & --- & --- & --- \\
\hline & P1 & 7,99 & 241,0 & --- & --- & --- & --- & --- & --- & --- & --- & --- & --- & $\begin{array}{ll}-- \\
\end{array}$ \\
\hline & $\mathbf{P 2}$ & 9,25 & 200,40 & --- & --- & --- & --- & --- & --- & --- & --- & --- & --- & --- \\
\hline & $\mathbf{P 3}$ & 9,45 & 202,30 & --- & --- & --- & --- & --- & --- & --- & --- & --- & --- & --- \\
\hline & $\mathbf{P 4}$ & 8,24 & $1.860,20$ & --- & --- & --- & --- & --- & --- & --- & --- & --- & --- & --- \\
\hline & P5 & 8,15 & $2.800,0$ & --- & --- & --- & --- & --- & --- & --- & --- & --- & --- & --- \\
\hline & P6 & 8,37 & 212,0 & --- & --- & --- & --- & --- & --- & --- & --- & --- & --- & --- \\
\hline & PI & --- & --- & --- & --- & --- & --- & --- & --- & --- & --- & --- & --- & --- \\
\hline & $\mathbf{P E}$ & --- & --- & --- & --- & --- & --- & --- & --- & --- & --- & --- & --- & --- \\
\hline \multirow{9}{*}{ 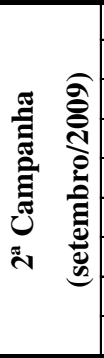 } & P0 & --- & --- & --- & --- & --- & --- & --- & --- & --- & --- & --- & --- & --- \\
\hline & $\mathbf{P 1}$ & 6,4 & 165 & 7,50 & 3,43 & 130 & 108,4 & 3,4 & 12 & 14,2 & 4,12 & 10,11 & 0,04 & --- \\
\hline & $\mathbf{P 2}$ & 6,5 & 91,15 & 7,33 & 5,68 & 65 & 103,7 & 3,62 & 9 & 8,25 & 2,07 & 6,18 & 0,03 & --- \\
\hline & P3 & 6,4 & 163,5 & 7,46 & 3,21 & 80 & 108,4 & 3,37 & 11 & 12,1 & 4,78 & 7,34 & - & --- \\
\hline & P4 & 6,7 & 92,85 & 7,38 & 6,87 & 85,5 & 91,93 & 3,54 & 8 & 4,73 & 1,61 & 3,12 & 0,03 & $\begin{array}{l}-- \\
\end{array}$ \\
\hline & P5 & 6,4 & 464,5 & 6,82 & 7,42 & 280 & 219,3 & 3,55 & 4 & 5,17 & 2,12 & 3,05 & 0,03 & --- \\
\hline & P6 & 6,7 & 89,01 & 7,14 & 7,8 & 82 & 127,3 & 3,45 & 8 & 5,15 & 1,81 & 3,34 & 0,02 & --- \\
\hline & PI & --- & --- & --- & --- & --- & --- & --- & --- & --- & --- & --- & --- & --- \\
\hline & PE & --- & --- & --- & --- & --- & --- & --- & --- & --- & --- & --- & --- & --- \\
\hline \multirow{9}{*}{ 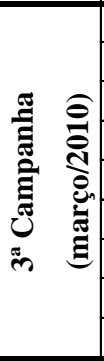 } & P0 & 7 & 31,1 & 7,25 & 17 & 77,5 & 14 & 0,31 & 5 & 6,77 & 1,22 & 5,55 & 0,02 & 0,06 \\
\hline & P1 & 7,53 & 127,3 & 8,00 & 5,68 & 120 & 28,91 & 0,12 & 11 & 13,4 & 6,34 & 15,07 & 0,01 & 0,05 \\
\hline & $\mathbf{P 2}$ & 7,92 & 117,3 & 8,04 & 5,35 & 48,5 & 28,92 & $\mathbf{0 , 1 1}$ & 9 & 11,5 & 5,47 & 13,18 & 0,02 & 0,05 \\
\hline & P3 & 7,82 & 120,5 & 7,91 & 4,51 & 108 & 28,29 & 0,05 & 5 & 19,7 & 7,29 & 21,43 & 0,02 & 0,05 \\
\hline & P4 & 8,11 & 119,5 & 7,54 & 4,81 & 108 & 22,31 & 0,1 & 5 & 13,7 & 6,89 & 15,04 & 0,02 & 0,07 \\
\hline & P5 & 8,26 & 122 & 8,10 & 5,85 & 98 & 31,75 & $\mathbf{0 , 1 2}$ & 11 & 33,1 & 9,2 & 4,35 & 0,02 & 0,05 \\
\hline & P6 & 8,3 & 122,7 & 7,93 & 6,25 & 62 & 31,12 & 0,11 & 9 & 13,2 & 5,72 & 14,86 & 0,05 & 0,14 \\
\hline & PI & --- & --- & --- & --- & --- & --- & --- & --- & --- & --- & --- & --- & --- \\
\hline & PE & --- & --- & --- & --- & --- & --- & --- & --- & --- & --- & --- & --- & --- \\
\hline \multirow{9}{*}{ 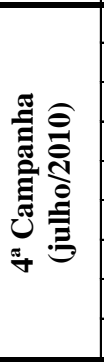 } & P0 & 7,3 & 34,66 & 7,84 & 1,21 & 4,0 & 16,75 & 0 & 2 & 8,47 & 2,26 & 6,21 & 0,04 & 0,11 \\
\hline & P1 & 7,59 & 92,7 & 7,78 & 5,4 & 7,5 & 27,37 & 0 & 4 & 20,8 & 4,61 & 16,22 & 0,03 & 0,09 \\
\hline & $\mathbf{P 2}$ & 7,55 & 88,18 & 7,73 & 3,26 & 40,5 & 23,05 & 0 & 8 & 24,1 & 5,47 & 18,71 & 0,03 & 0,07 \\
\hline & P3 & 7,82 & 112 & 7,87 & 3,83 & 41 & 29,94 & 0 & 5 & 25,7 & 5,78 & 19,95 & 0,03 & 0,08 \\
\hline & P4 & 7,85 & 102,3 & 8,18 & 4,55 & 16,5 & 25,93 & 0 & 5 & 25,0 & 5,75 & 19,32 & 0,03 & 0,05 \\
\hline & P5 & 7,43 & 111,4 & 8,17 & 3,73 & 10,5 & 29,17 & 0 & 9 & 24,7 & 5,81 & 18,97 & 0,02 & 0,07 \\
\hline & P6 & 8,07 & 64,85 & 8,32 & 4,32 & 45,5 & 21,07 & 0 & 5 & 20,8 & 5,09 & 15,73 & 0,04 & 0,1 \\
\hline & PI & 7,88 & 28,8 & 8,53 & 0,68 & 6,0 & 12,33 & 0 & 2 & 3,64 & 1,26 & 2,38 & 0,01 & 0,04 \\
\hline & PE & 7,22 & 36,68 & 7,41 & 1,51 & 7,0 & 18,56 & 0 & 2 & 4,59 & 1,26 & 3,33 & 0,03 & 0,07 \\
\hline \multirow{9}{*}{ 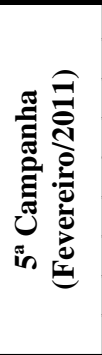 } & P0 & 8,64 & 41,2 & 8,49 & 1,40 & 25 & 3,08 & 0 & 3 & 7,53 & 1,33 & 6,20 & 0,03 & 0,05 \\
\hline & P1 & 7,96 & 147,9 & 8,32 & 9,42 & 35 & 7,48 & 0 & 7 & 14,6 & 6,22 & 8,45 & 0,04 & 0,07 \\
\hline & $\mathbf{P 2}$ & 7,91 & 126,2 & 8,54 & 10,5 & 85 & 4,78 & 0 & 6 & 12,2 & 4,44 & 7,80 & 0,04 & 0,06 \\
\hline & $\mathbf{P 3}$ & 7,77 & 140,1 & 8,51 & 7,06 & 20 & 6,68 & 0 & 7 & 13,5 & 4,53 & 9,03 & 0,04 & 0,08 \\
\hline & P4 & 7,96 & 150,9 & 8,50 & 4,54 & 65 & 7,58 & 0 & 5 & 16,4 & 5,42 & 11,01 & 0,02 & 0,05 \\
\hline & P5 & 8,01 & 373,0 & 8,33 & 6,16 & 200 & 18,48 & 0 & 10 & 18,2 & 4,78 & 13,43 & 0,02 & 0,07 \\
\hline & P6 & 7,88 & 159,7 & 8,66 & 7,76 & 110 & 7,18 & 0 & 9 & 15,3 & 4,57 & 10,77 & 0,03 & 0,06 \\
\hline & PI & 8,41 & 33,5 & 7,75 & 2,25 & 20 & 4,48 & 0 & 2 & 4,69 & 1,32 & 3,39 & 0,01 & 0,03 \\
\hline & PE & 7,83 & 41,5 & 7,36 & 2,80 & 5 & 4,38 & 0 & 2 & 5,73 & 1,45 & 4,43 & 0,02 & 0,05 \\
\hline
\end{tabular}

Legenda: UNT - unidade nefelométrica de turbidez; CT - carbono total ; CIT - carbono inorgânico total; COT - carbono orgânico total. 
Os valores mínimos e máximos, médias com desvio padrão para os parâmetros oxigênio dissolvido, condutividade, $\mathrm{pH}$, turbidez e sólidos totais obtidos foram apresentados na Tabela 8.

TABELA 8 - Faixa de valores determinados para oxigênio dissolvido, condutividade, $\mathrm{pH}$, turbidez e sólidos totais.

\begin{tabular}{|c|c|c|c|c|c|}
\hline & $\begin{array}{c}\text { Oxigênio } \\
\text { Dissolvido } \\
(\mathrm{mg} / \mathrm{L})\end{array}$ & $\begin{array}{l}\text { Condutividade } \\
\qquad(\mu \mathrm{S} / \mathrm{cm})\end{array}$ & pH & $\begin{array}{c}\text { Turbidez } \\
\text { (UNT) }\end{array}$ & $\begin{array}{c}\text { Sólidos Totais } \\
(\mathrm{mg} / \mathrm{L})\end{array}$ \\
\hline $\begin{array}{l}\mathbf{P} \\
\mathbf{0}\end{array}$ & $\begin{array}{c}7,00-8,64 \\
7,65 \pm 0,71 \\
(n=3)\end{array}$ & $\begin{array}{c}31,1-42,2 \\
35,65 \pm 5,12 \\
(n=3)\end{array}$ & $\begin{array}{c}7,25-8,49 \\
7,86 \pm 0,62 \\
(n=3)\end{array}$ & $\begin{array}{c}1,21-17 \\
6,54 \pm 7,40 \\
(n=3)\end{array}$ & $\begin{array}{c}4-77,5 \\
35,50 \pm 36,86 \\
(n=3)\end{array}$ \\
\hline $\begin{array}{l}\mathbf{P} \\
1\end{array}$ & $\begin{array}{c}6,4-7,99 \\
7,49 \pm 0,65 \\
(n=5)\end{array}$ & $\begin{array}{c}92,7-241 \\
154,78 \pm 55,21 \\
(n=5)\end{array}$ & $\begin{array}{c}7,50-8,32 \\
7,9 \pm 0,35 \\
(\mathrm{n}=4)\end{array}$ & $\begin{array}{c}3,43-9,42 \\
5,98 \pm 2,50 \\
(n=4)\end{array}$ & $\begin{array}{c}7,5-130 \\
73,13 \pm 61,08 \\
(n=4)\end{array}$ \\
\hline $\begin{array}{l}\mathbf{P} \\
2\end{array}$ & $\begin{array}{c}6,4-9,25 \\
7,83 \pm 0,98 \\
(n=5)\end{array}$ & $\begin{array}{c}88,18-200,4 \\
124,65 \pm 45,41 \\
(n=5)\end{array}$ & $\begin{array}{c}7,33-8,54 \\
7,91 \pm 0,51 \\
(n=4)\end{array}$ & $\begin{array}{c}3,26-10,5 \\
6,20 \pm 3,06 \\
(n=4)\end{array}$ & $\begin{array}{c}40,5-85 \\
59,75 \pm 19,68 \\
(n=4)\end{array}$ \\
\hline $\begin{array}{l}\mathbf{P} \\
\mathbf{3}\end{array}$ & $\begin{array}{c}6,7-9,45 \\
7,85 \pm 1,08 \\
(n=5)\end{array}$ & $\begin{array}{c}112-202,3 \\
147,68 \pm 36,41 \\
(n=5)\end{array}$ & $\begin{array}{c}7,46-8,51 \\
7,93 \pm 0,43 \\
(n=4)\end{array}$ & $\begin{array}{c}3,21-7,06 \\
4,65 \pm 1,69 \\
(n=4)\end{array}$ & $\begin{array}{c}20-108 \\
62,25 \pm 39,35 \\
(n=4)\end{array}$ \\
\hline $\begin{array}{l}P \\
4\end{array}$ & $\begin{array}{c}6,4-8,24 \\
7,77 \pm 0,62 \\
(n=5)\end{array}$ & $\begin{array}{c}92,85-1860,2 \\
465,15 \pm 780,17 \\
(n=5)\end{array}$ & $\begin{array}{c}7,38-8,50 \\
7,9 \pm 0,53 \\
(n=4)\end{array}$ & $\begin{array}{c}4,54-6,87 \\
5,19 \pm 1,13 \\
(n=4)\end{array}$ & $\begin{array}{c}65-108,5 \\
68,88 \pm 39,18 \\
(n=4)\end{array}$ \\
\hline $\begin{array}{l}\mathbf{P} \\
5\end{array}$ & $\begin{array}{c}6,70-8,26 \\
7,65 \pm 0,77 \\
(n=5)\end{array}$ & $\begin{array}{r}111,4-2.800,0 \\
774,18 \pm 1142,96 \\
(\mathrm{n}=5)\end{array}$ & $\begin{array}{c}6,82-8,33 \\
7,85 \pm 0,70 \\
(n=4)\end{array}$ & $\begin{array}{c}3,75-7,42 \\
5,79 \pm 1,53 \\
(n=4)\end{array}$ & $\begin{array}{c}10,5-117,66 \\
147,13 \pm 117,66 \\
(n=4)\end{array}$ \\
\hline $\begin{array}{l}\mathbf{P} \\
6\end{array}$ & $\begin{array}{c}7,22-8,37 \\
7,86 \pm 0,68 \\
(n=5)\end{array}$ & $\begin{array}{c}64,85-212 \\
129,65 \pm 58,27 \\
(n=5)\end{array}$ & $\begin{array}{c}7,14-8,66 \\
8,01 \pm 0,65 \\
(n=4)\end{array}$ & $\begin{array}{c}4,32-7,80 \\
6,53 \pm 1,64 \\
(n=4)\end{array}$ & $\begin{array}{c}45,5-110 \\
74,88 \pm 27,77 \\
(n=4)\end{array}$ \\
\hline $\begin{array}{l}\mathbf{P} \\
\mathbf{I}\end{array}$ & $\begin{array}{c}7,88-8,41 \\
8,15 \pm 0,37 \\
(n=2)\end{array}$ & $\begin{array}{c}28,8-33,5 \\
31,15 \pm 2,35 \\
(n=2)\end{array}$ & $\begin{array}{c}7,75-8,53 \\
8,14 \pm 0,55 \\
(n=2)\end{array}$ & $\begin{array}{c}0,68-2,25 \\
1,47 \pm 1,11 \\
(n=2)\end{array}$ & $\begin{array}{c}6-20 \\
13,00 \pm 9,90 \\
(n=2)\end{array}$ \\
\hline $\begin{array}{l}\mathbf{P} \\
\mathbf{E}\end{array}$ & $\begin{array}{c}7,22-7,83 \\
7,53 \pm 0,43 \\
(n=2)\end{array}$ & $\begin{array}{c}36,68-41,5 \\
39,09 \pm 2,41 \\
(n=2)\end{array}$ & $\begin{array}{c}7,36-7,41 \\
8,00 \pm 0,04 \\
(n=2)\end{array}$ & $\begin{array}{c}1,51-2,8 \\
2,16 \pm 0,91 \\
(n=2)\end{array}$ & $\begin{array}{c}5-7 \\
6,00 \pm 1,41 \\
(n=2)\end{array}$ \\
\hline
\end{tabular}

Os dados de oxigênio dissolvido (OD) obtidos em águas superficiais do rio Cubatão e seus contribuintes (afluentes), estão representados na Figura 29. 


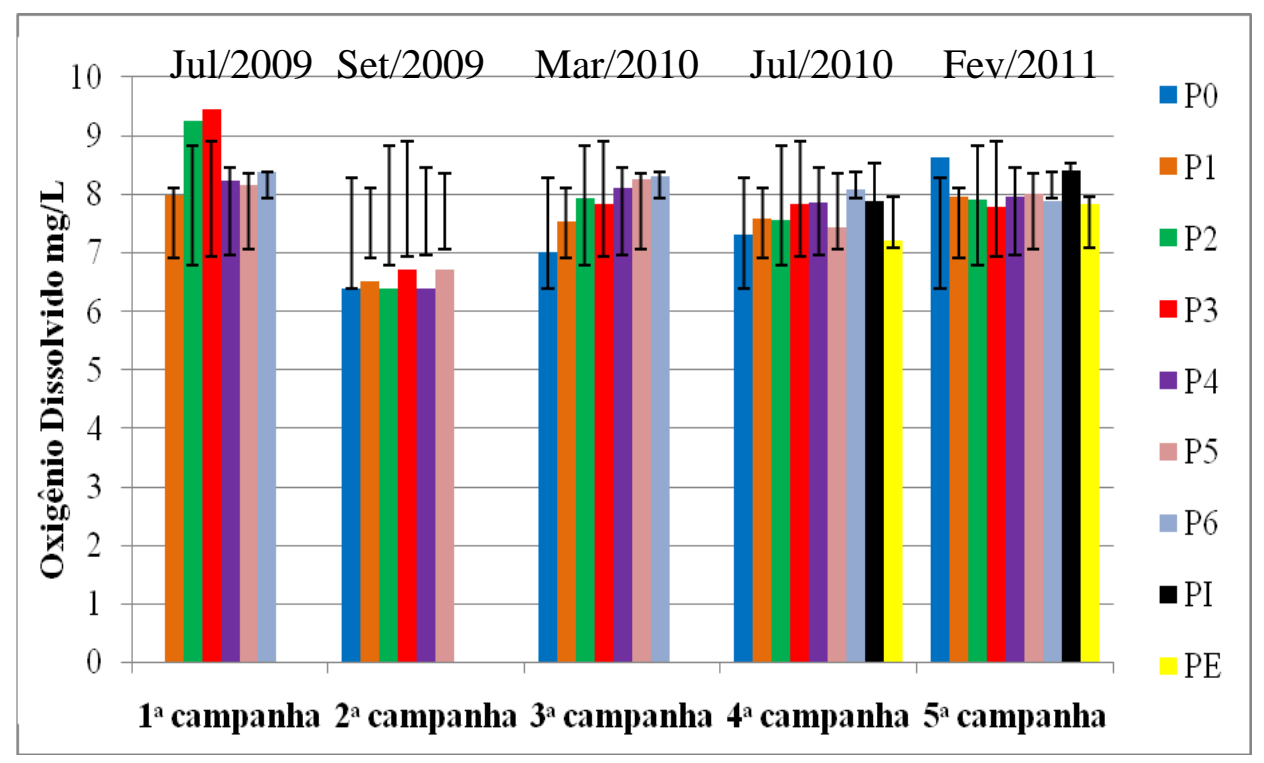

FIGURA 29 - variação de OD entre os pontos amostrados, por campanha.

Os valores da condutividade de águas superficiais coletadas no rio Cubatão e em seus contribuintes (afluentes), estão representados na Fig. 30. Os valores médios calculados, a partir dos resultados obtidos durante as campanhas estão representados na Fig. 31.

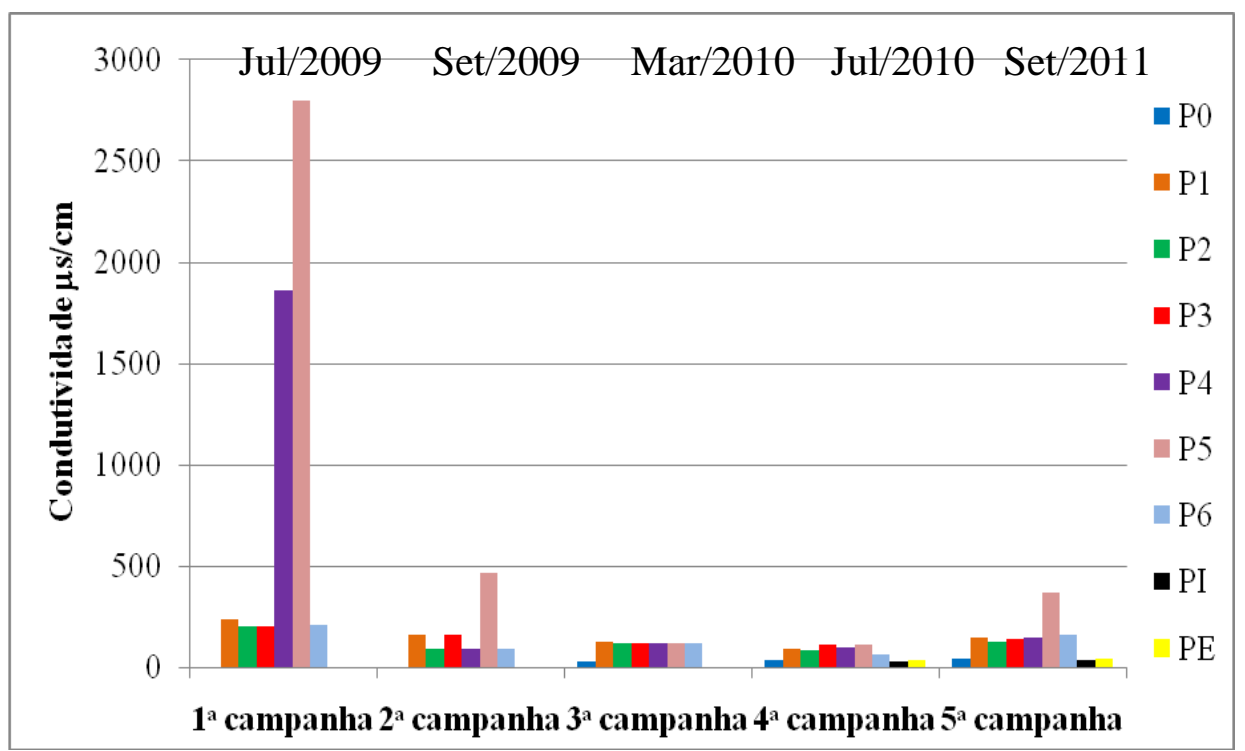

FIGURA 30 - variação dos valores de condutividade obtidos por campanha. 


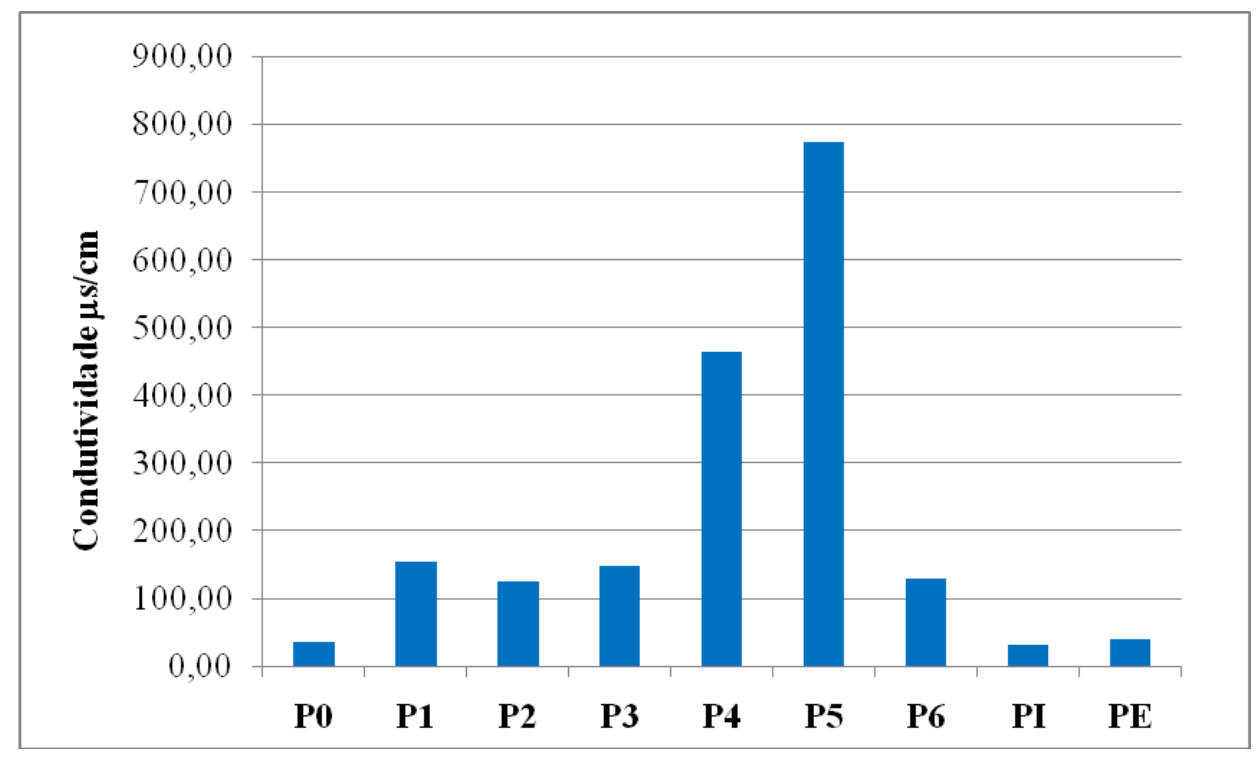

FIGURA 31 - valores médios da condutividade por ponto.

Os dados de $\mathrm{pH}$ obtidos em águas superficiais coletadas no rio Cubatão e seus contribuintes (afluentes), estão apresentados na Figura 32.

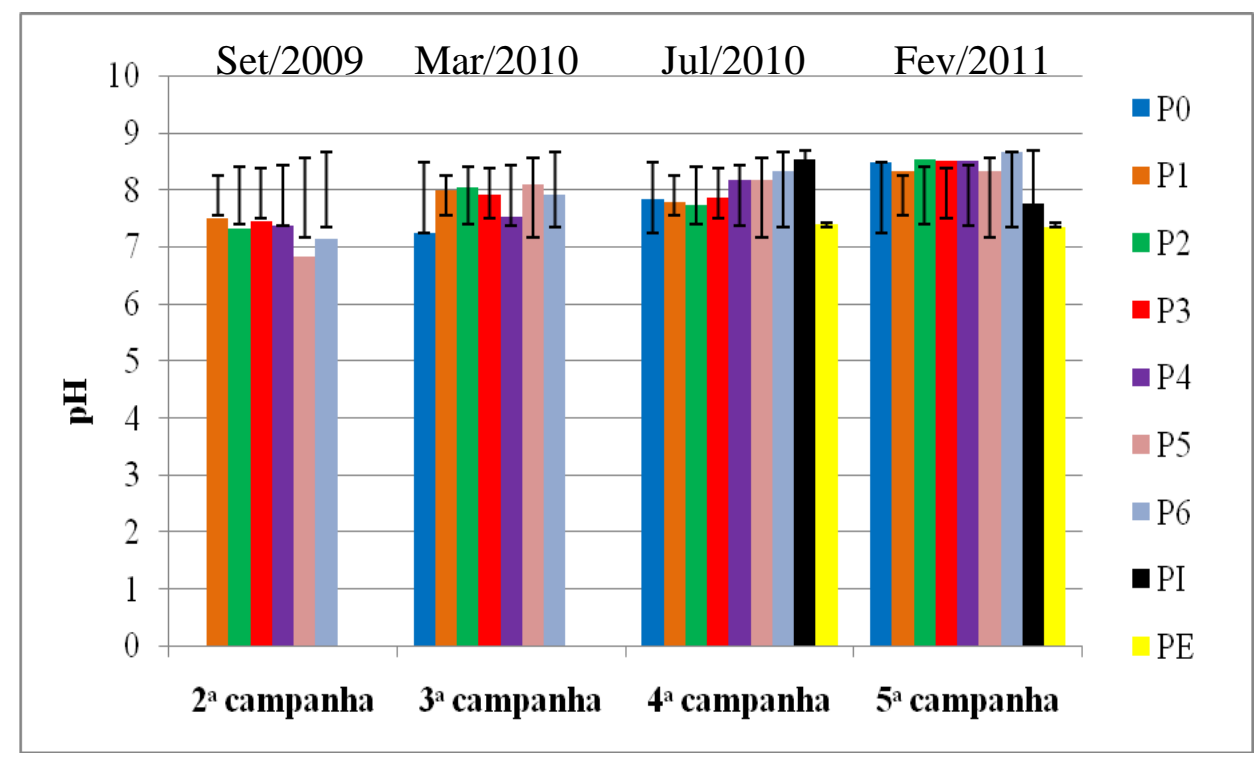

FIGURA 32 - variação do pH da água.

Os resultados de turbidez determinados em amostras de águas do rio Cubatão e seus contribuintes (afluentes), estão apresentados na Figura 33. Os valores médios calculados para este parâmetro estão representados na Figura 34. 


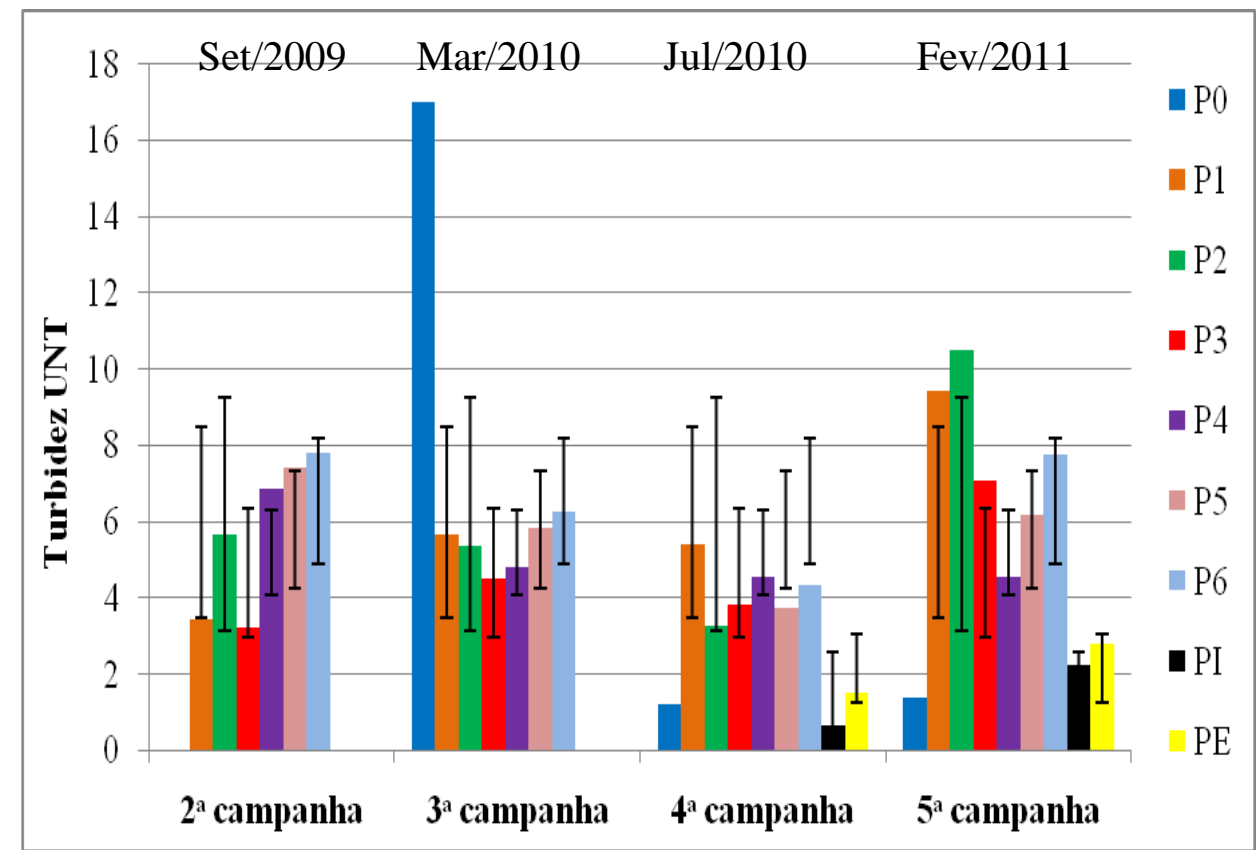

FIGURA 33 - variação da turbidez da água por campanha.

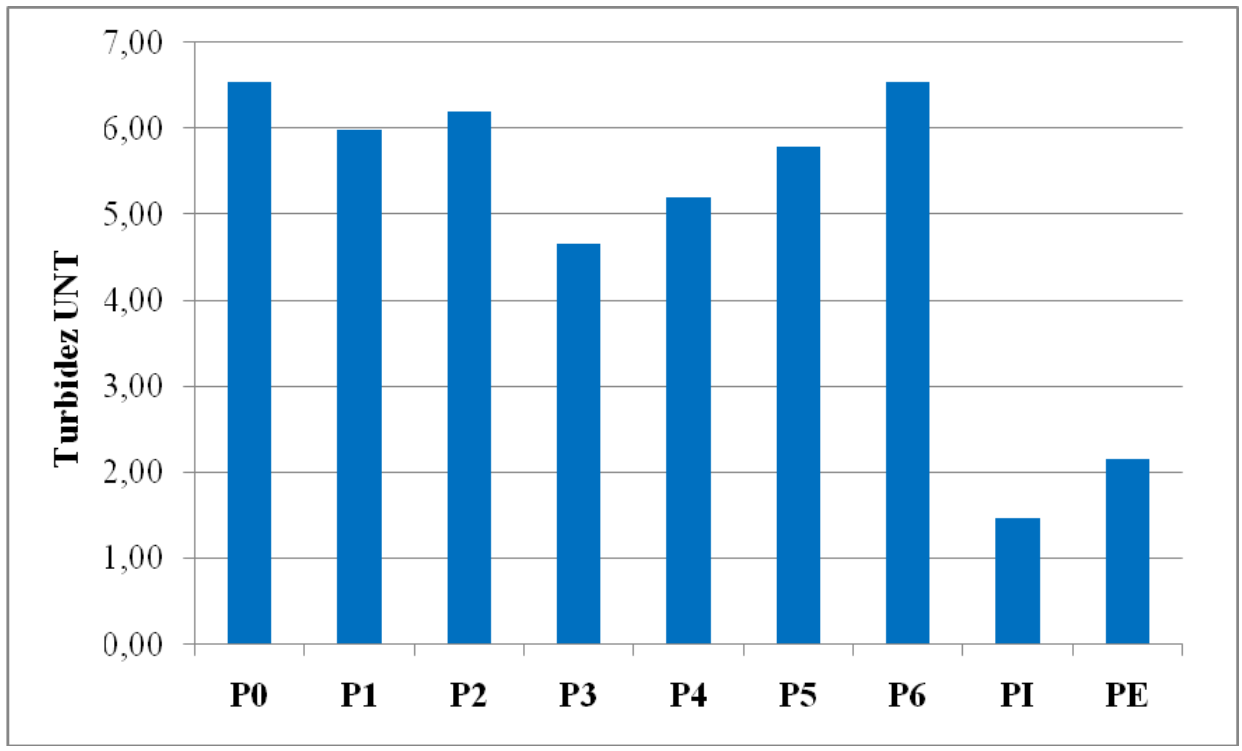

FIGURA 34 - valores médios de turbidez da água por ponto de coleta.

Os dados de sólidos totais obtidos das análises de águas superficiais coletadas no rio Cubatão e seus contribuintes (afluentes), estão apresentados na Figura 35. Os valores médios calculados para este parâmetro estão representados na Figura 36. 


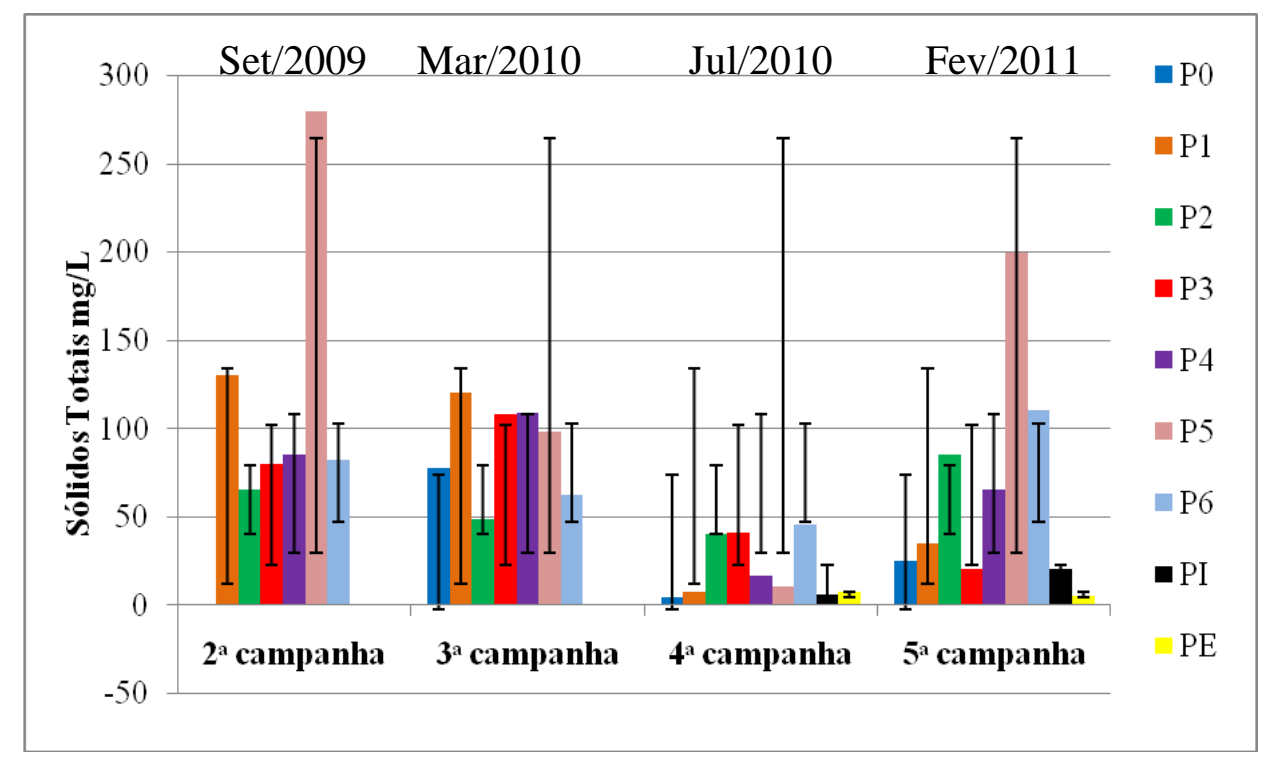

FIGURA 35 - variação de valores de sólidos totais por campanha.

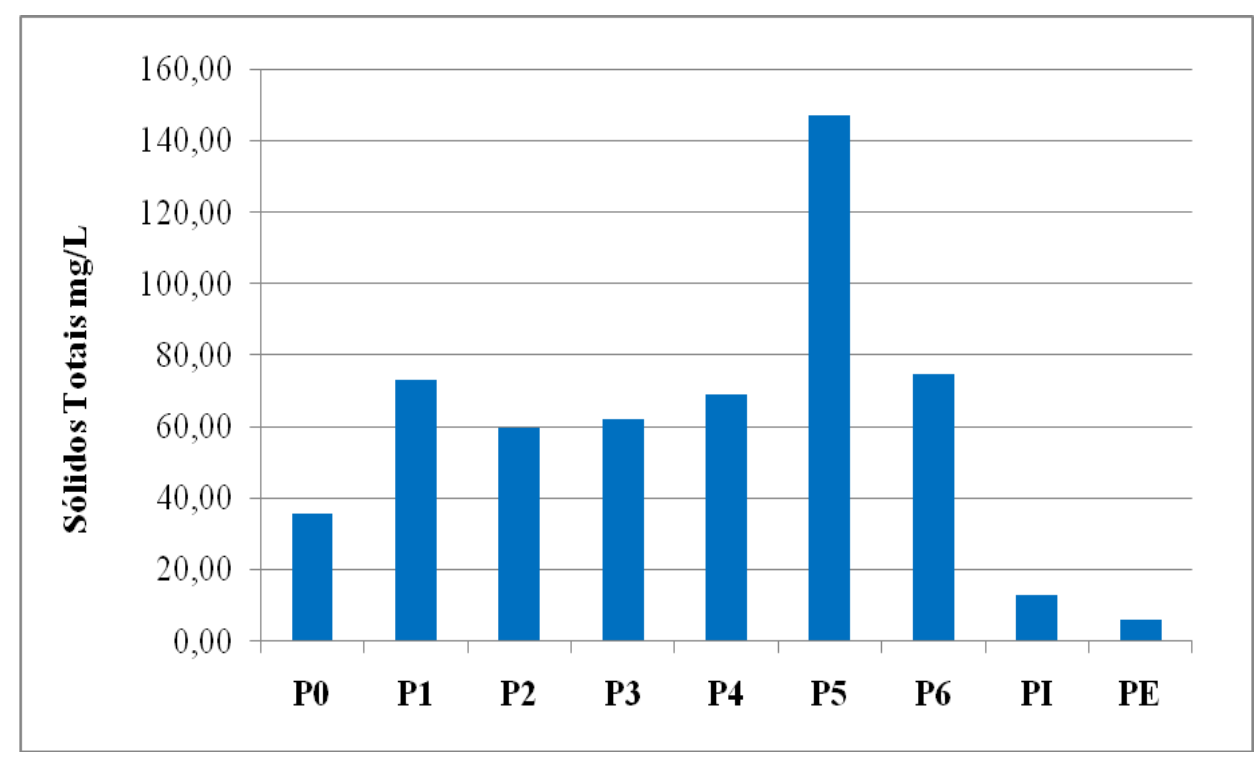

FIGURA 36 - valores médios obtidos para sólidos totais por ponto.

Os valores mínimos e máximos, médias com desvio padrão para os parâmetros Cloretos, $\operatorname{DBO}_{(5,20)}$, Carbono Total $(\mathrm{CT})$, Carbono Inorgânico Total (CIT) e Carbono Orgânico Total (COT), foram apresentados na Tabela 9. 
TABELA 9 - Faixa de valores determinados para cloretos, $\operatorname{DBO}_{(5,20)}$, carbono total, carbono inorgânico total e carbono orgânico total.

\begin{tabular}{|c|c|c|c|c|c|}
\hline & $\begin{array}{c}\text { Cloretos } \\
(\mathrm{mg} / \mathrm{L})\end{array}$ & $\begin{array}{c}\operatorname{DBO}_{(5,20)} \\
(\mathrm{mg} / \mathrm{L})\end{array}$ & $\begin{array}{c}\mathrm{CT} \\
(\mathrm{mg} / \mathrm{L}) \\
\end{array}$ & $\begin{array}{c}\mathbf{C I T} \\
(\mathrm{mg} / \mathrm{L})\end{array}$ & $\begin{array}{c}\text { COT } \\
(\mathrm{mg} / \mathrm{L})\end{array}$ \\
\hline \multirow{3}{*}{$\begin{array}{l}\mathbf{P} \\
\mathbf{0}\end{array}$} & $3,08-16,75$ & $2-5$ & $6,77-8,47$ & $1,22-2,26$ & $5,55-6,21$ \\
\hline & $11,28 \pm 7,23$ & $3,33 \pm 1,53$ & $7,59 \pm 0,85$ & $1,60 \pm 0,57$ & $5,98 \pm 0,37$ \\
\hline & $(n=3)$ & $(\mathrm{n}=3)$ & $(n=3)$ & $(n=3)$ & $(n=3)$ \\
\hline \multirow{3}{*}{$\begin{array}{l}\mathbf{P} \\
\mathbf{1}\end{array}$} & $7,48-108,4$ & $4-12$ & $13,41-20,13$ & $4,12-6,34$ & $8,45-16,22$ \\
\hline & $43,04 \pm 44,6$ & $8,50 \pm 3,70$ & $15,78 \pm 3,40$ & $5,32 \pm 1,12$ & $13,80 \pm 3,76$ \\
\hline & $(n=4)$ & $(n=4)$ & $(n=4)$ & $(n=4)$ & $(n=4)$ \\
\hline \multirow{3}{*}{$\begin{array}{l}\mathbf{P} \\
2\end{array}$} & $4,78-103,7$ & $6-9$ & $8,25-24,18$ & $2,07-5,47$ & $6,18-18,71$ \\
\hline & $40,11 \pm 43,62$ & $8,00 \pm 1,41$ & $14,04 \pm 6,97$ & $4,36 \pm 1,60$ & $11,46 \pm 5,68$ \\
\hline & $(n=4)$ & $(n=4)$ & $(n=4)$ & $(n=4)$ & $(\mathrm{n}=4)$ \\
\hline \multirow{3}{*}{$\begin{array}{l}\mathbf{P} \\
\mathbf{3}\end{array}$} & $6,68-108,4$ & $5-11$ & $12,12-25,73$ & $4,53-7,29$ & $7,34-21,43$ \\
\hline & $43,33 \pm 44,66$ & $7,00 \pm 2,83$ & $17,79 \pm 6,24$ & $5,59 \pm 1,25$ & $14,43 \pm 7,27$ \\
\hline & $(n=4)$ & $(n=4)$ & $(n=4)$ & $(n=4)$ & $(n=4)$ \\
\hline \multirow{3}{*}{$\begin{array}{l}P \\
4\end{array}$} & $7,58-91,53$ & $5-8$ & $4,73-25,07$ & $1,61-6,89$ & $3,12-19,32$ \\
\hline & $36,94 \pm 37,51$ & $5,75 \pm 1,50$ & $14,99 \pm 8,37$ & $4,91 \pm 2,29$ & $12,12 \pm 6,89$ \\
\hline & $(n=4)$ & $(n=4)$ & $(n=4)$ & $(n=4)$ & $(n=4)$ \\
\hline \multirow{3}{*}{$\begin{array}{l}P \\
5\end{array}$} & $18,48-210,3$ & $4-11$ & $5,17-33,14$ & $2,12-9,2$ & $3,05-18,97$ \\
\hline & $74,68 \pm 96,59$ & $8,50 \pm 3,11$ & $20,57 \pm 11,75$ & $5,72 \pm 2,89$ & $9,95 \pm 7,58$ \\
\hline & $(n=4)$ & $(n=4)$ & $(n=4)$ & $(n=4)$ & $(n=4)$ \\
\hline \multirow{3}{*}{$\begin{array}{l}P \\
6\end{array}$} & $7,18-127,3$ & $5-9$ & $5,15-20,83$ & $1,81-5,72$ & $3,34-15,73$ \\
\hline & $46,67 \pm 54,64$ & $7,75 \pm 1,89$ & $13,63 \pm 6,50$ & $4,21 \pm 1,72$ & $11,17 \pm 5,65$ \\
\hline & $(n=4)$ & $(n=4)$ & $(n=4)$ & $(n=4)$ & $(n=4)$ \\
\hline \multirow{3}{*}{$\begin{array}{l}\mathbf{P} \\
\mathbf{I}\end{array}$} & $4,48-12,33$ & $2-2$ & $3,64-4,69$ & $1,26-1,32$ & $2,38-3,39$ \\
\hline & $8,41 \pm 5,55$ & $2,00 \pm 0$ & $4,16 \pm 0,74$ & $1,29 \pm 0,04$ & $2,88 \pm 0,71$ \\
\hline & $(n=2)$ & $(n=2)$ & $(n=2)$ & $(n=2)$ & $(n=2)$ \\
\hline \multirow{3}{*}{$\begin{array}{l}\mathbf{P} \\
\mathbf{E}\end{array}$} & $4,38-18,56$ & $2-2$ & $4,59-5,73$ & $1,26-1,45$ & $3,33-4,43$ \\
\hline & $11,47 \pm 10,03$ & $2,00 \pm 0$ & $5,16 \pm 0,80$ & $1,35 \pm 0,13$ & $3,88 \pm 0,77$ \\
\hline & $(\mathrm{n}=2)$ & $(\mathrm{n}=2)$ & $(\mathrm{n}=2)$ & $(n=2)$ & $(\mathrm{n}=2)$ \\
\hline
\end{tabular}

Os valores para cloretos determinados em águas superficiais coletadas no rio Cubatão e em seus contribuintes (afluentes), estão apresentados na Figura 37. Os valores médios para este parâmetro calculados por ponto, estão representados na Figura 38. 


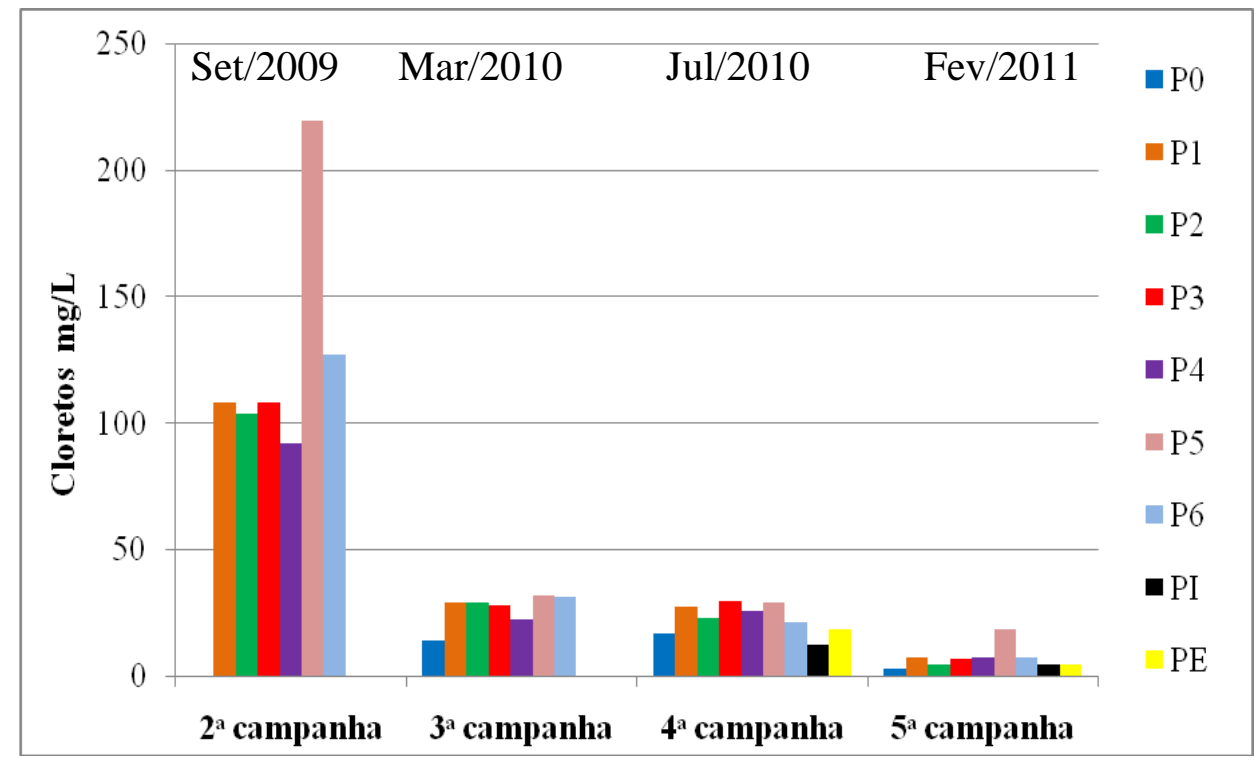

FIGURA 37 - variação dos valores obtidos para cloretos por campanha.

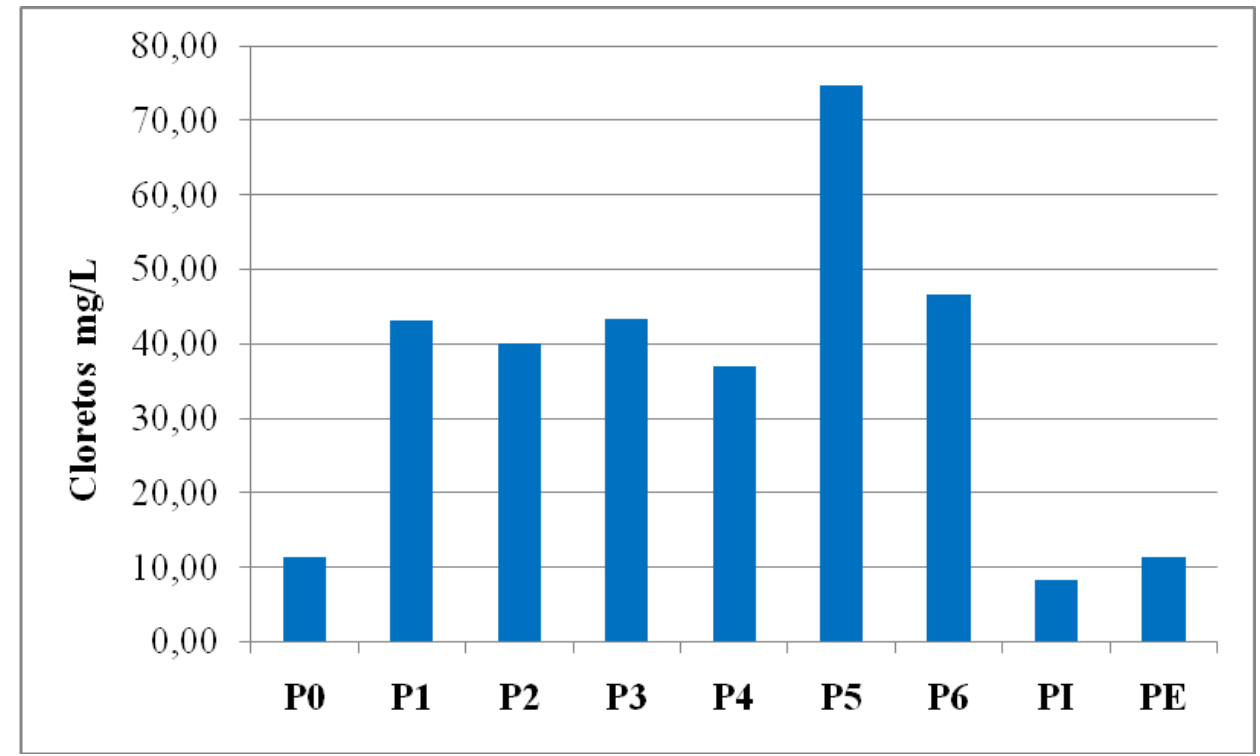

FIGURA 38 - valores médios de cloretos por ponto amostrado.

Os dados determinados de $\mathrm{DBO}_{(5,20)}$ em águas superficiais coletadas no rio Cubatão e seus contribuintes (afluentes), estão apresentados na Figura 39. 


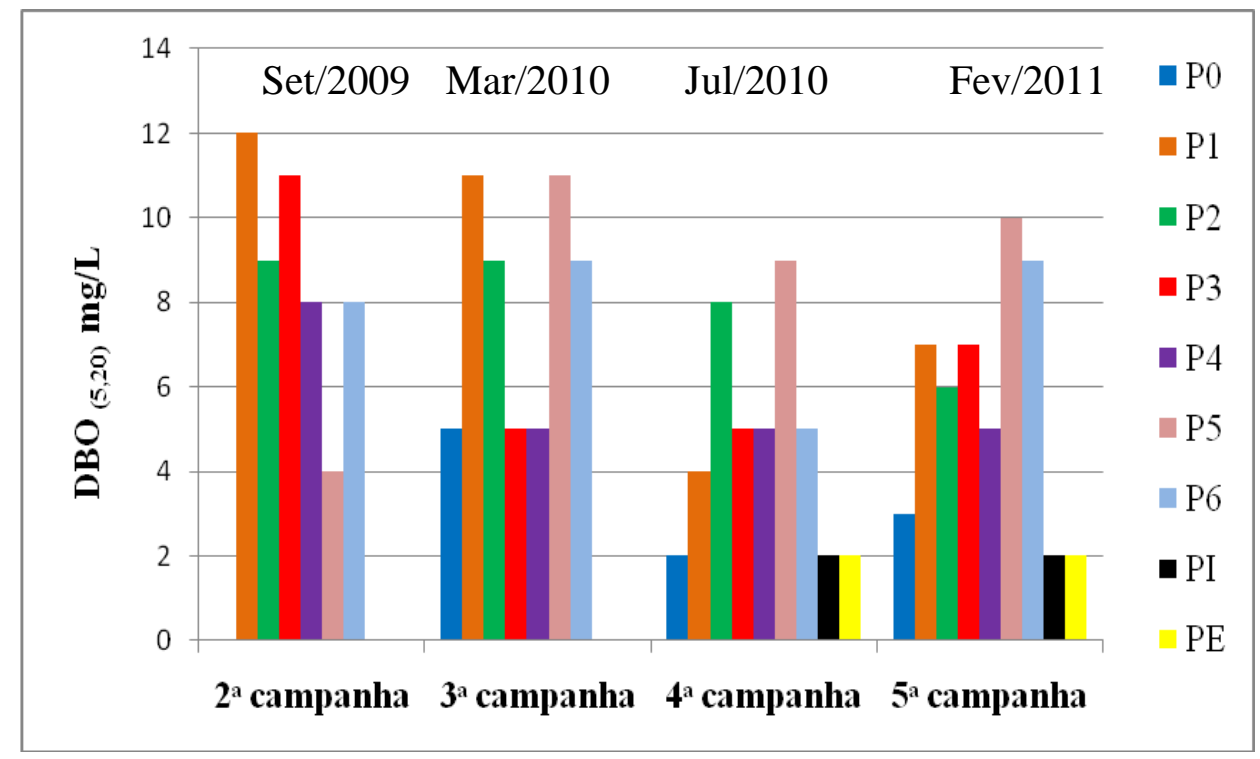

FIGURA 39 - variação dos dados de $\mathrm{DBO}_{(5,20)}$ por campanha.

Os valores para Carbono Total (CT), Carbono Inorgânico Total (CIT) e Carbono Orgânico Total (COT) determinados para as águas superficiais do rio Cubatão e seus contribuintes (afluentes), estão apresentados nas Figuras 40 a 42.

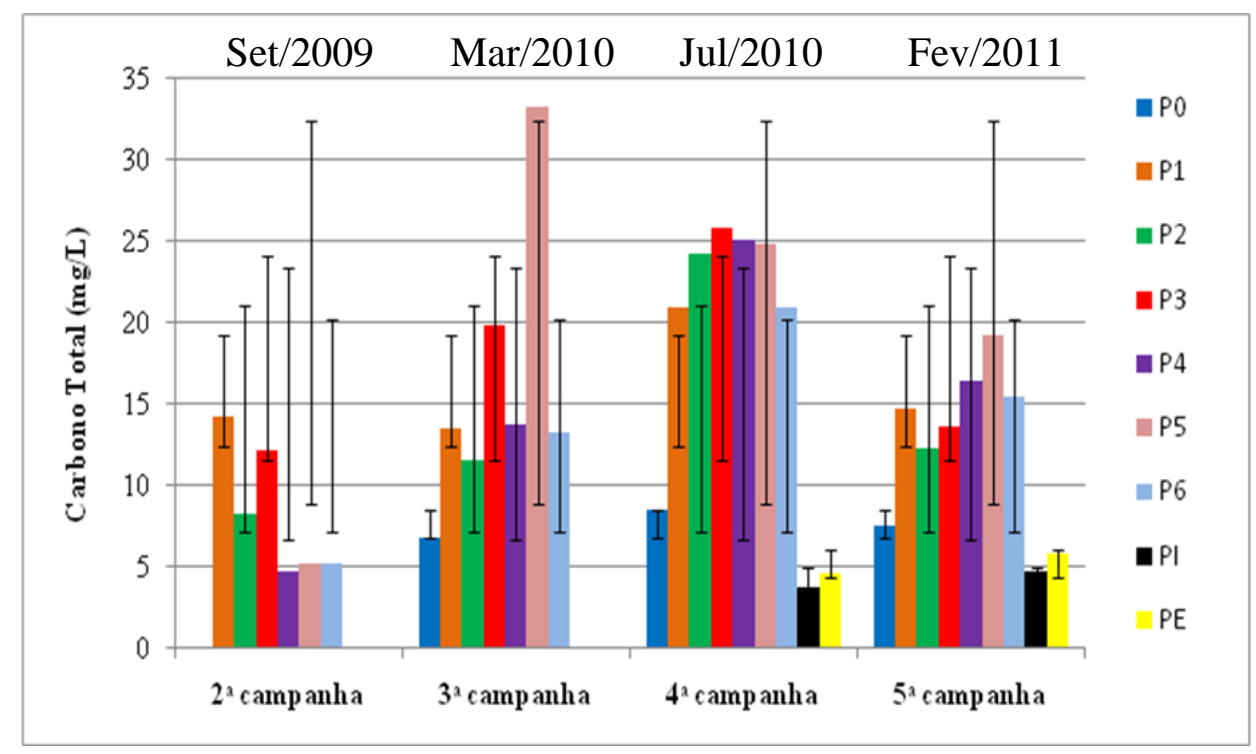

FIGURA 40 - variação dos valores de carbono total por campanha. 


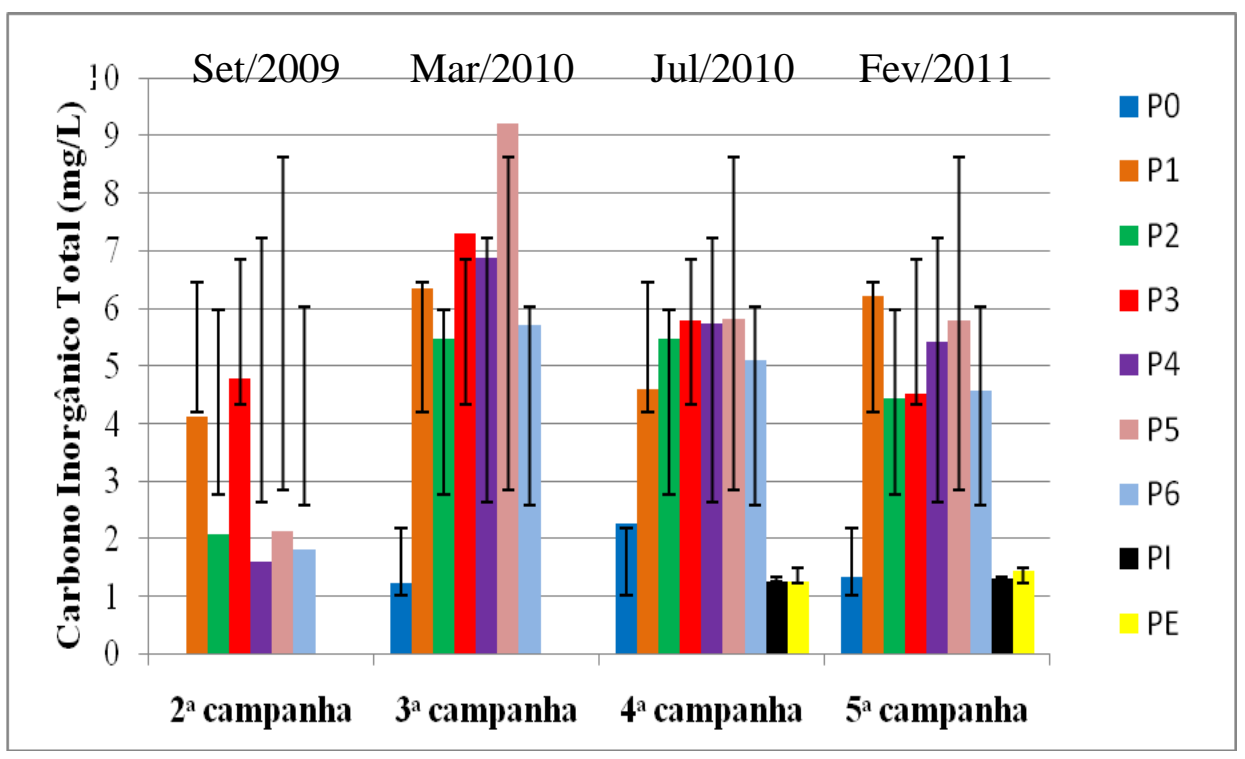

FIGURA 41 - variação dos valores para carbono inorgânico total por campanha.

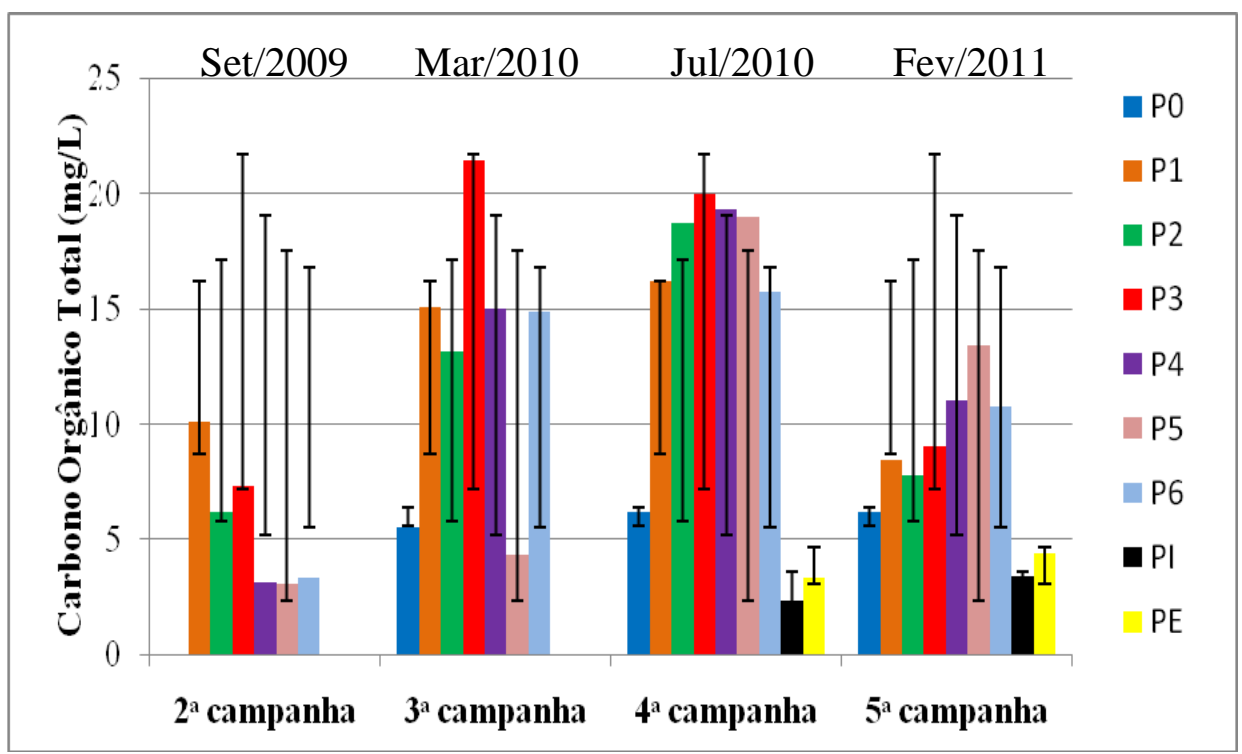

FIGURA 42 - variação dos valores de carbono orgânico total por campanha.

Na Figura 43 foram representados os valores médios das amostras de águas superficiais, para os parâmetros de $\mathrm{DBO}_{(5,20)}$ e carbono total (CT) para os pontos amostrados neste estudo. 


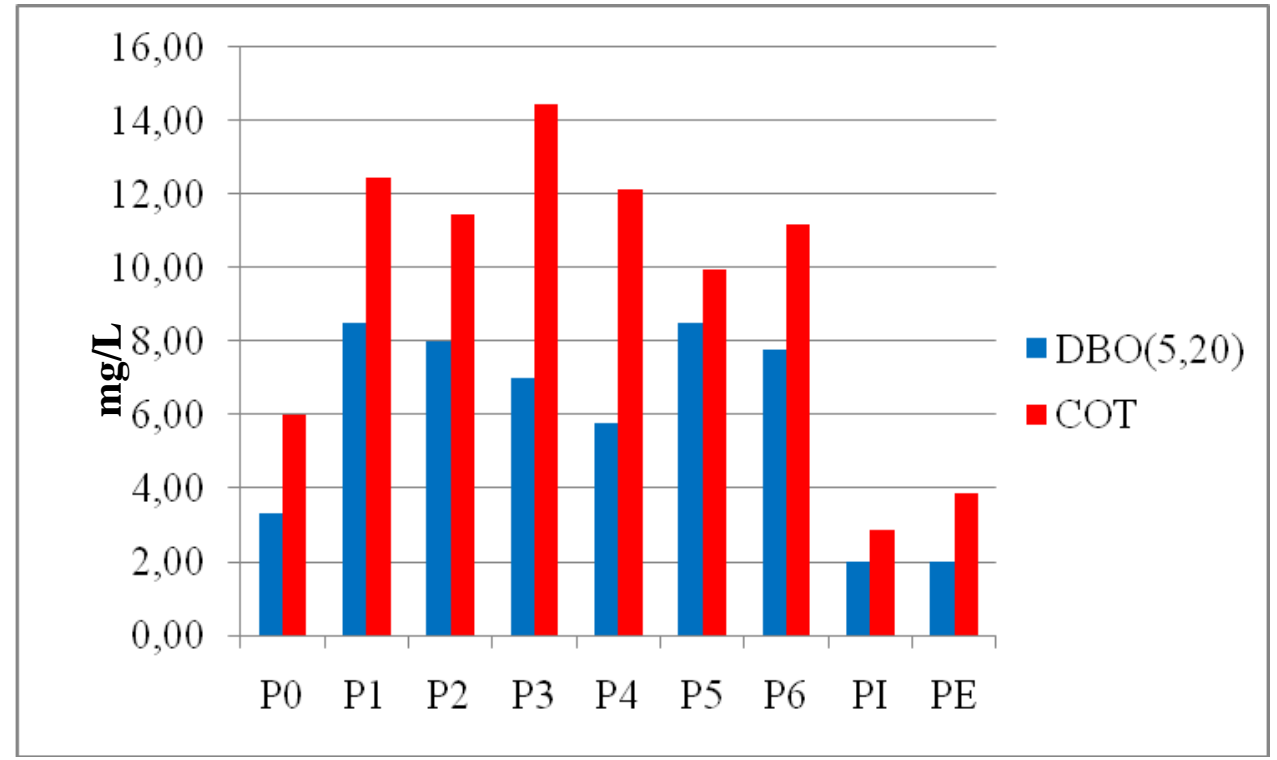

FIGURA 43 - valores médios para $\mathrm{DBO}_{(5,20) \mathrm{e}} \mathrm{CT}$.

Os dados para os surfactantes determinados em águas superficiais coletadas nos pontos amostrados neste estudo, empregando como substâncias de referências e calibração do método analítico na identificação de surfactantes aniônicos o (DSS) e o (LAS), estão apresentados nas Figuras 44 e 45, respectivamente.

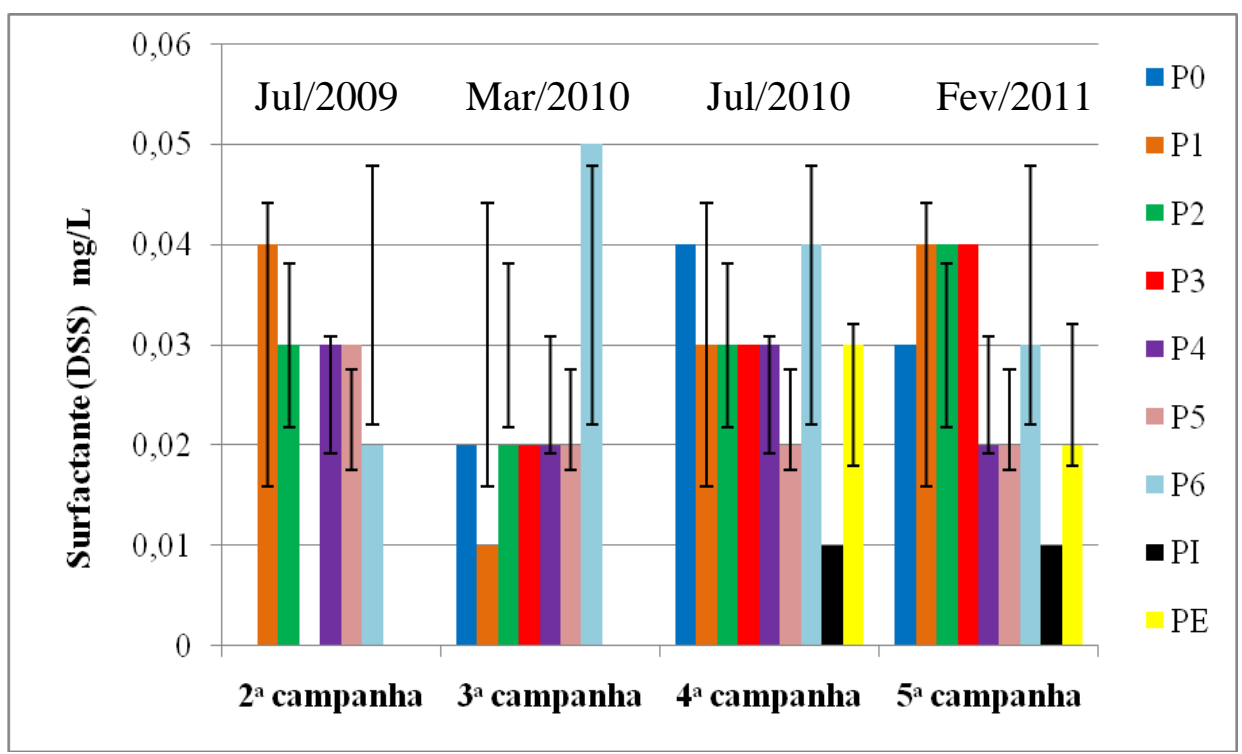

FIGURA 44 - variação da concentração de surfactantes, utilizando o (DSS) como substância de calibração do método analítico. 


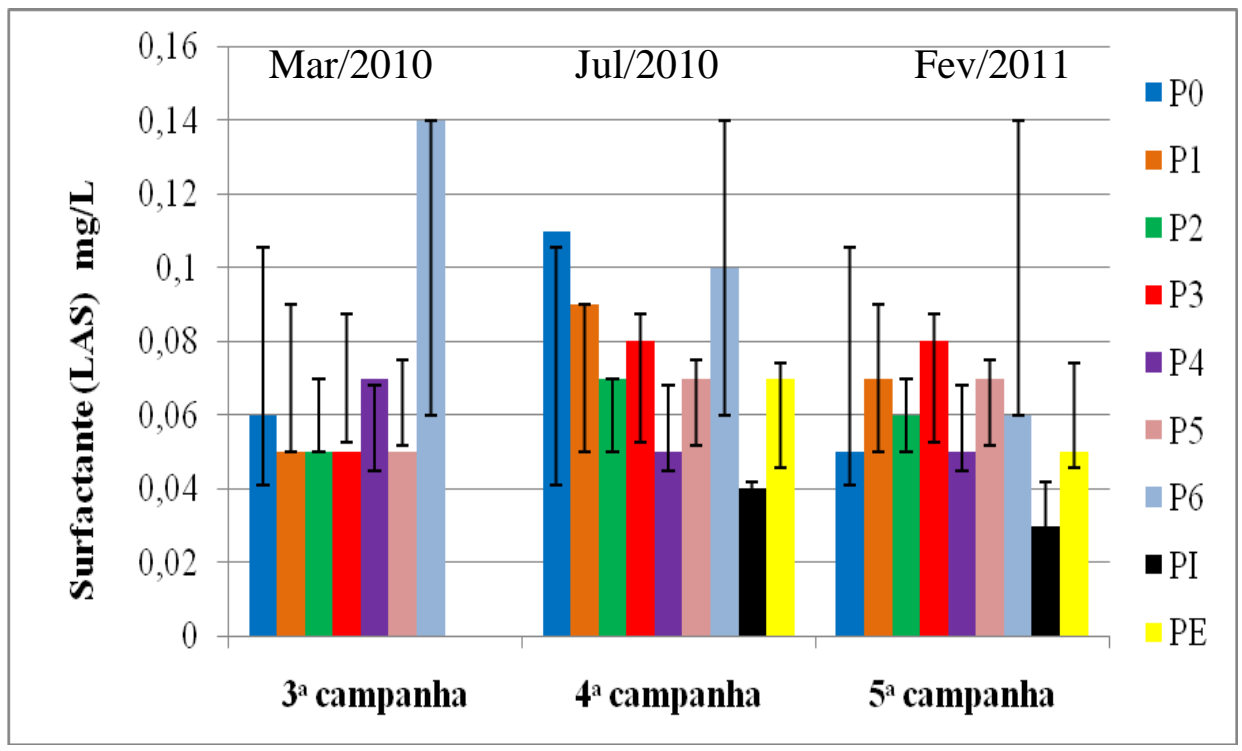

FIGURA 45 - variação da concentração de surfactantes, utilizando o (LAS) como substância de calibração do método analítico.

Os valores médios calculados para determinação de surfactantes, empregando o (LAS) e o (DSS) como substâncias de calibração do método analítico, estão representados na Figura 46.

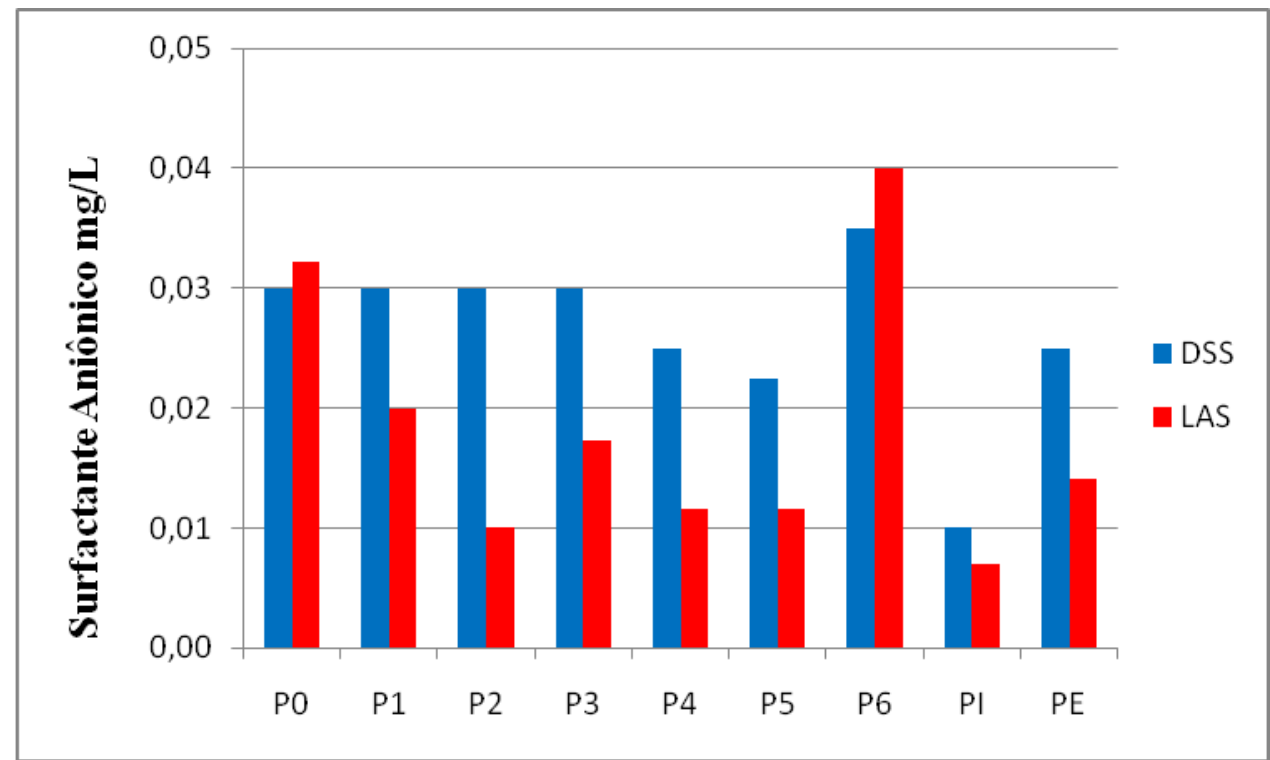

FIGURA 46 - valores médios da concentração de surfactantes, utilizando o (LAS) e o (DSS) como substância de calibração do método analítico $(p \leq 0,01)$. 
Na Tabela 10 descritos alguns compostos químicos encontrados em uma análise qualitativa, realizada com cromatografia gasosa em amostras de águas superficiais do rio Cubatão e seus afluentes (contribuintes), coletadas na quinta campanha realizada em fevereiro de 2011.

TABELA 10 - Dados qualitativos das analises químicas realizadas com cromatografia gasosa em águas amostradas neste estudo.

\begin{tabular}{|c|c|}
\hline Pontos & Compostos orgânicos ( $5^{\text {a }}$ campanha $)$ \\
\hline $\mathbf{P 0}$ & tolueno, etilbenzeno, xileno \\
\hline P1 & tolueno, etilbenzeno, xileno, 1,2 diclorobenzeno \\
\hline $\mathbf{P 2}$ & $\begin{array}{c}\text { tolueno, etilbenzeno, xileno, } 1,4 \text { diclorobenzeno, } 1 \text { metil } 3 \text { isopropil } \\
\text { benzeno }\end{array}$ \\
\hline $\mathbf{P 3}$ & tolueno, etilbenzeno, xileno, benzeno, 1,2 diclorobenzeno \\
\hline $\mathbf{P 4}$ & tolueno, etilbenzeno, xileno, benzeno, 1,4 diclorobenzeno \\
\hline P5 & tolueno, Etilbenzeno, xileno, benzeno \\
\hline P6 & tolueno, etilbenzeno, xileno, benzeno, 1,3 diclorobenzeno \\
\hline PE & tolueno, etilbenzeno, xileno, benzeno, 1,4 diclorobenzeno \\
\hline PI & tolueno, xileno, benzeno \\
\hline
\end{tabular}

\subsection{Avaliação ecotoxicológica}

Os resultados dos ensaios ecotoxicológicos foram apresentados na tabela 11 . Ceriodaphnia dubia foram empregadas para avaliar efeito crônico em águas superficiais do rio Cubatão, no período de setembro de 2009 a fevereiro de 2011. 
TABELA 11 - Resultados dos ensaios ecotoxicológicos utilizando C. dubia em todas as campanhas.

\begin{tabular}{|c|c|c|c|c|c|}
\hline & \multirow[b]{2}{*}{ Pontos } & \multicolumn{2}{|c|}{ Média de jovens } & \multicolumn{2}{|c|}{ Conclusão da análise estatística } \\
\hline & & $\begin{array}{c}\text { Ponto } \\
\text { referência }\end{array}$ & Amostra & Teste "t & $\begin{array}{c}\text { Teste "t por } \\
\text { bioequivalência" }\end{array}$ \\
\hline \multirow{6}{*}{ 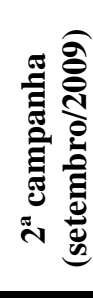 } & P1 & 16,5 & 12,4 & $\mathrm{~T}$ & NT \\
\hline & $\mathbf{P 2}$ & 16,5 & 12,8 & NT & NT \\
\hline & P3 & 16,5 & 12,7 & NT & NT \\
\hline & P4 & 16,5 & 12,6 & NT & NT \\
\hline & P5 & 16,5 & 11,1 & $\mathrm{~T}$ & NT \\
\hline & P6 & 16,5 & 9,9 & $\mathrm{~T}$ & NT \\
\hline \multirow{7}{*}{ 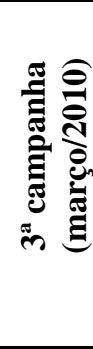 } & P0 & 18,4 & 5,9 & $\mathrm{~T}$ & $\mathrm{~T}$ \\
\hline & P1 & 18,4 & 6,7 & $\mathrm{~T}$ & $\mathrm{~T}$ \\
\hline & P2 & 18,4 & 12,6 & NT & NT \\
\hline & P3 & 18,4 & 2,9 & $\mathrm{~T}$ & $\mathrm{~T}$ \\
\hline & P4 & 18,4 & 10 & $\mathrm{~T}$ & $\mathrm{~T}$ \\
\hline & P5 & 18,4 & 6,8 & $\mathrm{~T}$ & $\mathrm{~T}$ \\
\hline & P6 & 18,4 & 9,9 & $\mathrm{~T}$ & $\mathrm{~T}$ \\
\hline \multirow{9}{*}{ 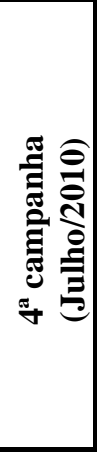 } & P0 & 25,2 & 21,0 & NT & NT \\
\hline & P1 & 25,2 & 19,7 & NT & NT \\
\hline & P2 & 25,2 & 18,7 & NT & NT \\
\hline & P3 & 25,2 & 21,0 & NT & NT \\
\hline & P4 & 25,2 & 19,5 & NT & NT \\
\hline & P5 & 25,2 & 17,7 & NT & NT \\
\hline & P6 & 25,2 & 17,0 & NT & NT \\
\hline & PI & 25,2 & 18,3 & NT & NT \\
\hline & PE & 25,2 & 16,9 & NT & NT \\
\hline \multirow{9}{*}{ 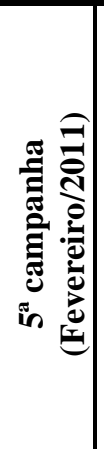 } & P0 & 21,6 & 19,4 & NT & NT \\
\hline & P1 & 21,6 & 22,1 & NT & NT \\
\hline & $\mathbf{P 2}$ & 21,6 & 19,9 & NT & NT \\
\hline & P3 & 21,6 & 18,3 & NT & NT \\
\hline & P4 & 21,6 & 17,6 & NT & NT \\
\hline & P5 & 21,6 & 17,9 & NT & NT \\
\hline & P6 & 21,6 & 16,2 & NT & NT \\
\hline & PI & 21,6 & 17,5 & NT & NT \\
\hline & PE & 21,6 & 16,3 & NT & NT \\
\hline
\end{tabular}

T- Tóxico

NT - Não Tóxico

Os resultados dos ensaios ecotoxicológicos realizados para avaliar efeito crônico das águas superficiais do rio Cubatão em Ceriodaphnia dubia estão representados na Figura 47. Teste "t por bioequivalência" (*) para os pontos que apresentaram toxicidade. 


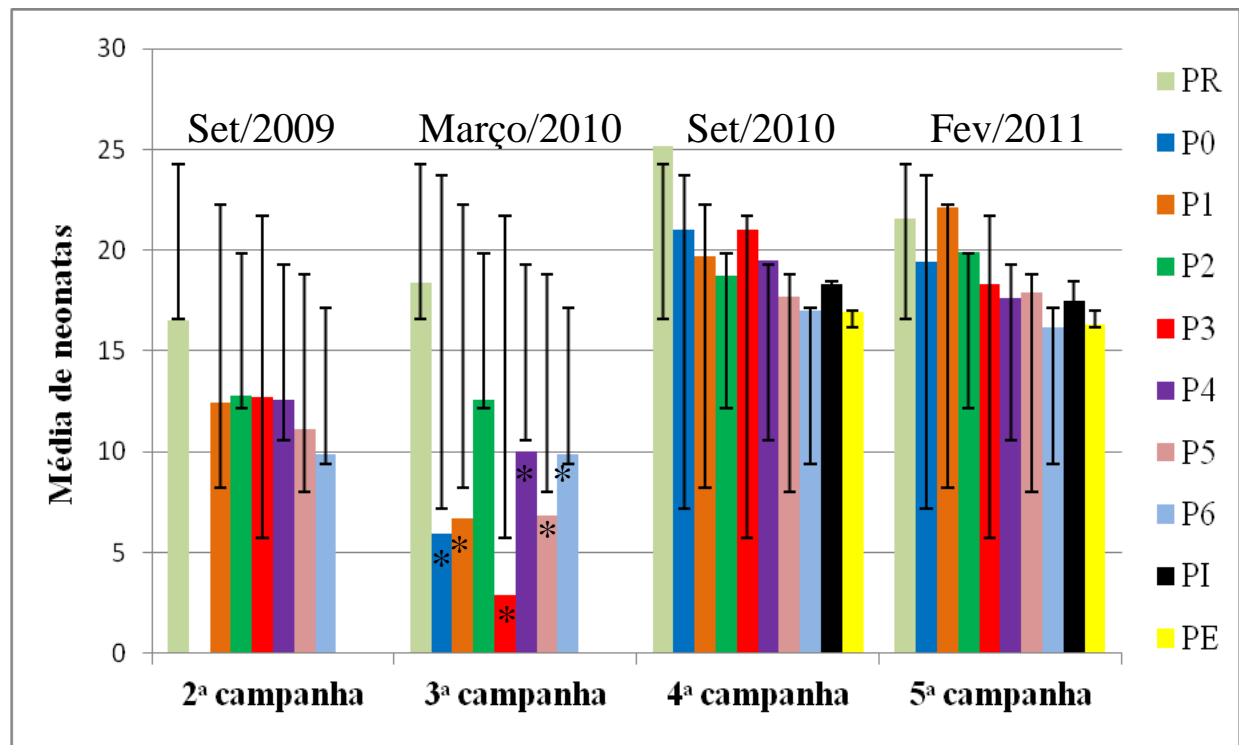

FIGURA 47 - Média de neonatas obtidas durante exposição de $C$. dubia em 9 pontos amostrais (rio Cubatão e seus contribuintes).

Na figura 48 foram apresentadas as médias de neonatas obtidas durante exposição de $C$. dubia às águas do rio Cubatão e seus contribuintes (afluentes) em todos os períodos amostrais.

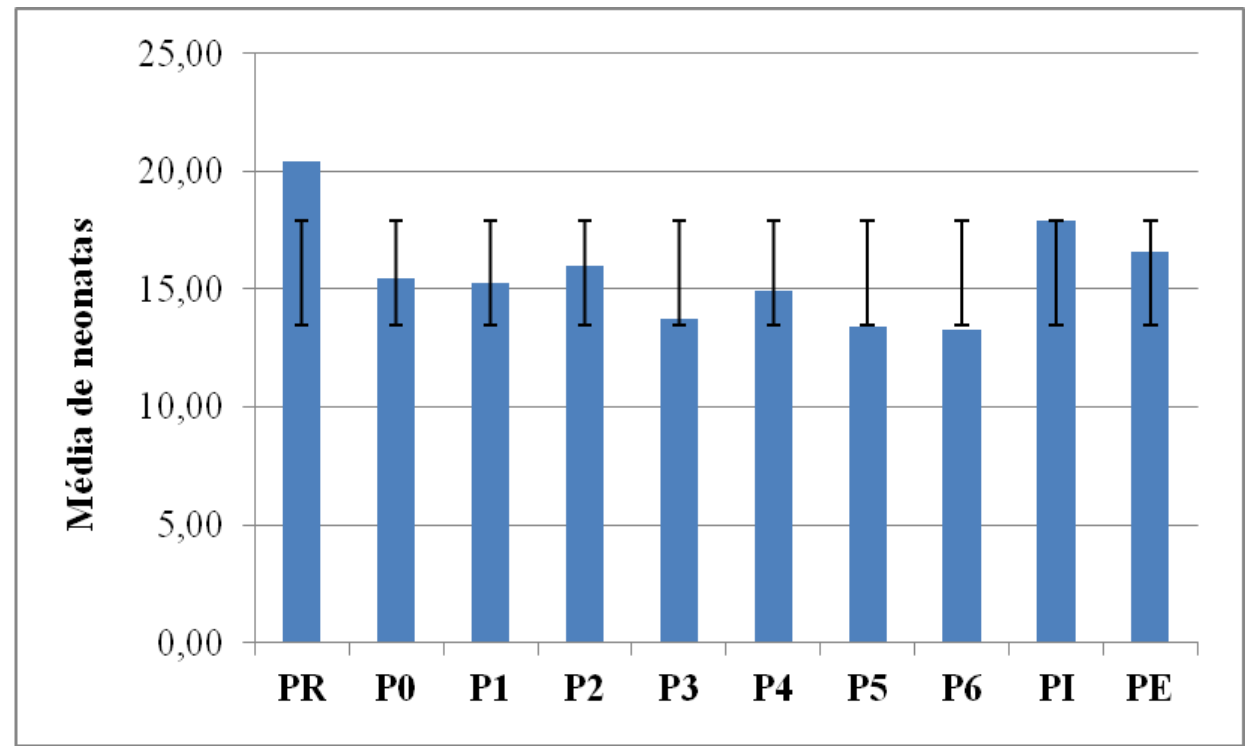

FIGURA 48 - Média de neonatas obtidas durante a exposição em sete dias (C.dubia) em todas as campanhas.

Os resultados dos ensaios ecotoxicológicos para avaliar efeito agudo em Vibrio fischeri são apresentados na Tabela 12. 
TABELA 12 - Valores de $\mathrm{CE}(\mathrm{I})_{50}$ obtidos para $V$. fischeri com intervalos de confiança.

\begin{tabular}{|c|c|c|c|c|c|}
\hline & \multicolumn{5}{|c|}{$\mathrm{CE}_{(50)}(\%, \mathrm{v} / \mathrm{v}, 15$ minutos $)$} \\
\hline & $\begin{array}{c}\text { 1a Campanha } \\
\text { Julho/2009 }\end{array}$ & $\begin{array}{c}2^{\mathrm{a}} \text { Campanha } \\
\text { Set/2009 }\end{array}$ & $\begin{array}{c}3^{\text {a Campanha }} \\
\text { Março/2010 }\end{array}$ & $\begin{array}{c}4^{\text {a }} \text { Campanha } \\
\text { Julho/2010 }\end{array}$ & $\begin{array}{c}5^{\text {a }} \text { Campanha } \\
\text { Fev/2011 }\end{array}$ \\
\hline P0 & - & -- & $\begin{array}{c}50,45 \\
(28,68-88,21)\end{array}$ & $\begin{array}{c}47,58 \\
(26,60-85,12)\end{array}$ & $\begin{array}{c}36,33 \\
(20,47-64,48)\end{array}$ \\
\hline P1 & & $\begin{array}{c}42,21 \\
(13,12-135,74)\end{array}$ & $\begin{array}{c}36,48 \\
(15,77-84,41)\end{array}$ & $\begin{array}{c}47,80 \\
(43,74-52,24)\end{array}$ & $\begin{array}{c}37,90 \\
(21,28-67,51)\end{array}$ \\
\hline P2 & ---------- & $\begin{array}{c}55,22 \\
(18,63-163,63)\end{array}$ & $\begin{array}{c}43,60 \\
(17,61-107,93)\end{array}$ & $\begin{array}{c}56,42 \\
(45,42-70,00)\end{array}$ & $\begin{array}{c}45,08 \\
(25,81-78,73)\end{array}$ \\
\hline P3 & $\begin{array}{c}45,95 \\
(20,03-105,40)\end{array}$ & $\begin{array}{c}42,78 \\
(15,80-115,81)\end{array}$ & $\begin{array}{c}49,86 \\
(36,66-76,11)\end{array}$ & $\begin{array}{c}31,77 \\
(26,72-37,78)\end{array}$ & $\begin{array}{c}39,11 \\
(27,97-78,73)\end{array}$ \\
\hline P4 & ---------- & $\begin{array}{c}40,19 \\
(15,09-107,02)\end{array}$ & $\begin{array}{c}41,21 \\
(18,18-93,38)\end{array}$ & $\begin{array}{c}44,93 \\
(34,32-58,84)\end{array}$ & $\begin{array}{c}35,66 \\
(18,46-68,87)\end{array}$ \\
\hline P5 & $\begin{array}{c}31,13 \\
(11,28-85,93)\end{array}$ & $\begin{array}{c}48,18 \\
(21,88-106,08)\end{array}$ & $\begin{array}{c}40,78 \\
(13,42-123,92)\end{array}$ & $\begin{array}{c}61,00 \\
(42,00-88,57)\end{array}$ & $\begin{array}{c}35,40 \\
(26,68-46,97)\end{array}$ \\
\hline P6 & $\begin{array}{c}25,98 \\
(14,40-46,84)\end{array}$ & $\begin{array}{c}51,26 \\
(17,71-148,38)\end{array}$ & $\begin{array}{c}41,41 \\
(11,01-155,75)\end{array}$ & $\begin{array}{c}31,26 \\
(21,93-44,57)\end{array}$ & $\begin{array}{c}37,15 \\
(22,96-60,11)\end{array}$ \\
\hline $\begin{array}{l}\mathbf{P} \\
\mathbf{E}\end{array}$ & & & & $\begin{array}{c}27,77 \\
(24,71-31,10)\end{array}$ & $\begin{array}{c}32,64 \\
(11,67-91,24)\end{array}$ \\
\hline PI & --- & --- & -- & $\begin{array}{c}35,37 \\
(24,41-51,26)\end{array}$ & $\begin{array}{c}36,73 \\
(20,39-66,14)\end{array}$ \\
\hline
\end{tabular}

Os resultados da $\mathrm{CE}(\mathrm{I})_{50}$ obtidos na exposição de Vibrio fischeri as amostras de águas superficiais durante 15 minutos estão representados na Figura 49. 


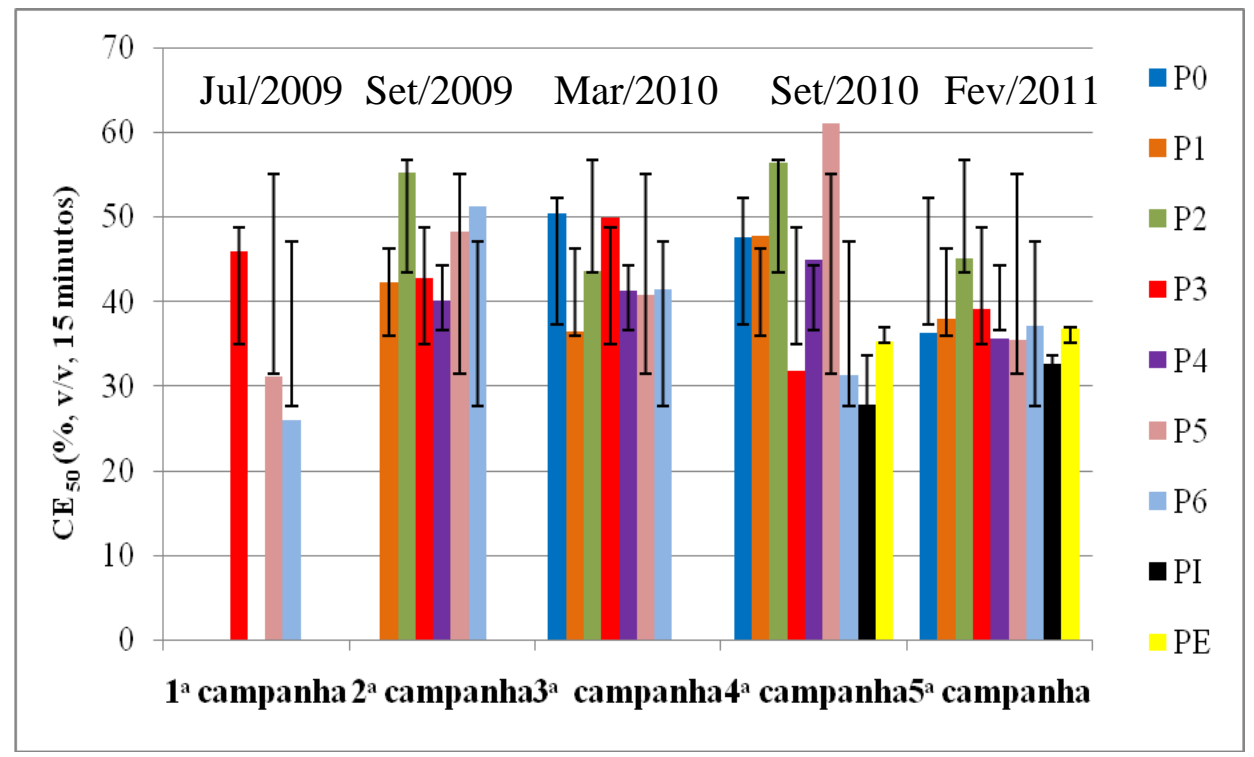

FIGURA 49 - Variação de $\mathrm{CE}(\mathrm{I})_{50}$ em decorrência da exposição de $V$. fischeri às águas superficiais.

Na figura 50, foram apresentadas as médias obtidas durante exposição de $V$. fischeri às águas do Rio Cubatão e seus contribuintes (afluentes).

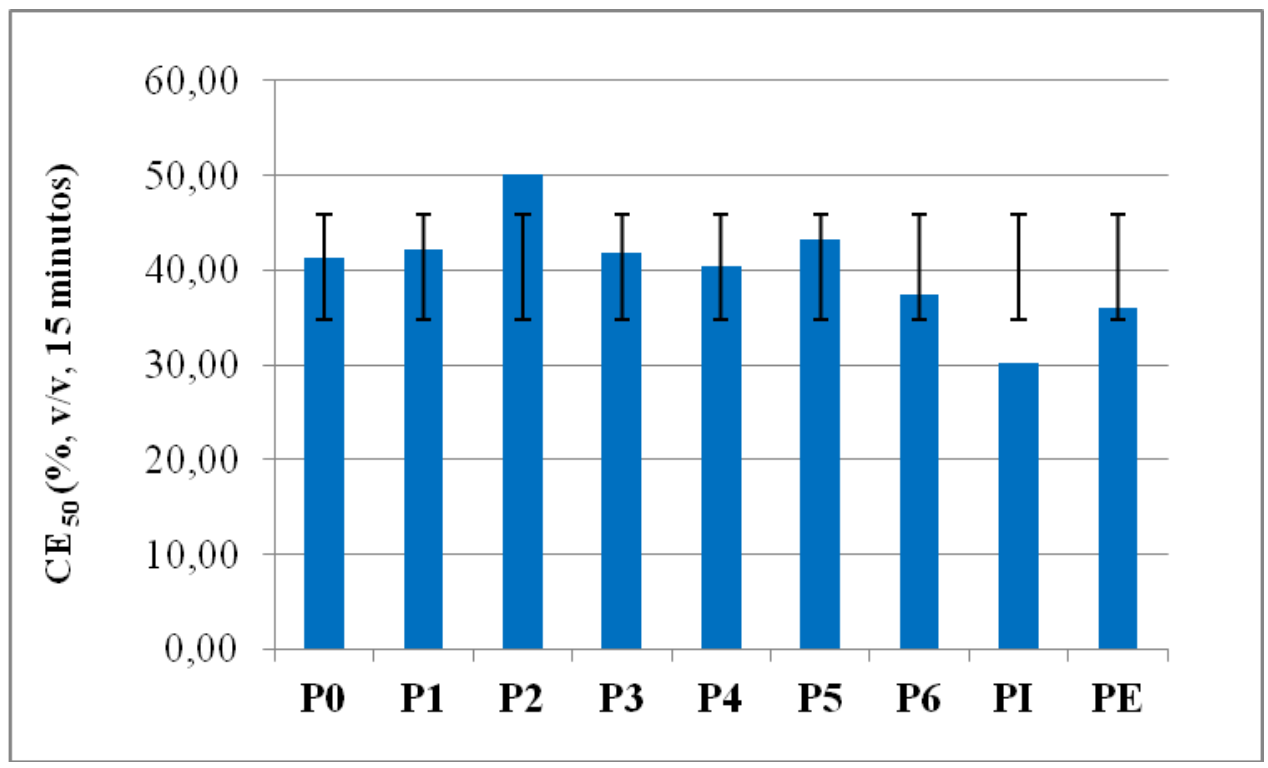

FIGURA 50 - Médias obtidas durante exposição de V. fischeri às águas do Rio Cubatão e seus contribuintes (afluentes) em todas as campanhas. 


\subsection{Resultados de sensibilidade}

$\mathrm{Na}$ figura 51 foram organizados os resultados dos ensaios de sensibilidade realizados para C. dubia, utilizando como substância de referência o cloreto de potássio $(\mathrm{KCl})$. Para avaliar sensibilidade desses organismos foram calculadas $\mathrm{CI}_{(25)} \mathrm{mg} / \mathrm{L}$, a partir do método de interpolação linear. A concentração inibitória, $\mathrm{CI}_{(25)}$ representa a concentração da substância referência que reduz a reprodução dos organismos em 25\% comparação com o controle ou ponto referência (EPA, 2002). Os limites de sensibilidade estiveram entre 35,59 - 212,97 mg/L, com média de 124,13 mg/L e desvio padrão de 44,42 .

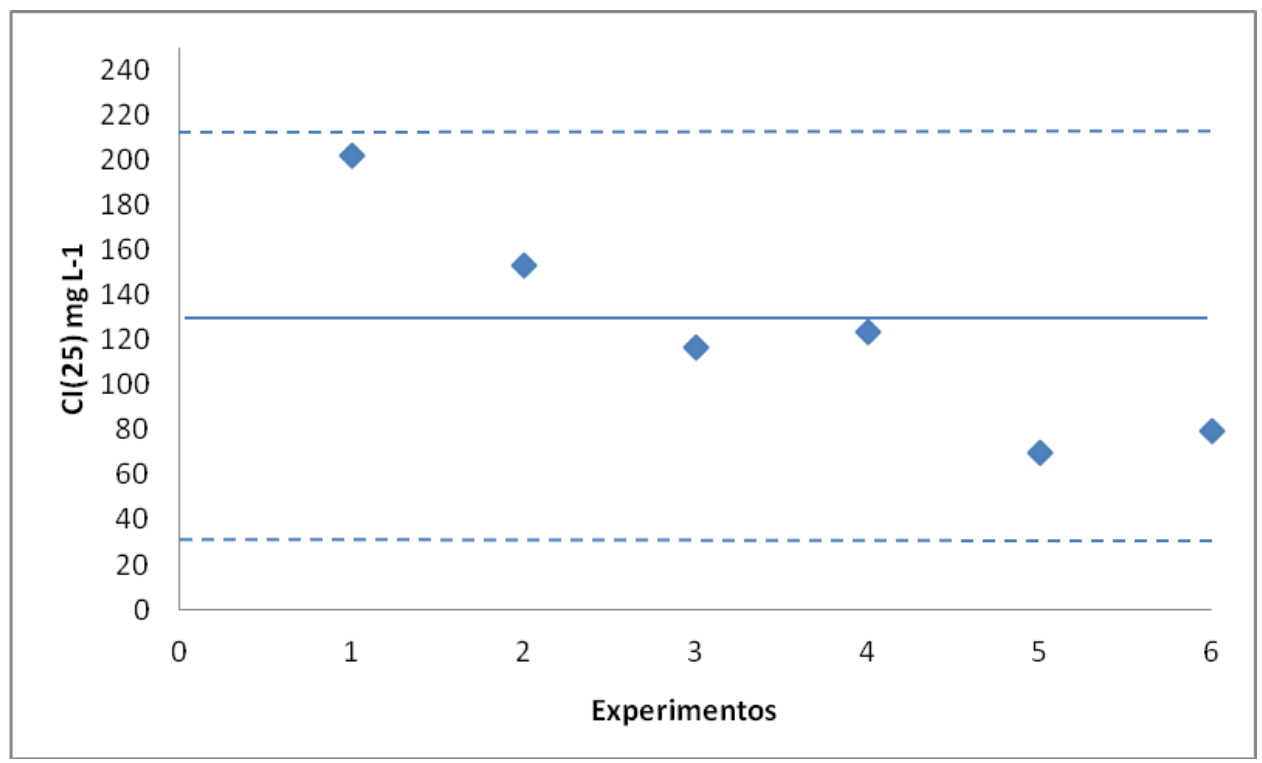

FIGURA 51 - Sensibilidade de C. dubia para substância referência - KCl

Na figura 52, estão os resultados para os ensaios de sensibilidade realizados para $V$. fischeri, utilizando como substância de referência o fenol. A faixa de sensibilidade para esta substância compreendida entre 17,54 mg/L a 23,72 mg/L. 


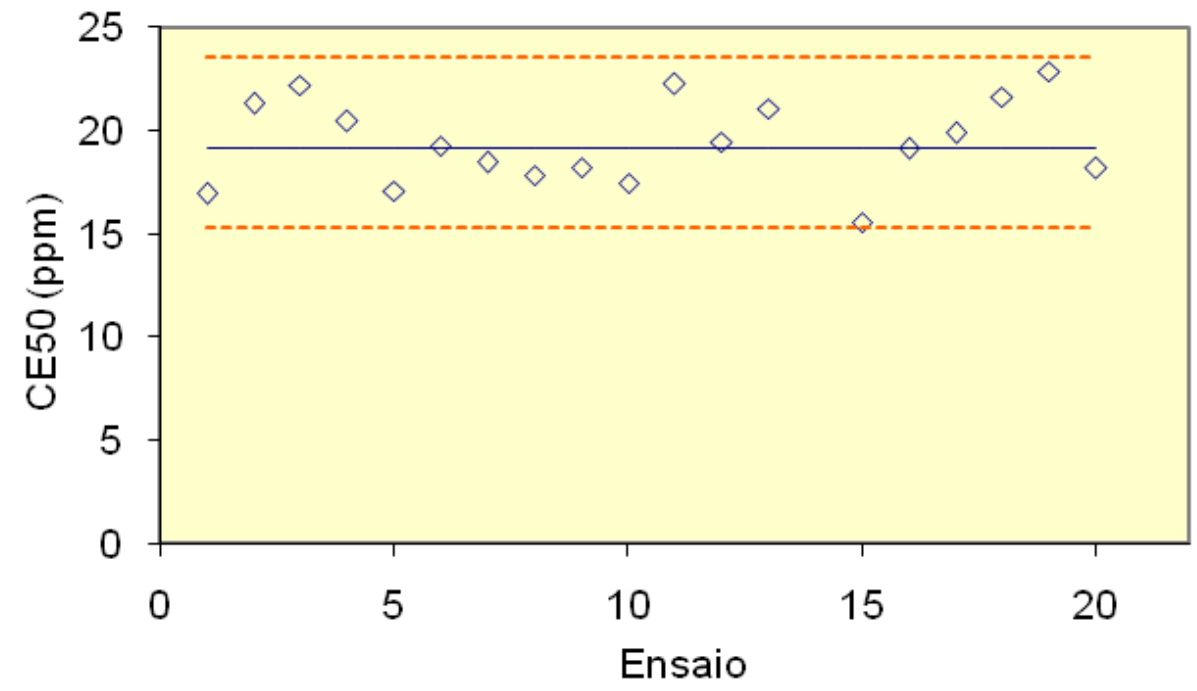

FIGURA 52 - Sensibilidade de V. fischeri para substância referência - Fenol

Afim de correlacionar a causa-efeito, foram feitas análises de correlação entre os valores médios determinados nas análises físico-químicas, junto aos resultados das análises de toxicidade crônica e aguda ( $C$. dubia e $V$. fischeri), e assim se obter o coeficiente de correlação (r) (Tabela 13).

Tabela 13 - Análise estatística de correlação (r) entre os resultados obtidos das análises físico-químicas e dos ensaios de toxicidade.

\begin{tabular}{|c|c|c|c|}
\hline \multirow{13}{*}{ 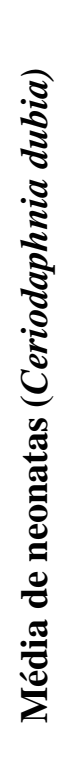 } & Parâmetros & (r) & Correlação \\
\hline & OD & $-0,07$ & Ínfima negativa \\
\hline & Condutividade & $-0,54$ & Moderada negativa \\
\hline & $\mathrm{pH}$ & $-0,10$ & Ínfima negativa \\
\hline & Turbidez & $-0,69$ & Moderada negativa \\
\hline & Sólidos Totais & $-0,78$ & Moderada negativa \\
\hline & Cloretos & $-0,80$ & Moderada negativa \\
\hline & DBO $(5,20)$ & $-0,73$ & Moderada negativa \\
\hline & $\mathrm{CT}$ & $-0,82$ & Forte negativa \\
\hline & COT & $-0,73$ & Moderada negativa \\
\hline & CIT & $-0,76$ & Moderada negativa \\
\hline & DSS & $-0,64$ & Moderada negativa \\
\hline & LAS & $-0,48$ & Fraca negativa \\
\hline
\end{tabular}




\begin{tabular}{|c|c|c|c|}
\hline \multirow{12}{*}{ 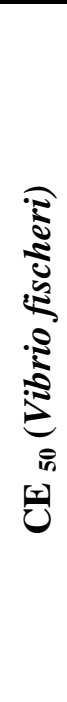 } & OD & $-0,51$ & Moderada negativa \\
\hline & Condutividade & 0,48 & Fraca positiva \\
\hline & $\mathrm{pH}$ & $-0,12$ & Ínfima negativa \\
\hline & Turbidez & 0,79 & Moderada positiva \\
\hline & Sólidos Totais & 0,67 & Moderada positiva \\
\hline & Cloretos & 0,64 & Moderada positiva \\
\hline & $\operatorname{DBO}_{(5,20)}$ & 0,72 & Moderada positiva \\
\hline & $\mathrm{CT}$ & 0,78 & Moderada positiva \\
\hline & COT & 0,72 & Moderada positiva \\
\hline & CIT & 0,71 & Moderada positiva \\
\hline & DSS & 0,65 & Moderada positiva \\
\hline & LAS & 0,13 & Ínfima positiva \\
\hline
\end{tabular}

Classificação do coeficiente de correlação:

$\mathrm{r}=1 \quad$ perfeita positiva

$0,8 \leq \mathrm{r}<1 \quad$ forte positiva

$0,5 \leq \mathrm{r}<0,8 \quad$ moderada positiva

$0,1 \leq \mathrm{r}<0,5 \quad$ fraca positiva

$0<\mathrm{r}<0,1 \quad$ ínfima positiva

$\mathrm{r}=0$ $0,1<\mathrm{r}<0$

$<0,5<\mathrm{r} \leq-0,1$

$-0,8<\mathrm{r} \leq-0,5$

$-1<\mathrm{r} \leq-0,8$

$r=-1$ ínfima negativa

fraca negativa

moderada negativa

forte negativa

perfeita negativa

Em complemento aos resultados obtidos, a partir de amostras de águas superficiais, entre as cinco campanhas amostradas neste estudo, foram feitas análises químicas em sedimentos em seis pontos de coletas. Esta coleta foi realizada em junho/2011, nos pontos P0, P2, P4, P5, PI e PE. Estas análises foram feitas pela Bioagri Ambiental que garante a qualidade de todas as analises e que estas foram executadas dentro do prazo de validade de cada parâmetro. Na tabela 14, estão as concentrações de alguns compostos químicos que estiveram acima ou próximos aos limites descritos no CONAMA 344/2004 - nível 1 VPM para água doce, nas amostras coletadas e analisadas nesta coleta. 
Tabela 14 - Variação de Hidrocarbonetos Policíclicos Aromáticos determinados em sedimentos do Rio Cubatão e contribuintes (afluentes).

\begin{tabular}{cccccccc}
\hline$\mu \mathrm{g} / \mathrm{kg}$ & $\mathrm{P} 0$ & $\mathrm{P} 2$ & $\mathrm{P} 4$ & $\mathrm{P} 5$ & $\mathrm{PI}$ & $\mathrm{PE}$ & $\begin{array}{c}\text { CONAMA } \\
344 / 2004\end{array}$ \\
\hline SOMA PAHs & 21 & 139 & 229 & 750 & $<3,94$ & 25 & 3000 \\
\hline Endrin & $<0,19$ & $<0,73$ & $<0,21$ & $\mathbf{8 , 2}$ & $<0,19$ & $<0,21$ & 2,67 \\
\hline $\begin{array}{c}\text { Dibenzo (a, h) } \\
\text { antraceno }\end{array}$ & 0,89 & $<2,88$ & 1,3 & $\mathbf{7 , 2}$ & $<0,31$ & $<0,35$ & 6,22 \\
\hline Antraceno & 0,35 & 7,6 & 2,4 & $\mathbf{1 5 0}$ & $<0,31$ & 1,2 & 85,3 \\
\hline Fluoreno & $<0,32$ & 4,1 & 0,77 & $\mathbf{1 8}$ & $<0,31$ & 0,73 & 19 \\
\hline
\end{tabular}

Os valores em destaque encontram-se acima ou próximos aos limites do CONAMA 344/2004 - Nível 1 VPM.

A Figura 53, representa uma possível fonte de contaminação por HPAs no ponto $\mathrm{P} 5$, provocada pela presença de uma oficina de transporte rodoviário.

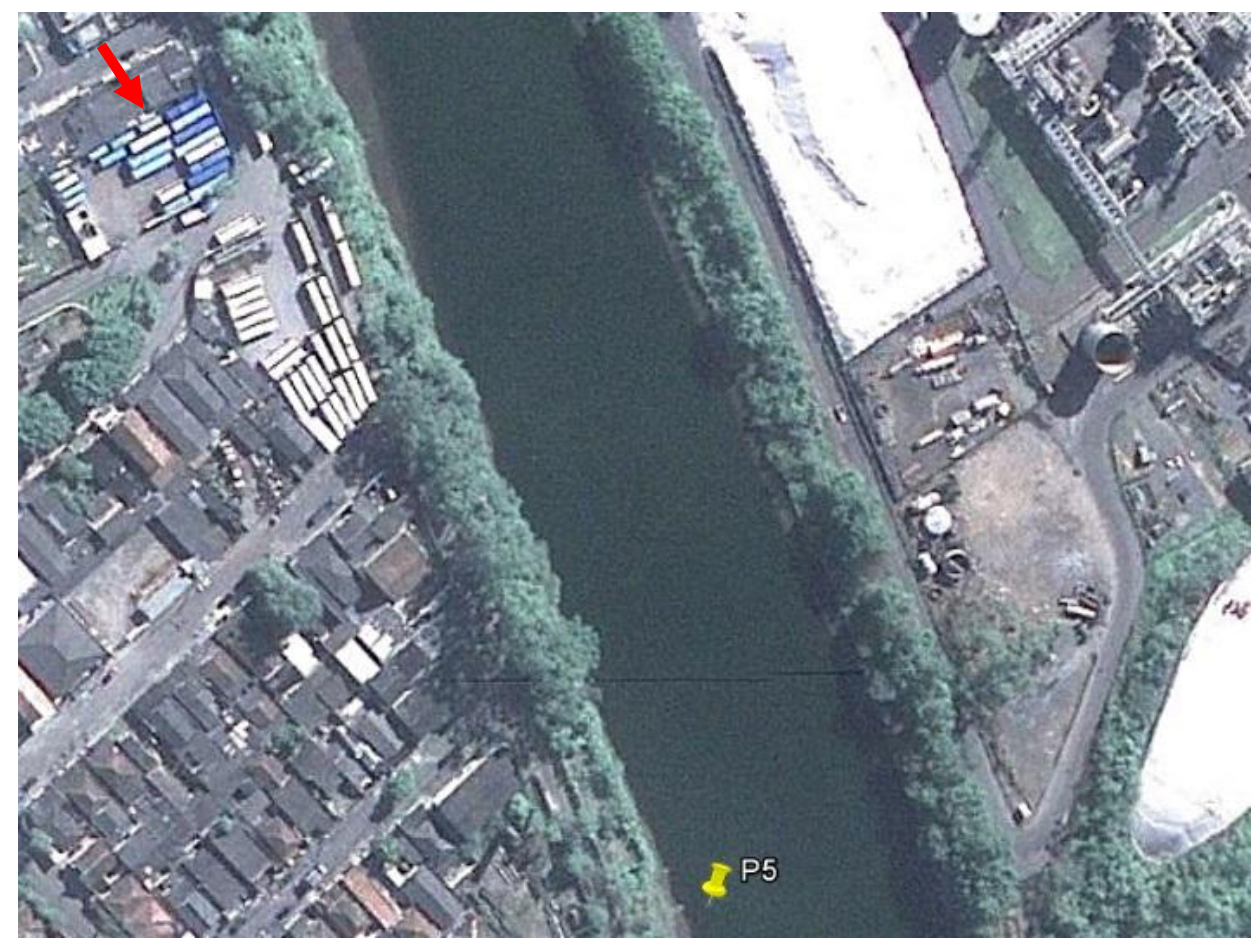

FIGURA 53 - Pátio de ônibus as margens do rio Cubatão (2352'33.00"S $\left.46^{\circ} 24^{\prime} 47.86 " \mathrm{O}\right)$, localizado próximo ao P5. 


\section{DISCUSSÃO}

Os valores de oxigênio dissolvido na água (OD) variaram entre 6,40 mg/L a 9,45 $\mathrm{mg} / \mathrm{L}$ no presente trabalho. A $1^{\mathrm{a}}$ Campanha apresentou maiores valores de OD em todos os pontos amostrais com média de $8,57 \mathrm{mg} / \mathrm{L}$. Enquanto na segunda amostragem, os valores variaram entre 6,40 a 6,70 mg/L. As concentrações superiores de (OD) no P6 em todas as coletas podem estar relacionadas a proximidade do ponto a uma barragem subalvea que serve para conter a cunha salina, local que facilita a aeração da massa de água, devido ao desnível gerado pela barragem. O P1 obteve média para OD $(8,15 \mathrm{mg} / \mathrm{L})$, maior em relação aos outros pontos, provavelmente por estar localizado em um ponto mais preservado e com influência das correntes de várias nascentes em seu percurso. Os valores médios obtidos para este parâmetro estão próximos aos encontrados nos relatórios de qualidade das águas dos interiores para os pontos em comum com este estudo $(6,6$ a $8,2 \mathrm{mg} / \mathrm{L})$. As concentrações de oxigênio dissolvido em todas as coletas estiveram dentro do limite estabelecido pelo CONAMA 357/2005 que estabelece $5 \mathrm{mg} / \mathrm{L}$ para os rios classe 1e 2 .

Com relação à condutividade das águas coletadas durante o estudo apresentaram valores entre 200,40 e $2.800 \mu \mathrm{S} / \mathrm{cm}^{-1}$, na primeira campanha. Entretanto, em P4 e P5 a condutividade apresentou-se mais elevada $\left(1860,0\right.$ e $2.800,0 \mu \mathrm{S} / \mathrm{cm}^{-1}$, respectivamente). Já na segunda amostragem o valor de condutividade para amostras do P5 manteve-se elevado em relação aos outros pontos $\left(464,5 \mu \mathrm{S} / \mathrm{cm}^{-1}\right)$, provavelmente por estar localizado em frente às salinas da Carbocloro S.A. Indústrias Químicas. Os pontos P0, PI e PE, apresentaram valor médio para condutividade menor em relação aos outros pontos $(35,65$; 31,15 e $36,68 \mu \mathrm{S} / \mathrm{cm}^{-1}$, respectivamente), possivelmente esses pontos possuem menor contribuição de efluentes domésticos e industriais em comparação aos demais pontos amostrais. Para a condutividade destaca-se o P5, que obteve valor médio de 774,18 $\mu \mathrm{S} / \mathrm{cm}^{-}$ 1, média significativamente maior em relação aos outros pontos. O P4 apresentou média $465,15 \mu \mathrm{S} / \mathrm{cm}^{-1}$ para condutividade, ponto este localizado próximo a Companhia Brasileira de Estireno e do Hospital Ana Costa.

Os dados do relatório de qualidade de águas interiores da CETESB (2009), o ponto CUBA 03900, ponto próximo ao ponto P5 deste estudo, apresenta valor médio de condutividade $2768 \mu \mathrm{S} / \mathrm{cm}^{-1}$ para o ano de 2009 e média de $1303 \mu \mathrm{S} / \mathrm{cm}^{-1}$ para os anos de 
2004 a 2008. Além disso, os valores para o rio Perequê afluente do rio Cubatão próximo a este ponto apresentou média para condutividade de $\mu \mathrm{S} / \mathrm{cm}^{-1}$, não interferindo para o aumento da condutividade neste ponto (CETESB, 2009). Em um trabalho realizado por PADILHA et al, 2006, também foi observado um aumento da condutividade das águas monitoradas no Rio Cubatão da nascente pra foz: $33 \mu \mathrm{S} / \mathrm{cm}^{-1}$ (nascente), $38 \mu \mathrm{S} / \mathrm{cm}^{-1}$ (entrada da cidade), para $699 \mu \mathrm{S} / \mathrm{cm}^{-1}$ na saída da cidade, após sofrer influência de efluentes industriais.

Os valores de $\mathrm{pH}$ encontraram-se nos limites da recomendação CONAMA 357/2005 (6,0 a 9,0 mg/L), com uma variação de 6,82 a 8,53, no rio Cubatão e seus contribuintes (afluentes).

Os valores para turbidez entre os pontos amostrais variaram entre 0,68 e 17 UNT. Estes valores estão de acordo com o CONAMA 357/2005 que estabelece 100 UNT para rios classe 1 e 2 . Os valores médios para turbidez na Tabela 14 se mostram baixos, variando entre 3 a 21 UNT, segundo relatórios da CETESB de qualidade das águas interiores. Segundo Piveli e Kato (2006), turbidez é o grau de atenuação de intensidade que um feixe de luz sofre ao atravessá-la. Esta redução se dá por absorção e espalhamento, uma vez que as partículas que promovem turbidez nas águas são maiores que o comprimento de onda da luz branca, devido à presença de sólidos em suspensão, tais como partículas inorgânicas (areia, silte, argila) e de detritos orgânicos, algas e bactérias, plâncton em geral, etc.

As amostras apresentaram concentrações de cloretos no limite previsto pela legislação para classificação de rios classe 1 e $2(250 \mathrm{mg} / \mathrm{L})$. Entretanto, a amostra procedente do P5 apresentou 219,33 mg/L de cloretos na $2^{a}$ campanha, valor próximo ao limite exigido pela legislação, podendo estar relacionado à proximidade da Carbocloro S.A. Indústrias Químicas e da ETE (Estação de Tratamento de Esgoto) da região, administrada pela SABESP, sendo que sua média para cloretos neste ponto destaca-se dos demais $(74,68 \mathrm{mg} / \mathrm{L})$. Os esgotos sanitários são fontes importantes de cloretos nas águas superficiais, sendo que cada pessoa expele através da urina cerca de $6 \mathrm{~g}$ de cloreto por dia, o que faz com que os esgotos apresentem concentrações de cloreto que ultrapassam a 15 $\mathrm{mg} / \mathrm{L}$. Diversos são os efluentes industriais que apresentam concentrações de cloretos elevadas, como os da indústria do petróleo, algumas indústrias farmacêuticas, curtumes, 
etc. Nas regiões costeiras, através da chamada intrusão da língua salina, são encontradas águas com níveis altos de cloreto (PIVELI \& KATO, 2006).

As concentrações determinadas para os compostos fenólicos foram superiores ao valor permitido pelo CONAMA 357/2005 para rios classe 1 e $2(0,003 \mathrm{mg} / \mathrm{L})$. Os valores para amostras na $2^{\mathrm{a}}$ coleta variaram entre 3,37 e $3,55(\mathrm{mg} / \mathrm{L})$. Na $3^{\mathrm{a}}$ campanha houve uma queda nas concentrações de fenóis em relação a $2^{\mathrm{a}}$ campanha que apresentou valor médio de 0,13 $\mathrm{mg} / \mathrm{L}$. Não foram encontrados compostos fenólicos nas amostras de águas superficiais nas demais coletas. Os compostos fenólicos são utilizados em várias atividades, tais como a fabricação de desinfetantes, preparação de resinas e polímeros; síntese da aspirina e de outros medicamentos; como catalisador; na fabricação de perfumes, vernizes, tintas, adesivos, cosméticos, corantes e explosivos; No processamento de indústrias de borracha, colas, componentes elétricos (plásticos); em siderúrgicas e petroquímicas. Devido a sua ampla utilização, esta substância tem se mostrado presente em altas concentrações em diversos ecossistemas, sendo necessário intensificar o monitoramento (PIVELI \& KATO, 2006; LAMPARELLI, 2001). Em outros estudos também foram encontrados valores elevados para fenóis totais acima dos limites pela Resolução CONAMA 357/05 nos pontos próximos ou em comum com este estudo. Analisando-se os dados históricos, observou-se que, do total de amostras analisadas para CETESB no período de 2003 a 2007, a concentração de fenóis totais foi ultrapassada em 10\% (CESTESB, 2008).

Segundo LAMPARELLI (2001), as amostras investigadas obtiveram freqüência de 9\% para contaminação de compostos fenólicos em águas na Baixada Santista. As principais fontes de contaminação relacionadas por estes compostos foram o Lixão de Pilões, a Companhia Brasileira de Estireno (CBE), a PETROBRAS/RBPC e a USIMINAS (Carboquímica). Os compostos fenólicos apresentam elevada toxicidade aos organismos aquáticos, o que requer o monitoramento permanente destes contaminantes, especialmente nas fontes industriais que possuem grande potencial de emissão.

Conforme Romanelli, 2004 os valores médios para a faixa de sensibilidade ao fenol variou entre $\left(\mathrm{CE}_{50} 13,83\right.$ a $\left.30,14 \mathrm{mg} / \mathrm{L}\right)$, em ensaios de toxicidade realizado com $V$. fischeri. Segundo Borrely et al. (2002), a toxicidade aguda do fenol para V. fischeri encontra-se na faixa de $19,75 \mathrm{mg} / \mathrm{L}$ e $26,22 \mathrm{mg} / \mathrm{L}$. 
Os dados referentes a matéria orgânica, expressos por $\operatorname{DBO}_{(5,20)}$ (Demanda Bioquímica de Oxigênio), variaram entre 2 a $12 \mathrm{mg} / \mathrm{L}$, sendo $5 \mathrm{mg} / \mathrm{L}$ o valor estabelecido pelo CONAMA 357/2005 para rios classe 2. Foram determinados valores médios de $\mathrm{DBO}_{(5,20)}$, dentro dos limites da legislação, nos pontos P0, PI e PE, cujo os valores variaram entre 2 e 3,33 mg/L. Esses pontos estão localizados em áreas mais preservadas, e portanto recebem menor aporte de carga orgânica, oriunda de efluente doméstico e industrial. A faixa de valores determinados para (COT), parâmetro também relacionado a matéria orgânica, mostram-se menores nos pontos PO, PI e PE (5,98, 2,38 e 3,33 mg/L), respectivamente.

O carbono orgânico total (COT) também é um parâmetro relacionado à matéria orgânica presente na água. Os valores para carbono orgânico total (COT) na $2^{\mathrm{a}}$ campanha variaram entre 3,05 e 10,11 mg/L. Enquanto os valores para carbono inorgânico total apresentaram-se em menores concentrações com uma variação entre 1,61 a 4,48 mg/L, em relação ao COT. Na $3^{\text {a }}$ coleta o P3 ponto localizado no canal de fuga II da Usina Henry Borden apresenta valor mais elevado na concentração de carbono orgânico total $(21,43$ mg/L) em relação aos outros pontos, a média para este parâmetro no mesmo ponto, se manteve maior $(14,43 \mathrm{mg} / \mathrm{L})$, o que pode estar relacionado a contribuição da Represa Billings. As concentrações médias do P5 para CT $(20,57 \mathrm{mg} / \mathrm{L})$ e CIT $(\mathrm{mg} / \mathrm{L})$ se mostraram maiores com relação aos outros pontos amostrais, podendo estar associada ao ponto estar localizado em frente à Carbocloro S.A. Indústrias Químicas que têm como principal matéria prima o cloro. Os valores para (CT) variaram entre 3,64 a 33,14 mg/L. Com exceção dos pontos PI e PE, os valores médios para COT estiveram maiores do que o permitido pelo CONAMA 357/05 para águas salobras, classe 1 (5 mg/L), já esta legislação não estabelece limite de (COT) para águas doces.

Além disso, foi possível observar uma correlação forte positiva entre $\operatorname{DBO}_{(5,20)} / \mathrm{COT}(\mathrm{r}=0,87)$, demonstrando que há maior biodegrabilidade dos compostos orgânicos em amostras do rio Cubatão nos pontos P5 e P6, com relação aos demais pontos.

Em água potável, o carbono inorgânico se apresenta nas formas do dióxido de carbono, ácido carbônico e suas formas dissociadas. Já o carbono orgânico é em grande parte originado pela matéria orgânica presente na água, bem como, resultante da sua reação com produtos desinfetantes. O nível de exposição da população aos subprodutos dessas 
reações passou a ser monitorado nos Estados Unidos a partir do ano 2000 na água destinada ao consumo humano, tendo em vista o potencial carcinogênico e de outros efeitos danosos à saúde da população. A agência de proteção ao meio ambiente daquele país estabeleceu que o monitoramento desses subprodutos passasse a ser feito através da análise do nível de carbono orgânico total presente na água (WALLACE et al, 2002; BISUTTI et al, 2004).

Os valores encontrados para surfactantes variaram entre 0,01 a $0,14 \mathrm{mg} / \mathrm{L}$, muito abaixo do limite da legislação CONAMA 357/2005 (0,5 mg/L). No entanto, 24\% das amostras no Estado de São Paulo apresentam valores não conformes para surfactantes, para rios classe 1 e 2 (CETESB, 2009). Os métodos utilizados para determinação de surfactantes aniônicos se mostraram eficientes para avaliar baixas concentrações dessas substâncias, com limite de detecção de 0,025 mg/L.

A metodologia aplicada para avaliar os surfactantes aniônicos utilizando o (LAS e DSS), mostra que não há diferença significativa no emprego dessas substâncias para a curva de calibração do método $(\mathrm{p} \leq 0,01)$.

Ainda relacionado à presença de surfactantes nas águas, embora efluentes industriais e domésticos sejam principais fontes, os valores médios para nitrato encontrados nas águas do Rio Cubatão pela CETESB variaram entre 0,32 e 0,86 mg/L nos anos de 2004 a 2009, sendo estes abaixo do valor estabelecido pelo CONAMA 357:2005 (10 mg/L). O nitrogênio amoniacal apresentou concentrações de 0,11 a 0,40 mg/L, os dados para este composto se mostram menores aos limites permitidos para rios classe 1 e 2 . No entanto, as concentrações para fósforo total apresentam valores entre 0,060 a 0,179 mg/L, alguns valores excedem os limites do CONAMA 357/2005.

No entanto, o monitoramento de surfactantes nos corpos hídricos são de suma importância, pois estes podem ocasionar sérios efeitos nocivos a biota aquática, segundo alguns autores. De acordo com Romanelli, (2004), a partir dos resultados obtidos pode-se observar que o DSS apresentou elevada toxicidade crônica a C. dubia, sendo a CENO $(3,6 \%)$ e a CEO (5,3\%). O organismo-teste C. dubia mostrou-se mais sensível ao DSS, que influenciou fortemente a reprodução dos organismos, em concentrações superiores a 5,3 
mg/L (5,3\%). Para o surfactante LAS a CENO foi de $(2,1 \%)$ e a CEO de $(3,0 \%)$, as concentrações acima de $3 \mathrm{mg} / \mathrm{L}(3 \%)$.

A faixa de sensibilidade obtida para Ceriodaphnia silvestrii exposta ao LAS foi de 12,11 a $15,93 \mathrm{mg} / \mathrm{L}$, enquanto o valor da $\mathrm{CE}(\mathrm{I})_{50}$; $48 \mathrm{~h}$ foi de $13,52( \pm 1,20) \mathrm{mg} / \mathrm{L}$ com coeficiente de variação de $10,64 \%$. A faixa de sensibilidade obtida para $C$. silvestrii exposta ao DSS foi de 3,41 a $8,01 \mathrm{mg} / \mathrm{L}$, enquanto o valor da $\mathrm{CE}(\mathrm{I})_{50}$; $48 \mathrm{~h}$ foi de 5,42 $( \pm 1,60) \mathrm{mg} / \mathrm{L}$ com coeficiente de variação de 29,52\% (COELHO \& ROCHA, 2010).

Os valores médios para CE 50 48h utilizando o DSS como substância referência em ensaios realizados com o copepoda Calanoida Argyrodiaptomus furcatus para os três estágios de desenvolvimento do organismo foram (Adulto - 12,30), (copepodito -8,85) e (náuplios - 6,56). No entanto, os valores médios para CE 50 48h utilizando o DSS apara a espécie Notodiaptomus iheringi, estes apresentaram menores valores (Adulto - 2,49), (copepodito -2,36) e (náuplios - 1,86), mostrando que possivelmente esses organismos são mais sensíveis a esta substância (OKUMURA, 2011).

Em análise qualitativa realizada neste estudo para compostos aromáticos, foram encontrados nas águas superficiais coletadas solventes aromáticos: benzeno, etilbenzeno, tolueno e xileno. Com relação à presença de compostos orgânicos, os principais solventes aromáticos são o benzeno, etilbenzeno, tolueno e xileno (BETX) sendo os mais manipulados pelo setor industrial. O benzeno, além de atuar como solvente em processos industriais é um composto intermediário na síntese do estireno, detergentes, pesticidas e ciclohexano, além de outros usos. Há, também, uma contribuição difusa destes solventes a partir de pequenas fontes que estocam e consomem combustíveis em geral (incluindo postos de gasolina, pátios de lavagem de máquinas e caminhões, marinas, entre outras).

Os hidrocarbonetos aromáticos clorados constituem matéria prima da indústria petroquímica podendo ter aplicação como pesticidas. São, em geral, substâncias tóxicas de difícil degradação pelos microrganismos e de grande persistência no ambiente terrestre e aquático. Destes compostos organoclorados aromáticos pesquisados foram encontrados nos sedimentos: 1,2-diclorobenzeno (48\% das amostras), 1,3-diclorobenzeno (46\% das amostras) e hexaclorobenzeno (13\% das amostras) (LAMPARELLI, 2001). 
Os hidrocarbonetos policíclicos aromáticos também estão presentes ao longo dos rios de Cubatão, possivelmente associados a outras fontes potenciais como a refinaria da PETROBRAS/RPBC. Outra forma possível de contribuição de PAHs seria através da queima de combustíveis no pólo industrial que gera material particulado atmosférico, o qual se deposita nos solos e nas águas.

Os resultados obtidos para os ensaios realizados com $C$. dubia na terceira campanha, apresentaram toxicidade crônica em amostras coletadas nos pontos P0; P1; P3; P4; P5 e P6. Esta coleta foi realizada em março de 2010 após período com altos índices pluviométricos que ocasionaram a abertura das comportas do Reservatório do Rio das Pedras que recebe águas do Sistema Billings e desce em direção ao rio Cubatão através dos Canais de Fuga da Usina. Pois o aumento da vazão do rio, devido às intensas chuvas neste período podem ter provocado a resuspensão e a biodisponibilidade de metais ou até mesmo compostos orgânicos, que muitas vezes se acumular nos sedimentos em concentrações maiores do que as encontradas em águas superficiais. A ausência de toxicidade apenas para o P2, pode estar associada a falta de sedimentos neste ponto amostrado, pois está localizado próximo aos canais de fuga da Usina Henry Borden, que promovem uma vazão constante, impedindo que os sedimentos decantem neste ponto amostrado. Os resultados obtidos nestes ensaios foram tratados pelo Teste "t por bioequivalência" que é empregado para detectar diferenças estatísticas e biológicas nas médias de neonatas obtidas durante a exposição de C. dubia as amostras e ao controle. Os resultados dos ensaios realizados com C. dubia utilizando o teste " $t$ " como tratamento estatístico na segunda campanha, apresentaram toxicidade nos pontos (P1, P5 e P6), enquanto na terceira campanha, apenas o P2 no apresentou toxicidade (Tabela 11 e Figura 47).

$\mathrm{Na}$ segunda e na terceira campanha, os valores médios da reprodução para os ensaios com $C$. dubia variaram entre 2,9 e 12,8 neonatas. Estes valores mostraram-se abaixo dos valores médios obtidos para o ponto referência (16,5 e 18,4 neonatas), nestas campanhas. Além disso, esses valores mostraram possível efeito observado para a espécie, já que estes valores estiveram abaixo 15 organismos, número mínimo recomendado pela ABNT NBR 13373:2004 para C.dubia (Tabela 11 e Figura 48).

A toxicidade e os valores médios de reprodução abaixo do determinado pela norma ABNT a espécie, observada nos ensaios realizados com o organismo $C$. dubia pode estar 
associada a presença de compostos fenólicos nas águas coletadas na segunda e terceira campanha, onde as concentrações determinadas variaram entre 0,05 e 3,62 mg/L. Já que não foram encontrados compostos fenólicos nas amostras de águas superficiais nas demais coletas.

As amostras de águas superficiais apresentaram toxicidade para a bactéria bioluminescente $V$. fischeri em todos os pontos e campanhas amostradas, neste estudo. Como forma de avaliar quantativamente a qualidades das águas superficiais do rio Cubatão e seus contribuintes (afluentes), as amostras coletadas foram diluídas, a fim de calcular a $\mathrm{CE}(\mathrm{I}) 50$, as amostras ambientais foram diluídas.

Os valores de toxicidade para $V$. fischeri entre as cinco campanhas, variaram entre CE(I)50 25,98\% a $61 \%$ para os pontos P6 e P5, respectivamente. As amostras variaram entre tóxicas $(\mathrm{CE}(\mathrm{I}) 50<25 \%)$ e moderadamente tóxicas $(\mathrm{CE}(\mathrm{I}) 50$ entre $51 \%$ e $75 \%)$, segundo classificação de Bullich, 1982. Os resultados dos valores médios da CE(I)50 variaram entre $30,21 \%$ e 43,30\%, para os pontos PI e P5, respectivamente. Os valores médios da CE50 calculados, a partir resultados obtidos em todas as campanhas amostrais, apresentaram correlação moderada positiva entre os parâmetros turbidez $(r=0,79)$, sólidos totais $(r=0,67)$, cloretos $(r=0,64), \mathrm{DBO}_{(5,20),}(\mathrm{r}=0,72)$ e carbono total $(\mathrm{r}=0,78)$, carbono orgânico total $(r=0,72)$, carbono inorgânico total $(r=0,71)$ e DSS $(r=0,65)$ (Tabela 13).

Os valores médios da $\mathrm{CE}_{50}$ para os pontos $\mathrm{P} 1$, P2 e P3 foram $(42,16 \%, 50,08 \%$ e 41,89\%), respectivamente. No relatório de águas interiores $100 \%$ das amostras avaliadas para o ponto CFUG02900, apresentaram resultados não conformes para a toxicidade em 2009, sendo que este que corresponde ao P1 deste estudo. O ponto P1 pode interferir diretamente nos resultados determinados nos pontos P2 e P3 devido a sua proximidade.

O relatório de águas interiores destaca a presença de cianobactérias potencialmente tóxicas em $100 \%$ das amostras coletadas no canal de fuga da Usina Henry Borden (CFUG02900) em 2009, parâmetro este que não foi determinado no presente estudo e pode estar presença de toxicidade aguda ( $V$.fischeri). O número de células de cianobactérias para o ponto CFUG 02900 variou entre 660.700 céls $/ \mathrm{mL}$ (fevereiro) a 54.665 céls./mL (agosto), ultrapassando o valor de 50.000 céls./mL estabelecido pela Resolução CONAMA 357/2005 para Classe 2 em todos os meses, exceto em outubro (CESTESB, 2008). Este 
ponto foi classificado como ruim para IVA (Índice de Qualidade das Águas para Proteção da Vida Aquática) de 2003 a 2009, apontando piora no resultado médio obtido em 2009 $(8,2)$ Tabela 4. Ainda com relação a este estudo, a presença desses microrganismos é um reflexo do reservatório Billings que desce para a baixada santista através dos canais de fuga da Usina Henry Borden. O número de células de cianobactérias ultrapassou os valores estabelecidos pela resolução CONAMA 357/05 em todos os períodos amostrados, chegando a 1.768.374 céls/ml no Reservatório Barra Bonita, em janeiro de 2009. O Sistema Billings apresenta qualidade Regular e Ruim para IVA (índice de qualidade para proteção da vida aquática), com ocorrência elevada de efeito tóxico crônico e agudo. Destaca-se a presença das espécies Asterionella formosa e Cyclotella stelligera. Além dos gêneros, Microcystis, Aphanizomenon, Anabaena e Synechocystis (CETESB, 2009).

Como já abordado nesta discussão, no presente estudo foi diagnosticado maiores valores para carbono orgânico total nos pontos P1, P2 e P3(13,80, 14,43 e 12,12 mg/L), respectivamente. O relatório de águas dos interiores (2008), apontam que a toxicidade presente nos canais de fuga da Usina Henry Borden podem ser também atribuída a formação de trihalometanos (THM), devido a presença de material orgânico dissolvido nas águas. Os pontos (P1, P2 e P3), estão localizados próximos a ETA-3 Cubatão. A água utilizada para abastecimento público sofre desinfecção com o uso do cloro. A reação do cloro com alguns compostos orgânicos leva à formação de (THM). A formação de trihalometanos em função da cloração da água é conhecida desde 1974 e por isso controlada. A Portaria n. ${ }^{o} 36$ de 19.01.90, do Ministério da Saúde, que regulamenta a qualidade de água destinada ao consumo humano, limita o teor de (THM) em $100 \mu / \mathrm{L}$.

A presença de toxicidade crônica e aguda, observada nas amostras de águas superficiais coletadas no rio Cubatão e seus contribuintes (afluentes), em pontos localizados em áreas mais preservadas (P0 e PI), podem estar associada a vulnerabilidade destes pontos, as fontes difusas oriundas do Sistema Anchieta-Imigrantes, que pode ser fonte potencial de poluição para os rios do município de Cubatão, segundo Agenda 21 da cidade.

Neste trabalho em caráter complementar a coleta de sedimentos realizada em junho de 2011, mostram que os valores para alguns Hidrocarbonetos Policíclicos Aromáticos (HPAs): dibenzoantraceno, antraceno e fluoreno, além de um pesticida organoclorado 
(Endrin), encontram-se acima ou próximo dos limites estabelecidos na legislação CONAMA 344/2004 - nível 1 para águas doces, no ponto P5, deste estudo. É também observada que a concentração da soma dos HPAs para este ponto é elevada em comparação com os demais pontos avaliados $(750 \mu \mathrm{g} / \mathrm{kg}$ ) (Tabela 14). Este ponto, esta localizado a jusante das salinas da Carbocloro e de um pátio de ônibus, localizado as margens do rio Cubatão (2352'33.00"S 46²4'47.86"O), que pode estar contribuindo para a presença de HPAs no P5. É importante ressaltar que no Brasil, os primeiros trabalhos que avaliaram a toxicidade de sedimentos foram realizados na década de 1980, com materiais provenientes da represa Billings e do Rio Cubatão, como parte de projetos mais amplos para o controle da poluição e recuperação ambiental desenvolvido pela CETESB a, b, 1983 apud ARAÚJO et al., 2006).

Apesar das concentrações dos compostos inorgânicos avaliados nesta coleta mostrarem-se inferiores aos limites tolerados pela legislação referente a este compartimento aquático. Conforme Luiz-Silva et al. (2006), os resultados geoquímicos sugerem que o Rio Cubatão tem elevadas concentrações de $\mathrm{Hg}$ (anomalias 0,65 - 6,77 mg $\mathrm{kg}^{-1}$ ), poluição conhecida desde da década de 70. Silva et al, (2006), também encontrou valores elevados para $\mathrm{Hg}$ em sedimentos coletados em 5 pontos amostrais do Rio Cubatão com variação entre 71 a $143 \mu \mathrm{g} . \mathrm{kg}^{-1}$. Em um estudo realizado por Luiz-Silva et al (2006), que determina concentrações mais significativas do mercúrio no rio Cubatão, mostra que os sedimentos do sistema estuarino de Santos-Cubatão alcançaram níveis de concentração multi-elementar que podem afetar o equilíbrio do ecossistema local. $\mathrm{O}$ mercúrio apresentou ampla dispersão, influenciada provavelmente por origens difusas. Em um estudo realizado por Lamparelli, (2001), o mercúrio foi encontrado nos sedimentos do rio Cubatão nas concentrações de $(<0,005$ e 0,082), valores estes acima do permitido pela legislação CONAMA 357/2005 (0,0002 mg/L). Este mesmo trabalho, aponta como fontes potencias os efluentes industriais das empresas COSIPA, Carbocloro, Companhia Brasileira de Estireno, Companhia Santista de Papel, entre outras, lançam seus efluentes no rio Cubatão. Sendo a principal fonte de mercúrio em Cubatão são as unidades eletrolíticas de fabricação de clorosoda da indústria Carbocloro, que utilizam eletrodos a base de mercúrio. (LAMPARELLI, 2001). 


\section{CONCLUSÕES}

A condutividade das águas superficiais, coletadas no P5 apresentaram valores médios maiores em relação aos demais pontos amostrados. Outros parâmetros físicoquímicos (oxigênio dissolvido, pH, sólidos totais, turbidez, surfactantes, cloretos), estão conforme os limites estabelecidos pelo CONAMA 357/2005.

As concentrações elevadas de compostos fenólicos foram observadas em setembro de 2009 e março de 2010, ultrapassando limites exigidos pela legislação para rios classe 1 e 2 .

Em análise qualitativa foram encontrados em águas superficiais os solventes aromáticos: benzeno, etilbenzeno, tolueno, xileno e diclorobenzeno.

Foram obtidos efeitos crônicos em C.dubia em amostras de água, coleta de março de 2010, em todos os locais amostrados, exceto o P2.

O tratamento estatístico utilizando o teste "t por bioequivalência", para os resultados de C. dubia, apontou 6 ocorrências de toxicidade na terceira campanha. Enquanto que o tratamento estatístico utilizando o teste " $T$ ", para os resultados obtidos com C. dubia, apontou 9 ocorrências de toxicidade, sendo 3 e 9 ocorrências, na $2^{\text {a }}$ e $3^{\text {a }}$ campanha, respectivamente.

$\mathrm{Na} 2^{\mathrm{a}}$ campanha (set/2009) e na $3^{\mathrm{a}}$ campanha (mar/2010), a média para reprodução de $C$. dubia foi menor em relação aos valores encontrados no ponto referência deste estudo.

Foram detectadas toxicidade aguda em águas superficiais do rio Cubatão e em seus afluentes (Rio Pilões e Perequê) para $V$. fischeri em todo o período amostrado.

Os parâmetros turbidez, sólidos totais, cloretos, $\mathrm{DBO}_{(5,20)}$, CT, COT, CIT, DSS, apresentaram moderada correlação em relação aos valores da $\mathrm{CE}_{50}$ (V. fischeri) determinados neste estudo. 


\section{REFERÊNCIAS BIBLIOGRAFICAS}

ABESSA, D.M.S.; SOUZA, E.C.P.M. Políticas Públicas para a Baixada Santista: Ecotoxicologia no apoio à Tomada de Decisões. Revista de Gestão Costeira Integrada Brasil. 4 p. 2005.

ALVES, C.A., Liveraro et al. Avaliação da toxicidade do sedimento do rio Jaguari, Município de Americana, utilizando o cladocera Daphnia similis. VIII Congresso Brasileiro de Ecotoxicologia. Livro de Resumos. 49 p. 2004.

AMERICAN PUBLIC HEALTH ASSOCIATION (APHA). Standard methods for the examination of water \& wasterwaster. 21st edition. Centennial edition. Andrew D. Eaton, Lenore S. Clesceri, Eugene W. Rice \& Arnald E. Greenberg. 800 I Street, NW. Washington, DC 20001-3710. 2005.

ASSOCIAÇÃO BRASILEIRA DE NORMAS TÉCNICAS (ABNT NBR 12713). Ecotoxicologia Aquática - Toxicidade Aguda- Método de Ensaio com Daphnia spp (CLADOCERA, CRUSTACEA). 21 p. 2004.

ASSOCIAÇÃO BRASILEIRA DE NORMAS TÉCNICAS (ABNT NBR 13373). Ecotoxicologia Aquática - Toxicidade Crônica - Método de Ensaio com Ceriodaphnia spp_(CLADOCERA, CRUSTACEA). 15 p. 2005.

ASSOCIAÇÃO BRASILEIRA DE NORMAS TÉCNICAS (ABNT NBR 15469). Ecotoxicologia aquática: Preservação e Preparo de Amostras título. Rio de Janeiro, 7 p. 2007.

ASSOCIAÇÃO BRASILEIRA DE NORMAS TÉCNICAS (ABNT NBR 5761). Ecotoxicologia aquática: eterminação do efeito inibitório de amostras de água sobre a emissão de luz de Vibrio fischeri (Ensaio de bactéria luminescente). parte 4.14 p. 2006.

BISUTTI, I., HILKE, I., RAESSLER, M., Determination of total organic carbon . An Overview of Current Methods, Trends in Analytical Chemistry, Vol.23, No.10-11, 2004.

BORRELY, S. I.; DREWICZ, P.; TROJANOWICZ, , M.; DUARTE, C. L.; SAMPA, M. H.O.; OIKAWA, H. Avaliação da toxicidade aguda do 2,4 diclorofenol tratado por irradiação com feixe de elétrons. In; VII Congresso Brasileiro de Ecotoxicologia. 06 a 09 de outubro, 2002, Vitória-ES. Livro de Resumos, p. 260. 2002.

BOSQUILHA, G. E. Estudo da Distribuição de surfactantes aniônicos e de polifosfatos no sistema estuarino de Santos/São Vicente e Baía de Santos (SP, Brasil) e avaliação das metodologias aplicadas. Dissertação de mestrado. Instituto Oceonográfico - USP. 179 p. 2002 
BRASIL. Leis Decretos, etc. Portaria no 36, de 19 de janeiro de 1990. O Ministério da Saúde aprova normas e padrões de potabilidade de água destinada ao consumo humano. Diário Oficial, Brasília, seção 1. p. 1651-1654. 1990

BRASIL. Lei Federal $\mathbf{n}^{\mathbf{0}}$ 9.433, de 8 de janeiro de 1997. Institui a Política Nacional de Recursos Hídricos, cria o Sistema Nacional de Gerenciamento de Recursos Hídricos, regulamenta o inciso XIX do art. 21 da Constituição Federal e altera o art. 1 o da Lei 8.001, de 13 de março de 1990, que modificou a Lei 7.990, de 28 de dezembro de 1989. Brasilia. 21 p. 1997.

BRASIL. Portaria $\mathbf{n}^{0} 518$ de 25 de março de 2004. Estabelece os procedimentos e responsabilidades relativos ao controle e vigilância da qualidade da água para consumo humano e seu padrão de potabilidade, e dá outras providências. Brasilia. 15 p. 2004.

BRASIL. Portaria n 685 de 30 de março de 1998 da Secretaria de Vigilância Sanitária do Ministério da Saúde. Diário Oficial da República Federativa do Brasil, Poder Executivo, Brasília, DF. Seção 1, n0 60-E, p.5-6. 1998.

BUCKUP L. \& BOND-BUCKUP G. Os Crustáceos do Rio Grande do Sul. Porto Alegre: Editora da Universidade $1^{\text {a }}$ ed. 14-19 p. 1999

BULICH, A. A. A practical and reliable method for monitoring the toxicity of aquatic samples. Process Biochemistry, march/april, 45-47 p., 1982.

BURATINI, S.V. \& BERTOLETTI, E. Análise Estatística. In: ZAGATTO, Pedro A. \& BERTOLETTI, Eduardo. Ecotoxicologia Aquática - Princípios e Aplicações. São Carlos: Rima. 478 p. 2006.

CAROLEI L. Determinação de surfactantes e água em formulações de sabonetes líquidos e shampoos por infravermelho por transformada de Fourier (FTIR) utilizando a técnica de reflectância total atenuada (ATR). Tese de Doutorado. Universidade de São Paulo Instituto de Química. 102 p. 2005.

CETESB (Companhia Ambiental do Estado de São Paulo). Relatório de Qualidade de Águas Interiores do Estado de São Paulo - São Paulo: Relatório Técnico. 310 p. 2009.

CETESB (Companhia Ambiental do Estado de São Paulo). Relatório de Qualidade de Águas Interiores do Estado de São Paulo - São Paulo: Relatório Técnico. 531 p. 2008.

CETESB (Companhia Ambiental do Estado de São Paulo). Relatório de Qualidade de Aguas Interiores do Estado de São Paulo - São Paulo: Relatório Técnico. 540 p. 2007.

CETESB (Companhia Ambiental do Estado de São Paulo). Relatório de Qualidade de Águas Interiores do Estado de São Paulo - São Paulo: Relatório Técnico. 327 p. 2006. 
CETESB (Companhia Ambiental do Estado de São Paulo). Relatório de Qualidade de Águas Interiores do Estado de São Paulo - São Paulo: Relatório Técnico. 485 p. 2005.

CETESB (Companhia Ambiental do Estado de São Paulo). Relatório de Qualidade de Águas Interiores do Estado de São Paulo - São Paulo: Relatório Técnico. 307 p. 2004.

CETESB (Companhia Ambiental do Estado de São Paulo). Relatório de Qualidade de Águas Interiores do Estado de São Paulo - São Paulo: Relatório Técnico. 307 p. 2003.

CETESB (Companhia Ambiental do Estado de São Paulo). Relatório de Qualidade de Águas Interiores do Estado de São Paulo - São Paulo: Relatório Técnico. 273 p. 2002.

CLEMENTINO, M. R. A., ROLIM, P. J. N. \& ALENCAR, J. R. B.Carbono orgânico total: metodologia analítica e aplicações para indústria farmacêutica. Rev. Bras. Farm., 89(1): 74-80,2008.

COELHO, K.S. \& ROCHA, O. Assessment of the potential toxicity of a linear alkylbenzene sulfonate (LAS) to freshwater animal life by means of cladoceran bioassays. Ecotoxicology. v. 10, n. 4, p. 812-818. 2010.

CONAMA (Conselho Nacional de Meio Ambiente. Resolução n. 357, de 17 de março de 2005. Dispõe sobre a classificação dos corpos de água e diretrizes ambientais para o seu enquadramento, bem como estabelece as condições e padrões de lançamento de efluentes, e da outras providências. Diário Oficial da União, Brasília, DF. 23p, 2005.

CUBATÃO 2020. A Cidade que Queremos. Agenda 21. Realização: Centro de Integração e Desenvolvimento Empresarial da Baixada Santista. Cubatão. Ciesp. 190p. 2006.

DOMINGUES Daniel F. \& BERTOLETTI Eduardo. Seleção, Manutenção e Cultivo de Organismos Aquáticos. In: ZAGATTO, Pedro A. \& BERTOLETTI, Eduardo. Ecotoxicologia Aquática - Princípios e Aplicações. São Carlos: Rima. 478 p. 2006.

EPA (Environmental Protection Agency). Determinative Chromatographic Separations. Method 8000B. Revision 2. December 1996. 46 p. 1996.

EPA (Environmental Protection Agency). Short-term Methods for Estimating the Chronic Toxicity of Effluents and Receiving Waters to Freshwater Organisms. Fourth Edition. Office of Water (4303T), NW Washington, DC 20460. October 2002. 350 p. 2002.

EPA (Environmental Protection Agency). Organic Extraction and Sample Preparation. Method 3500C. Revision 3.February 2007. 19 p. 2007.

FERREIRA, C. C. \& PASSERANI. M. Conto, canto e encanto com a minha história... Cubatão. A Rainha das Serras. Noovha América. Edição1. 120 p . 2005. 
FERREIRA, C. C.; TORRES, F. \& BORGES, W. Cubatão - Caminhos da História. Edição do Autor. 98 p. 2008.

FUNDAÇAO NACIONAL DA SAÚDE (FUNASA). Ministério da Saúde. Engenharia de Saúde Pública. Manual Prático de Análise de Água. Brasília, 147 p. 2006.

Governo municipal de CUBATÃO. Prefeitura Municipal de Cubatão. http://www.cubatao.sp.gov.br/publico/index.php?option=com_content $\&$ view=article $\& \mathrm{id}=3$ 2\&Itemid=24. Acesso em: 02 de setembro de 2010.

GULLEY, D. Toxstat 3.5, West Inc. University of Wyomimg. Cheyenne, Wyoming. 1996.

KALINKA S.L et al. Sensibilidade do cultivo de Daphnia magna no laboratório de toxicologia ambiental Babtox/ENS/UFSC.VIII Congresso Brasileiro de Ecotoxicologia. Livro de Resumos. 105 p. 2004.

KNIE Joaquim. L.W. \& LOPES Ester.W.B. Testes ecotoxicológicos: métodos, técnicas e aplicações. Florianópolis. 288 p. 2004.

LAMPARElli, M. L. Sistema Estuarino de Santos e São Vicente. Relatório Técnico CETESB. São Paulo. 2001. 141p.

LUIZ-SILVA W. Geoquímica e índice de geacumulaçao de mercúrio em sedimentos de superfície do estuário Santos-Cubatão (SP). Química Nova. Vol. 25. No 5, 753-756 p., 2002.

LUIZ-SILVA, W.; Matos, R.H.R.; Kristosch, G.C.; Machado, W. Variabilidade espacial e sazonal da concentração de elementos traços em sedimentos do sistema estuário de SantosCubatão (SP). Química Nova, 29: 256-263. 2006

MAGALHÃES, D.P.\& FERRÃO FILHO, A. S. A Ecotoxicologia como ferramenta no biomonitoramento de ecossistemas aquaticos. Oecol. Bras., 12 (3): 355-381, 27 p. 2008.

MAGALHÃES, V. G.; NAVEIRA, NAVEIRA, M.C.M. \& GONÇALVES, C.D.C.R.. O Bioma Mata Atlântica. Leopoldianum. Revista de Estudos e Comunicações da Universidade Católica de Santos. Ano 35-maio- agosto/2009 - n ${ }^{\circ} 96$. I Meio ambiente na Zona Costeira. 41 - 57 p. 2009.

MEYER, S. T. O uso de cloro na desinfecção de águas, a formação de trihalometanos e os riscos potenciais à saúde pública. Cad. Saúde Públ., Rio de Janeiro, 10 (1): 99-110, jan/mar, 1994

MONTEIRO, K.V.; MARCUZZO, S.F.; MADALENA A; PAIM, E.S.; BARCELLOS, C.; BLAUTH, N.; MALTEZ, H.M. \& LOPES, L.A.J. Mata Atlântica: A floresta em que vivemos. Núcleo Amigos da Terra. Porto Alegre, 70 p. 2003. 
MOZETO, Antonio A. \& ZAGATTO, Pedro A.Introdução de Agentes Químicos no Ambiente. In: ZAGATTO, Pedro A. \& BERTOLETTI, Eduardo. Ecotoxicologia Aquática - Princípios e Aplicações. São Carlos: Rima. 478 p. 2006.

NORRIS, R. H. \& C. P. HAWKINS. Monitoring river health. Hydrobiologia 435:5-17. 2000.

NUNES, D.C.L. \& FONSECA A. L. Avaliação da Eficiência da ETE (Estação de Tratamento de Esgoto de Afluentes) da Indústria Mahle/Itajubá Utilizando Bioensaios de Toxicidade Aguda com Microcrustáceos. VII Congresso Brasileiro de Ecotoxicologia. Livro de Resumos. 163 p. 2002

OKUMURA, D. T. Estudos ecotoxicológicos com as espécies Argyrodiaptomus furcatus e Notodiaptomus iheringi (Copepoda, Calanoida). Tese de doutorado. Universidade de São Carlos. São Carlos, SP. 312 p. 2011

OLIVEIRA-NETO,A.L. \& BOTTA-PASCHOAL,C.M.R. Sensibilidade do Cladócera Lacustre Planctônico Ceriodaphnia silvestrii ( Família Daphnidae) aos Metais Cádmio, Cromo e Chumbo. Novas Metodologias e Abordagens em Ensaios Ecotoxicológicos. Ecotoxicologia. In: Perspectivas para o Século XXI. São Carlos: Rima. 537-543 p. 2000.

PADILHA, P.M., ROXO, G.C., NEVES, R.C.F., SILVA, F.A., OLIVEIRA, J.D, FLORENTINO, A.O. \& VALENTE, J.P.S. Avaliação da Qualidade da Água do Rio Cubatão - SP. XLVI Congresso Brasileiro de Química. 25 a 29 de setembro de 2006.

PIVELI, R. P. \& KATO, M.T. Qualidade das Águas e Poluição: Aspectos Físicoquímicos. ABES (Associação Brasileira de Engenharia Sanitária e Ambiental. Capítulo Nacional da AIDIS. 285 p. 2006.

PÓLO INDUSTRIAL DE CUBATÃO. Relatório Anual. 10p. 2004.

PÓLO INDUSTRIAL DE CUBATÃO. Relatório Anual. 8p. 2008.

PÓLO INDUSTRIAL DE CUBATÃO. Relatório Anual. 8p. 2009.

PÓLO INDUSTRIAL DE CUBATÃO. Relatório Anual. 8p. 2009.

PROSPERI, V.A.; ROMANILLI, M.F.; BURATINI, S.V., CACHATTORI, D., SÁFADI, R.S., TIRITAN, A.R. Determinação da constante de proporcionalidade utilizada no teste $\mathrm{t}$ por bioequivalência para o ensaio com o anfípoda estuarino Leptocherus plumulosus. In: $\mathbf{X}$ Congresso Brasileiro de EcotoxicologiaBento Gonçalves, RS. Livro de resumos. 2008 
PRÜSS-ÜSTÜN A, BOS R, GORE F, BARTRAM J. World health organization (WHO). Safer water, better health: costs, benefits and sustainability ofinterventions to protect and promote health. c, Geneva, 53p. 2008.

RAND, G.M. Fundamental of Aquatic Toxicology: Effects, Environmental Fate and Risk Assessment ( $2^{\text {nd }}$ ed). Taylor Ss Francis.1995.

REBOUÇAS, A. da C.; BRAGA, B. \& TUNDISI, J.G.. Águas Doces no Brasil. Capital ecológico, uso e conservação. $2^{\mathrm{a}}$ edição revisada e ampliada.703 p. São Paulo, 2002.

ROMANELLI, M. F. Avaliação da toxicidade aguda e crônica dos surfactantes DSS e LAS submetidos à irradiação com feixes de elétrons. Dissertação de mestrado. IPEN Instituto de Pesquisas Energéticas e Nucleares/ USP. 146 p. 2004

ROMANELLI, M. F., G. P. SILVA, G.P. \& S. I. BORRELY, S. I. Redução da Toxicidade do Surfactante LAS Tratado com o Feixe de Elétrons. J. Braz. Soc. Ecotoxicol., v. 1, n. 2, 103-107 p. 2006.

RUPPERT E. E. \& BARNES R. D. Zoologia dos invertebrados. São Paulo: Roca $6^{\mathrm{a}}$ ed. 731-737 p. 1996.

SANCHEZ, P. S. \& SATO, M. I. Z. Microbiologia Aquática: Metodologia e Aplicações. Apostila do curso Diagnóstico de Ecossistemas aquáticos. São Paulo:Faculdade de Saúde Pública - USP, 2002.

SANTOS, E. O. Estudo comparativo entre as técnicas de diluição e manométrica na quantificação da demanda bioquímica de oxigênio. $22^{\circ}$ Congresso Brasileiro de Engenharia Sanitária e Ambiental. 14 a 19 de Setembro, Joinville/ SC. 8 p. 2003

SÃO PAULO (Estado). Decreto no 27.576, de 11 de novembro de 1987 de São Paulo. Cria o Conselho Estadual de Recursos Hídricos, dispõe sobre o Plano Estadual de Recursos Hídricos e o Sistema Estadual de Gestão de Recursos Hídricos e dá outras providências. São Paulo. Pag 2. 1987

SÃO PAULO (Estado). Lei Estadual $\mathbf{N}^{\circ} \mathbf{7 . 6 3 3}$ de 30 de dezembro de 1991. Estabelece normas de orientação à Política Estadual de Recursos Hídricos bem como ao Sistema Integrado de Gerenciamento de Recursos Hídricos. São Paulo.16 p. 1991.

SÃO PAULO (Estado). Lei Estadual n 9.866, de 28 de novembro de 1997. Dispõe sobre diretrizes e normas para a proteção e recuperação das bacias hidrográficas dos mananciais de interesse regional do Estado de São Paulo, e dá outras providencias.São Paulo. 15 p. 1997. 
SÃO PAULO (Estado). Resolução Conjunta SMA/ SSE-002 de 19 de fevereiro de 2010. Trata de procedimentos a serem adotados em casos de emergência na operação do sistema hídrico da bacia do Alto Tietê e bacias a ela interligadas. 2p. 2010.

Secretaria do Meio Ambiente (SMA). Coordenadoria de Educação Ambiental (CEA). Caderno Ambiental Billings. Secretaria de Estado do Meio Ambiente. Coordenadoria de Educação Ambiental.São Paulo, 148 p. 2010.

Secretaria do Meio Ambiente (SMA). Coordenadoria de Educação Ambiental (CEA). Caderno Ambiental Guarapiranga. Secretaria de Estado do Meio Ambiente. Coordenadoria de Educação Ambiental.São Paulo. 84p. 2008.

SLONCZEWSKI, J. L. \& FOSTER, J. W. Microbiology. An Evolving Science. second edition. Hardcover. 1100 pag. 2010.

SOS

MATA

ATLÂNTICA.

http://www.sosmatatlantica.org.br/index.php?section=info\&action=agua. Acesso em: 20 de janeiro de 2011.

VIRGA, R. H. P.; GERALDO, L. P.; SANTOS, F. H. Avaliação de contaminação por metais pesados em amostras de siris azuis. Ciênc. Tecnol. Aliment., Campinas, 27(4): 779-785. 2007.

ZAGATTO, P. A. O uso de substâncias de referência no controle de qualidade de ensaios ecotoxicológicos. In: ZAGATTO, Pedro A. \& BERTOLETTI, Eduardo. Ecotoxicologia Aquática - Princípios e Aplicações. São Carlos: Rima. 478 p. 2006. 


\section{ANEXO I}

Tabela 1 - Dados brutos dos ensaios de toxicidade utilizando Ceriodaphnia dubia para as análises das águas superficiais do Rio Cubatão e seus contribuintes (afluentes) - $2^{\mathrm{a}}$ campanha

\section{$2^{\text {a }}$ Campanha}

Início do ensaio: 14/09/2009 - Fim do ensaio: 21/10/2009

Controle: Dureza: $44 \mathrm{mg} / \mathrm{L} \quad$ Condutividade: $159,1 \mu \mathrm{s} / \mathrm{cm} \quad \mathrm{pH}: 7,21 \quad$ OD: $7,47 \mathrm{mg} / \mathrm{L}$

\begin{tabular}{|c|c|c|c|c|c|c|c|c|c|c|c|c|}
\hline \multirow{5}{*}{$\begin{array}{l}\frac{0}{0} \\
0 \\
0 \\
0\end{array}$} & Data & $\mathrm{R} 1$ & $\mathrm{R} 2$ & $\mathrm{R} 3$ & $\mathrm{R} 4$ & R5 & R6 & R7 & $\mathrm{R} 8$ & $\mathrm{R} 9$ & $\mathrm{R} 10$ & Média \\
\hline & $16 / 10 / 2009$ & 0 & 0 & 0 & 0 & 0 & 0 & 0 & 0 & 0 & 0 & \multirow{4}{*}{16,3} \\
\hline & $19 / 10 / 2009$ & 3 & 4 & 2 & 6 & 4 & 9 & 6 & 2 & 1 & 7 & \\
\hline & $21 / 10 / 2009$ & 14 & 21 & 14 & 9 & 3 & 6 & 18 & 13 & 16 & 5 & \\
\hline & Total & 17 & 25 & 16 & 15 & 7 & 15 & 24 & 15 & 17 & 12 & \\
\hline \multirow{5}{*}{$\bar{a}$} & Data & R1 & R2 & R3 & R4 & R5 & R6 & R7 & R8 & R9 & $\mathrm{R} 10$ & Média \\
\hline & $16 / 10 / 2009$ & 0 & 0 & 0 & 0 & 0 & 0 & 0 & 0 & 0 & 0 & \multirow{4}{*}{12,4} \\
\hline & $19 / 10 / 2009$ & 0 & 1 & 2 & 2 & 6 & 4 & 4 & 3 & 6 & 1 & \\
\hline & $21 / 10 / 2009$ & 9 & 5 & 14 & 13 & 2 & 6 & 10 & 10 & 14 & 12 & \\
\hline & Total & 9 & 6 & 16 & 15 & 8 & 10 & 14 & 13 & 20 & 13 & \\
\hline \multirow{5}{*}{$\stackrel{N}{\Omega}$} & Data & R1 & $\mathrm{R} 2$ & $\overline{\mathrm{R} 3}$ & R4 & R5 & R6 & R7 & $\overline{\mathrm{R} 8}$ & R9 & $\overline{\mathrm{R} 10}$ & Média \\
\hline & $16 / 10 / 2009$ & 0 & 0 & 0 & 0 & 0 & 0 & 0 & 0 & 0 & 0 & \multirow{4}{*}{12,0} \\
\hline & $19 / 10 / 2009$ & 2 & 0 & 2 & 0 & 5 & 4 & 6 & 3 & 2 & 4 & \\
\hline & $21 / 10 / 2009$ & 0 & 5 & 13 & 10 & 10 & 19 & 14 & 10 & 0 & 11 & \\
\hline & Total & 2 & 5 & 15 & 10 & 15 & 23 & 20 & 13 & 2 & 15 & \\
\hline \multirow{5}{*}{$\tilde{\alpha}$} & Data & $\mathrm{R} 1$ & $\mathrm{R} 2$ & R3 & $\mathrm{R} 4$ & $\mathrm{R} 5$ & R6 & R7 & $\mathrm{R} 8$ & R9 & $\mathrm{R} 10$ & Média \\
\hline & $16 / 10 / 2009$ & 0 & 0 & 0 & 0 & 0 & 0 & 0 & 0 & 0 & 0 & \multirow{4}{*}{12,5} \\
\hline & $19 / 10 / 2009$ & 2 & 3 & 2 & 2 & 3 & 6 & 1 & 7 & 6 & + & \\
\hline & $21 / 10 / 2009$ & 10 & 8 & 3 & 19 & 15 & 15 & 7 & 6 & 10 & + & \\
\hline & Total & 12 & 11 & 5 & 21 & 18 & 21 & 8 & 13 & 16 & 0 & \\
\hline \multirow{5}{*}{$\stackrel{+}{2}$} & Data & $\mathrm{R} 1$ & $\mathrm{R} 2$ & R3 & $\mathrm{R} 4$ & $\mathrm{R} 5$ & R6 & R7 & $\mathrm{R} 8$ & R9 & $\mathrm{R} 10$ & Média \\
\hline & $16 / 10 / 2009$ & 0 & 0 & 0 & 0 & 0 & 0 & 0 & 0 & 0 & 0 & \multirow{4}{*}{12,8} \\
\hline & $19 / 10 / 2009$ & 1 & 6 & 1 & 4 & 4 & 2 & 4 & 2 & 4 & 7 & \\
\hline & $21 / 10 / 2009$ & 4 & 3 & 11 & 16 & 9 & 13 & 7 & 10 & 12 & 6 & \\
\hline & Total & 5 & 9 & 14 & 20 & 13 & 15 & 11 & 12 & 16 & 13 & \\
\hline \multirow{5}{*}{$\curvearrowleft$} & Data & R1 & $\mathrm{R} 2$ & R3 & $\mathrm{R} 4$ & $\mathrm{R} 5$ & R6 & R7 & $\mathrm{R} 8$ & R9 & $\mathrm{R} 10$ & Média \\
\hline & $16 / 10 / 2009$ & 0 & 0 & 0 & 0 & 0 & 0 & 0 & 0 & 0 & 0 & \multirow{4}{*}{10,7} \\
\hline & $19 / 10 / 2009$ & 0 & 0 & 2 & 2 & 3 & 4 & + & 3 & 0 & 0 & \\
\hline & $21 / 10 / 2009$ & 9 & 17 & 6 & 8 & 6 & 13 & + & 8 & 10 & 16 & \\
\hline & Total & 9 & 17 & 8 & 10 & 9 & 17 & + & 11 & 10 & 16 & \\
\hline \multirow{5}{*}{ ڤ } & Data & $\mathrm{R} 1$ & $\mathrm{R} 2$ & R3 & $\mathrm{R} 4$ & $\mathrm{R} 5$ & R6 & R7 & $\mathrm{R} 8$ & R9 & $\mathrm{R} 10$ & Média \\
\hline & $16 / 10 / 2009$ & 0 & 0 & 0 & 0 & 0 & 0 & 0 & 0 & 0 & 0 & \multirow{4}{*}{9,9} \\
\hline & $19 / 10 / 2009$ & 3 & 5 & 4 & 6 & 1 & 0 & + & 3 & 2 & 6 & \\
\hline & $21 / 10 / 2009$ & 3 & 5 & 15 & 4 & 5 & 10 & + & 10 & 15 & 2 & \\
\hline & Total & 6 & 10 & 19 & 10 & 6 & 10 & + & 13 & 17 & 8 & \\
\hline
\end{tabular}


Tabela 2 - Dados brutos dos ensaios de toxicidade utilizando Ceriodaphnia dubia para as análises das águas superficiais do Rio Cubatão e seus contribuintes (afluentes) - $3^{\mathrm{a}}$ campanha

\section{$3^{\text {a }}$ Campanha}

Início do ensaio: 23/04/2010 - Fim do ensaio: 30/04/2010

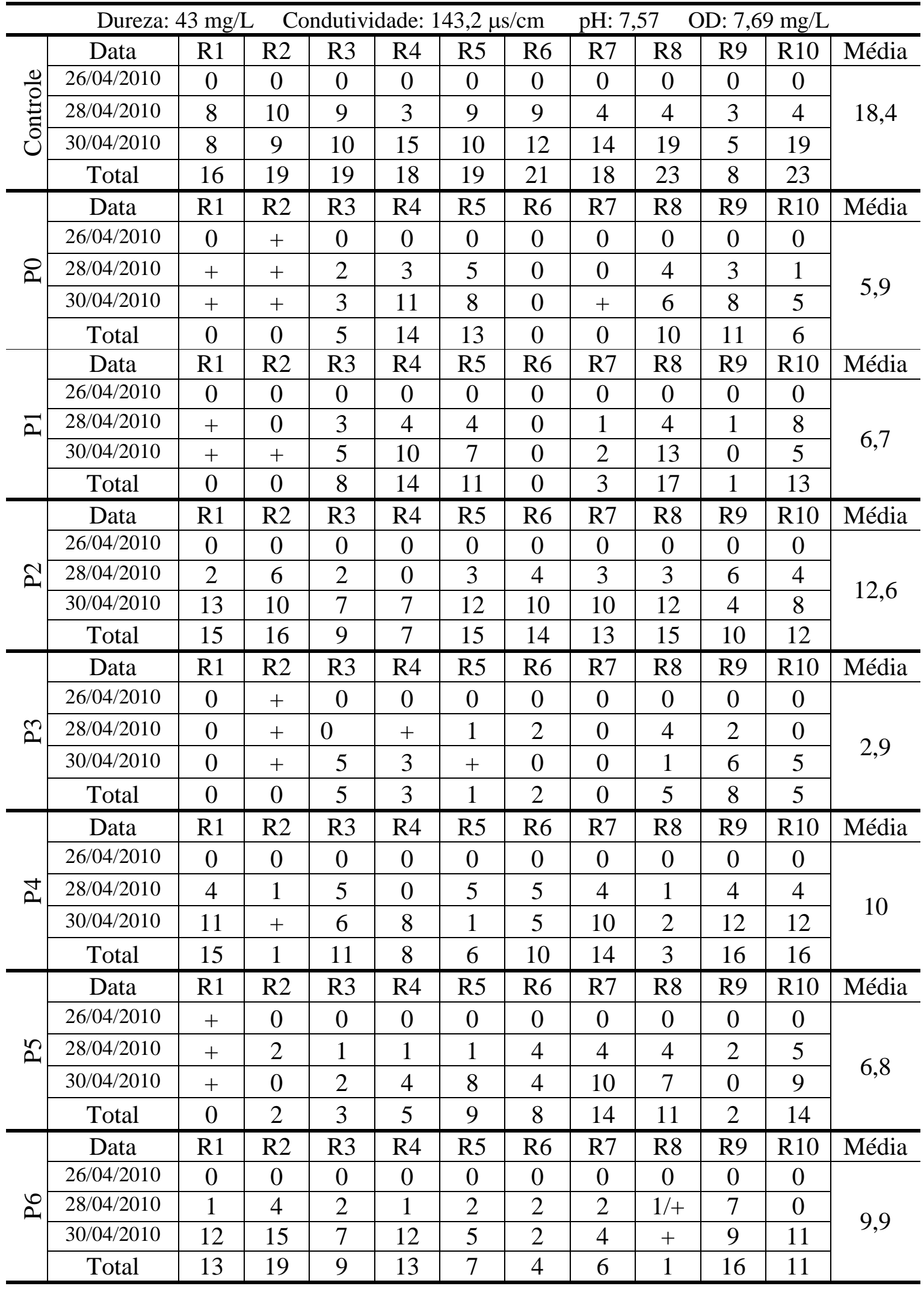


Tabela 3 - Dados brutos dos ensaios de toxicidade utilizando Ceriodaphnia dubia para as análises das águas superficiais do Rio Cubatão e seus contribuintes (afluentes) - $4^{\mathrm{a}}$ campanha.

\section{$4^{\mathrm{a}}$ Campanha}

Início do ensaio: 13/08/2010 - Fim do ensaio: 20/08/2010

\begin{tabular}{|c|c|c|c|c|c|c|c|c|c|c|c|c|}
\hline & \multicolumn{3}{|c|}{ Dureza: $44 \mathrm{mg} / \mathrm{L}$} & \multicolumn{4}{|c|}{ Condutividade: $162,3 \mu \mathrm{s} / \mathrm{cm}$} & \multicolumn{2}{|c|}{$\mathrm{pH}: 7,32$} & \multicolumn{2}{|c|}{ D: $7,66 \mathrm{mg} / \mathrm{L}$} & \\
\hline \multirow{5}{*}{ 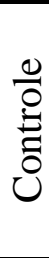 } & Data & $\mathrm{R} 1$ & $\mathrm{R} 2$ & R3 & $\mathrm{R} 4$ & $\mathrm{R} 5$ & R6 & R7 & $\mathrm{R} 8$ & R9 & $\mathrm{R} 10$ & Média \\
\hline & $16 / 08 / 2010$ & 0 & 0 & 0 & 0 & 0 & 0 & 0 & 0 & 0 & 0 & \multirow{4}{*}{25,2} \\
\hline & $18 / 08 / 2010$ & 15 & 16 & 14 & 12 & 15 & 12 & 16 & 13 & 16 & 11 & \\
\hline & $20 / 08 / 2010$ & 20 & 10 & 3 & 15 & 14 & 10 & 9 & 10 & 9 & 12 & \\
\hline & Total & 35 & 26 & 17 & 27 & 29 & 22 & 25 & 23 & 25 & 23 & \\
\hline \multirow{5}{*}{ 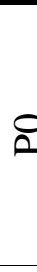 } & Data & R1 & R2 & R3 & $\mathrm{R} 4$ & $\mathrm{R} 5$ & R6 & R7 & R8 & R9 & R10 & Média \\
\hline & $16 / 08 / 2010$ & 0 & 3 & 0 & 0 & 0 & 0 & 0 & 0 & 0 & 0 & \multirow{4}{*}{21,3} \\
\hline & $18 / 08 / 2010$ & 7 & $+/ 0$ & 11 & 13 & 13 & 14 & 13 & 8 & 9 & 11 & \\
\hline & $20 / 08 / 2010$ & 15 & + & 10 & 12 & 5 & 15 & 11 & 13 & 17 & 13 & \\
\hline & Total & 22 & 3 & 21 & 25 & 18 & 29 & 24 & 21 & 26 & 24 & \\
\hline \multirow{5}{*}{$\bar{a}$} & Data & $\mathrm{R} 1$ & $\mathrm{R} 2$ & R3 & $\mathrm{R} 4$ & R5 & R6 & R7 & R8 & R9 & R10 & Média \\
\hline & $16 / 08 / 2010$ & 0 & 0 & 0 & 0 & 0 & 0 & 0 & 0 & 0 & 0 & \multirow{4}{*}{19,7} \\
\hline & $18 / 08 / 2010$ & 10 & 10 & 12 & 11 & 12 & 12 & 10 & 9 & 9 & 10 & \\
\hline & $20 / 08 / 2010$ & 8 & 7 & 10 & 10 & 10 & 10 & 7 & 9 & 8 & 13 & \\
\hline & Total & 18 & 17 & 22 & 21 & 22 & 22 & 17 & 18 & 17 & 23 & \\
\hline \multirow{5}{*}{$\Sigma$} & Data & $\mathrm{R} 1$ & $\mathrm{R} 2$ & R3 & $\mathrm{R} 4$ & R5 & R6 & R7 & $\mathrm{R} 8$ & R9 & R10 & Média \\
\hline & $16 / 08 / 2010$ & 0 & 0 & 0 & 0 & 0 & 0 & 0 & 0 & 0 & 0 & \multirow{4}{*}{18,7} \\
\hline & $18 / 08 / 2010$ & 12 & 12 & 12 & 9 & 16 & 6 & 9 & $+/ 0$ & 9 & 8 & \\
\hline & $20 / 08 / 2010$ & 7 & 14 & 10 & 13 & 9 & 7 & 10 & + & 16 & 8 & \\
\hline & Total & 19 & 26 & 22 & 22 & 25 & 13 & 19 & + & 25 & 16 & \\
\hline \multirow{5}{*}{$\tilde{n}$} & Data & $\mathrm{R} 1$ & $\mathrm{R} 2$ & R3 & $\mathrm{R} 4$ & R5 & R6 & R7 & $\mathrm{R} 8$ & R9 & $\mathrm{R} 10$ & Média \\
\hline & $16 / 08 / 2010$ & 0 & 0 & 0 & 0 & 0 & 0 & 0 & 0 & 0 & 0 & \multirow{4}{*}{21,0} \\
\hline & $18 / 08 / 2010$ & 4 & 9 & 11 & 14 & 8 & 1 & 9 & 11 & 9 & 9 & \\
\hline & $20 / 08 / 2010$ & 7 & 11 & 13 & 11 & 12 & $+/ 4$ & 14 & 17 & 16 & 18 & \\
\hline & Total & 11 & 20 & 24 & 25 & 20 & 5 & 23 & 28 & 27 & 27 & \\
\hline \multirow{5}{*}{$\stackrel{+}{2}$} & Data & $\mathrm{R} 1$ & $\mathrm{R} 2$ & R3 & $\mathrm{R} 4$ & R5 & R6 & R7 & $\mathrm{R} 8$ & R9 & R10 & Média \\
\hline & $16 / 08 / 2010$ & 0 & 0 & 0 & 0 & 0 & 0 & 0 & 0 & 0 & 0 & \multirow{4}{*}{19,5} \\
\hline & $18 / 08 / 2010$ & 4 & 8 & $+/ 1$ & 3 & 10 & 11 & 8 & 6 & 13 & 13 & \\
\hline & $20 / 08 / 2010$ & 7 & 12 & + & 6 & 12 & 12 & 14 & 14 & 20 & 21 & \\
\hline & Total & 11 & 20 & 1 & 9 & 22 & 23 & 22 & 20 & 33 & 34 & \\
\hline \multirow{5}{*}{$\curvearrowleft$} & Data & $\mathrm{R} 1$ & $\mathrm{R} 2$ & R3 & $\mathrm{R} 4$ & R5 & R6 & R7 & $\mathrm{R} 8$ & R9 & $\mathrm{R} 10$ & Média \\
\hline & $16 / 08 / 2010$ & 0 & 0 & 0 & 0 & 0 & 0 & 0 & 0 & 0 & 0 & \multirow{4}{*}{17,7} \\
\hline & $18 / 08 / 2010$ & 0 & 5 & 11 & 5 & 9 & 8 & 5 & 6 & 7 & 6 & \\
\hline & $20 / 08 / 2010$ & $+/ 1$ & 7 & 12 & 17 & 11 & 17 & 11 & 14 & 12 & 13 & \\
\hline & Total & 1 & 12 & 23 & 22 & 20 & 25 & 16 & 20 & 19 & 19 & \\
\hline \multirow{5}{*}{2} & Data & $\mathrm{R} 1$ & $\mathrm{R} 2$ & R3 & $\mathrm{R} 4$ & R5 & R6 & R7 & $\mathrm{R} 8$ & $\mathrm{R} 9$ & $\mathrm{R} 10$ & Média \\
\hline & $16 / 08 / 2010$ & 0 & 0 & 0 & 0 & 0 & 0 & 0 & 0 & 0 & 0 & \multirow{4}{*}{17,0} \\
\hline & $18 / 08 / 2010$ & 5 & 4 & 7 & 4 & 8 & $+/ 1$ & 10 & 8 & 12 & 12 & \\
\hline & $20 / 08 / 2010$ & 12 & 12 & 9 & 14 & 9 & + & 14 & 8 & 10 & 11 & \\
\hline & Total & 17 & 16 & 16 & 18 & 17 & 1 & 24 & 16 & 22 & 23 & \\
\hline
\end{tabular}




\begin{tabular}{|c|c|c|c|c|c|c|c|c|c|c|c|c|}
\hline \multirow{5}{*}{$\bar{a}$} & Data & $\mathrm{R} 1$ & $\mathrm{R} 2$ & R3 & R4 & $\mathrm{R} 5$ & R6 & R7 & R8 & R9 & R10 & Média \\
\hline & $16 / 08 / 2010$ & 0 & 0 & 0 & 0 & 0 & 0 & 0 & 0 & 0 & 0 & \multirow{4}{*}{18,3} \\
\hline & $18 / 08 / 2010$ & 0 & 5 & 3 & 2 & 6 & 6 & 7 & 3 & 3 & 5 & \\
\hline & $20 / 08 / 2010$ & + & 16 & 19 & 19 & 13 & 15 & 10 & 14 & 18 & 19 & \\
\hline & Total & + & 21 & 22 & 21 & 19 & 21 & 17 & 17 & 21 & 24 & \\
\hline \multirow{5}{*}{$\frac{1}{2}$} & Data & $\mathrm{R} 1$ & $\mathrm{R} 2$ & R3 & R4 & $\mathrm{R} 5$ & R6 & R7 & R8 & R9 & $\mathrm{R} 10$ & Média \\
\hline & $16 / 08 / 2010$ & 0 & 0 & 0 & 0 & 0 & 0 & 0 & 0 & 0 & 0 & \multirow{4}{*}{16,9} \\
\hline & $18 / 08 / 2010$ & 6 & 4 & 4 & 5 & 3 & 4 & 8 & 8 & 10 & 5 & \\
\hline & $20 / 08 / 2010$ & 14 & 12 & 14 & 13 & 15 & 16 & 9 & 9 & 9 & 1 & \\
\hline & Total & 20 & 16 & 18 & 18 & 18 & 20 & 17 & 17 & 19 & 6 & \\
\hline
\end{tabular}

Tabela 4 - Dados brutos dos ensaios de toxicidade utilizando Ceriodaphnia dubia para as análises das águas superficiais do Rio Cubatão e seus contribuintes (afluentes) - $5^{\text {a }}$ campanha.

\section{5 a Campanha}

Início do ensaio: 18/03/2011 - Fim do ensaio: 25/03/2011

\begin{tabular}{|c|c|c|c|c|c|c|c|c|c|c|c|c|}
\hline & \multicolumn{2}{|c|}{ Dureza: $44 \mathrm{mg} / \mathrm{L}$} & \multicolumn{5}{|c|}{ Condutividade: $159,1 \mu \mathrm{s} / \mathrm{cm}$} & \multicolumn{2}{|c|}{$\mathrm{pH}: 7,68$} & \multicolumn{2}{|c|}{ DD: $7,47 \mathrm{mg} / \mathrm{L}$} & \\
\hline \multirow{5}{*}{\begin{tabular}{l}
$\frac{0}{0}$ \\
\multirow{0}{0}{} \\
0
\end{tabular}} & Data & R1 & R2 & R3 & $\mathrm{R} 4$ & R5 & R6 & $\mathrm{R} 7$ & R8 & R9 & R10 & Média \\
\hline & $20 / 03 / 2011$ & 0 & 0 & 1 & 3 & 1 & 1 & 3 & 3 & 0 & 3 & \multirow{4}{*}{21,6} \\
\hline & $23 / 03 / 2011$ & 10 & 2 & 4 & 5 & 6 & 9 & 12 & 5 & 5 & 8 & \\
\hline & $25 / 03 / 2011$ & 10 & 15 & 10 & 20 & 14 & 12 & 11 & 18 & 17 & 8 & \\
\hline & Total & 20 & 17 & 15 & 28 & 21 & 22 & 26 & 26 & 22 & 19 & \\
\hline \multirow{5}{*}{ 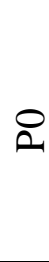 } & Data & R1 & $\mathrm{R} 2$ & R3 & $\mathrm{R} 4$ & R5 & R6 & R7 & $\mathrm{R} 8$ & R9 & $\mathrm{R} 10$ & Média \\
\hline & $20 / 03 / 2011$ & 0 & 2 & 0 & 1 & 1 & 1 & 2 & 1 & 0 & 1 & \multirow{4}{*}{19,4} \\
\hline & $23 / 03 / 2011$ & 6 & 4 & 8 & 9 & 10 & 17 & 10 & 8 & 7 & 13 & \\
\hline & $25 / 03 / 2011$ & 9 & 15 & 8 & 10 & 9 & 6 & 7 & 12 & 9 & 7 & \\
\hline & Total & 15 & 21 & 16 & 20 & 20 & 24 & 19 & 22 & 16 & 21 & \\
\hline \multirow{5}{*}{$\bar{a}$} & Data & $\mathrm{R} 1$ & $\mathrm{R} 2$ & $\mathrm{R} 3$ & $\mathrm{R} 4$ & $\mathrm{R} 5$ & $\mathrm{R} 6$ & $\mathrm{R} 7$ & $\mathrm{R} 8$ & R9 & $\mathrm{R} 10$ & Média \\
\hline & $20 / 03 / 2011$ & 2 & 2 & 2 & 2 & 3 & 3 & 2 & 0 & 2 & 2 & \multirow{4}{*}{22,1} \\
\hline & $23 / 03 / 2011$ & 12 & 8 & 8 & 7 & 8 & 12 & 15 & 8 & 11 & 2 & \\
\hline & $25 / 03 / 2011$ & 11 & 15 & 13 & 11 & 12 & 10 & 8 & 8 & 8 & 14 & \\
\hline & Total & 25 & 25 & 23 & 20 & 23 & 25 & 25 & 16 & 21 & 18 & \\
\hline \multirow{5}{*}{ 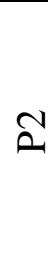 } & Data & $\mathrm{R} 1$ & $\mathrm{R} 2$ & R3 & $\overline{\mathrm{R} 4}$ & R5 & R6 & R7 & $\mathrm{R} 8$ & R9 & R10 & Média \\
\hline & $20 / 03 / 2011$ & 0 & 0 & 0 & 0 & 0 & 0 & 0 & 0 & 0 & 0 & \multirow{4}{*}{19,9} \\
\hline & $23 / 03 / 2011$ & 5 & 7 & 8 & 9 & 11 & 12 & 10 & 7 & 7 & 8 & \\
\hline & $25 / 03 / 2011$ & 11 & 7 & 10 & 15 & 15 & 14 & 8 & 11 & 9 & 10 & \\
\hline & Total & 16 & 14 & 20 & 24 & 26 & 26 & 20 & 18 & 17 & 18 & \\
\hline \multirow{5}{*}{$\hat{\alpha}$} & Data & R1 & R2 & R3 & $\overline{\mathrm{R} 4}$ & R5 & R6 & R7 & $\mathrm{R} 8$ & R9 & $\mathrm{R} 10$ & Média \\
\hline & $20 / 03 / 2011$ & 0 & 0 & 0 & 0 & 0 & 0 & 0 & 0 & 0 & 0 & \multirow{4}{*}{18,3} \\
\hline & $23 / 03 / 2011$ & 9 & 2 & 13 & 2 & 5 & 3 & 4 & 5 & 7 & 8 & \\
\hline & $25 / 03 / 2011$ & 11 & 15 & 8 & 15 & 11 & 12 & 15 & 16 & 11 & 11 & \\
\hline & Total & 20 & 17 & 21 & 17 & 16 & 15 & 19 & 21 & 18 & 19 & \\
\hline \multirow{4}{*}{ 吉 } & Data & R1 & $\mathrm{R} 2$ & R3 & $\mathrm{R} 4$ & R5 & R6 & R7 & R8 & R9 & R10 & Média \\
\hline & $20 / 03 / 2011$ & 1 & 1 & 1 & 0 & 0 & 2 & 2 & 2 & 1 & 1 & \multirow{3}{*}{17,6} \\
\hline & $23 / 03 / 2011$ & 10 & 9 & 12 & 9 & 12 & 6 & 13 & 7 & 11 & 12 & \\
\hline & $25 / 03 / 2011$ & 6 & 6 & 7 & 9 & 7 & 10 & 3 & 9 & 3 & 4 & \\
\hline
\end{tabular}




\begin{tabular}{|c|c|c|c|c|c|c|c|c|c|c|c|c|}
\hline & Total & 17 & 16 & 20 & 18 & 19 & 18 & 18 & 18 & 15 & 17 & \\
\hline \multirow{5}{*}{$n$} & Data & $\mathrm{R} 1$ & $\mathrm{R} 2$ & R3 & $\mathrm{R} 4$ & $\mathrm{R} 5$ & R6 & R7 & R8 & R9 & R10 & Média \\
\hline & $20 / 03 / 2011$ & 1 & 0 & 1 & 0 & 0 & 0 & 0 & 0 & 0 & 0 & \multirow{4}{*}{17,9} \\
\hline & $23 / 03 / 2011$ & 14 & 8 & 8 & 10 & 10 & 11 & 13 & 6 & 6 & 7 & \\
\hline & $25 / 03 / 2011$ & 8 & 8 & 8 & 5 & 11 & 7 & 9 & 10 & 9 & 9 & \\
\hline & Total & 23 & 16 & 17 & 15 & 21 & 18 & 22 & 16 & 15 & 16 & \\
\hline \multirow{5}{*}{ ڤ } & Data & $\mathrm{R} 1$ & R2 & R3 & $\mathrm{R} 4$ & $\mathrm{R} 5$ & R6 & R7 & R8 & R9 & R10 & Média \\
\hline & $20 / 03 / 2011$ & 0 & 1 & 0 & 3 & 0 & 0 & 0 & 0 & 0 & 0 & \multirow{4}{*}{16,2} \\
\hline & $23 / 03 / 2011$ & 11 & 8 & 12 & 7 & 10 & 14 & 8 & 7 & 8 & 7 & \\
\hline & $25 / 03 / 2011$ & 5 & 8 & 8 & 10 & 5 & 3 & 8 & 6 & 8 & 5 & \\
\hline & Total & 16 & 17 & 20 & 20 & 15 & 17 & 16 & 13 & 16 & 12 & \\
\hline \multirow{5}{*}{$\bar{\alpha}$} & Data & $\mathrm{R} 1$ & $\mathrm{R} 2$ & $\mathrm{R} 3$ & $\mathrm{R} 4$ & $\mathrm{R} 5$ & R6 & R7 & R8 & R9 & $\mathrm{R} 10$ & Média \\
\hline & $20 / 03 / 2011$ & 0 & 0 & 0 & 0 & 1 & 0 & 0 & 0 & 0 & 0 & \multirow{4}{*}{17,5} \\
\hline & $23 / 03 / 2011$ & 9 & 7 & 8 & 10 & 2 & 3 & 6 & 6 & 9 & 9 & \\
\hline & $25 / 03 / 2011$ & 6 & 9 & 8 & 13 & 12 & 13 & 10 & 10 & 6 & 8 & \\
\hline & Total & 15 & 16 & 16 & 23 & 15 & 26 & 26 & 16 & 15 & 17 & \\
\hline \multirow{5}{*}{$\frac{11}{2}$} & Data & $\mathrm{R} 1$ & $\mathrm{R} 2$ & R3 & $\mathrm{R} 4$ & $\mathrm{R} 5$ & R6 & R7 & R8 & R9 & $\mathrm{R} 10$ & Média \\
\hline & $24 / 04 / 2010$ & 0 & 1 & 0 & 0 & 0 & 0 & 0 & 0 & 0 & 0 & \multirow{4}{*}{16,3} \\
\hline & $26 / 04 / 2010$ & 10 & 8 & 8 & 9 & 9 & 9 & 7 & 9 & 9 & 4 & \\
\hline & $30 / 04 / 2010$ & 7 & 9 & 8 & 6 & 6 & 7 & 11 & 7 & 11 & 11 & \\
\hline & Total & 17 & 18 & 16 & 15 & 15 & 16 & 15 & 15 & 20 & 15 & \\
\hline
\end{tabular}

Tabela 5 - Dados brutos dos ensaios de toxicidade utilizando Vibrio fischeri das análises das águas superficiais do Rio Cubatão e seus contribuintes (afluentes) $-1^{\mathrm{a}}$ campanha.

\section{$1^{\text {a }}$ Campanha}

\section{Data dos ensaios: Lote da bactéria:}

\begin{tabular}{|c|c|c|c|c|c|c|}
\hline \multirow{4}{*}{$\hat{\Omega}$} & Leitura & Controle & $10,23 \%$ & $20,47 \%$ & $40,95 \%$ & $81,9 \%$ \\
\hline & Inicial (I0) & 93 & 83 & 81 & 89 & 82 \\
\hline & Final (I15) & 84 & 62 & 52 & 47 & 06 \\
\hline & \multicolumn{6}{|c|}{ CE50 $=45,95(20,03-105,40)$} \\
\hline \multirow{4}{*}{$\curvearrowleft$} & Leitura & Controle & $10,23 \%$ & $20,47 \%$ & $40,95 \%$ & $81,9 \%$ \\
\hline & Inicial (I0) & 95 & 85 & 80 & 80 & 82 \\
\hline & Final (I15) & 83 & 62 & 50 & 45 & 05 \\
\hline & \multicolumn{6}{|c|}{ CE50 = 31,13 $(11,28-85,93)$} \\
\hline \multirow{4}{*}{ \& } & Leitura & Controle & $10,23 \%$ & $20,47 \%$ & $40,95 \%$ & $81,9 \%$ \\
\hline & Inicial (I0) & 92 & 87 & 87 & 85 & 90 \\
\hline & Final (I15) & 82 & 59 & 47 & 37 & 08 \\
\hline & \multicolumn{6}{|c|}{ CE50 $=25,98(14,40-46,84)$} \\
\hline
\end{tabular}


Tabela 6 - Dados brutos dos ensaios de toxicidade utilizando Vibrio fischeri das análises das águas superficiais do Rio Cubatão e seus contribuintes (afluentes) - $2^{\mathrm{a}}$ campanha.

\begin{tabular}{|c|c|c|c|c|c|c|}
\hline \multicolumn{7}{|c|}{$2^{\mathrm{a}}$ Campanha } \\
\hline \multicolumn{7}{|c|}{ Data dos ensaios: Lote da bactéria: } \\
\hline \multirow{4}{*}{$\bar{a}$} & Leitura & Controle & $24,26 \%$ & $36,4 \%$ & $54,6 \%$ & $81,9 \%$ \\
\hline & Inicial (I0) & 94 & 96 & 108 & 108 & 109 \\
\hline & Final (I15) & 86 & 77 & 69 & 52 & 02 \\
\hline & \multicolumn{6}{|c|}{ CE50 = 42,21 $(13,12-135,74)$} \\
\hline \multirow{4}{*}{ ¿ } & Leitura & Controle & $24,26 \%$ & $36,4 \%$ & $54,6 \%$ & $81,9 \%$ \\
\hline & Inicial (I0) & 72 & 93 & 95 & 95 & 97 \\
\hline & Final (I15) & 58 & 64 & 60 & 59 & 10 \\
\hline & \multicolumn{6}{|c|}{ CE50 = 55,22 $(18,65-163,63)$} \\
\hline \multirow{4}{*}{$\tilde{\Omega}$} & Leitura & Controle & $24,26 \%$ & $36,4 \%$ & $54,6 \%$ & $81,9 \%$ \\
\hline & Inicial (I0) & 99 & 111 & 110 & 108 & 109 \\
\hline & Final (I15) & 100 & 94 & 80 & 56 & 04 \\
\hline & \multicolumn{6}{|c|}{ CE50 $=42,78(15,80-115,81)$} \\
\hline \multirow{4}{*}{ Z } & Leitura & Controle & $24,26 \%$ & $36,4 \%$ & $54,6 \%$ & $81,9 \%$ \\
\hline & Inicial (I0) & 92 & 82 & 90 & 93 & 91 \\
\hline & Final (I15) & 92 & 66 & 56 & 45 & 03 \\
\hline & \multicolumn{6}{|c|}{ CE50 $=40,19(15,09-107,02)$} \\
\hline \multirow{4}{*}{$\curvearrowleft$} & Leitura & Controle & $24,26 \%$ & $36,4 \%$ & $54,6 \%$ & $81,9 \%$ \\
\hline & Inicial (I0) & 88 & 93 & 88 & 94 & 84 \\
\hline & Final (I15) & 83 & 68 & 62 & 53 & 10 \\
\hline & \multicolumn{6}{|c|}{ CE50 $=48,18(21,88-106,08)$} \\
\hline \multirow{4}{*}{$\stackrel{0}{2}$} & Leitura & Controle & $24,26 \%$ & $36,4 \%$ & $54,6 \%$ & $81,9 \%$ \\
\hline & Inicial (I0) & 98 & 95 & 88 & 91 & 84 \\
\hline & Final (I15) & 85 & 66 & 62 & 54 & 08 \\
\hline & \multicolumn{6}{|c|}{ CE50 $=51,26(17,71-148,38)$} \\
\hline
\end{tabular}

Tabela 7 - Dados brutos dos ensaios de toxicidade utilizando Vibrio fischeri das análises das águas superficiais do Rio Cubatão e seus contribuintes (afluentes) - $3^{\text {a }}$ campanha.

\begin{tabular}{|c|c|c|c|c|c|c|}
\hline \multicolumn{7}{|c|}{$3^{\text {a }}$ Campanha } \\
\hline \multicolumn{7}{|c|}{ Data dos ensaios: } \\
\hline \multirow{4}{*}{ 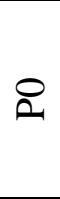 } & Leitura & Controle & $24,26 \%$ & $36,4 \%$ & $54,6 \%$ & $81,9 \%$ \\
\hline & Inicial (I0) & 93 & 89 & 99 & 97 & 94 \\
\hline & Final (I15) & 81 & 64 & 63 & 50 & 13 \\
\hline & \multicolumn{6}{|c|}{ CE50 $=50,45(28,68-88,21)$} \\
\hline \multirow{4}{*}{$\bar{a}$} & Leitura & Controle & $10,23 \%$ & $20,47 \%$ & $40,95 \%$ & $81,9 \%$ \\
\hline & Inicial (I0) & 91 & 110 & 113 & 92 & 103 \\
\hline & Final (I15) & 88 & 94 & 85 & 59 & 10 \\
\hline & \multicolumn{6}{|c|}{ CE50 = 36,48 $(15,77-84,41)$} \\
\hline \multirow{4}{*}{ 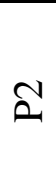 } & Leitura & Controle & $24,26 \%$ & $36,4 \%$ & $54,6 \%$ & $81,9 \%$ \\
\hline & Inicial (I0) & 92 & 86 & 80 & 76 & 72 \\
\hline & Final (I15) & 88 & 67 & 53 & 40 & 04 \\
\hline & \multicolumn{6}{|c|}{$\operatorname{CE50}=43,60(17,61-107,93)$} \\
\hline
\end{tabular}




\begin{tabular}{|c|c|c|c|c|c|c|}
\hline \multirow{4}{*}{$\hat{\rho}$} & Leitura & Controle & $20,7 \%$ & $31,6 \%$ & $46,6 \%$ & $70 \%$ \\
\hline & Inicial (I0) & 92 & 89 & 88 & 108 & 102 \\
\hline & Final (I15) & 84 & 71 & 60 & 53 & 13 \\
\hline & \multicolumn{6}{|c|}{ CE50 $=49,86(32,66-76,11)$} \\
\hline \multirow{4}{*}{$\stackrel{t}{2}$} & Leitura & Controle & $20,7 \%$ & $31,6 \%$ & $46,6 \%$ & $70 \%$ \\
\hline & Inicial (I0) & 93 & 85 & 85 & 77 & 87 \\
\hline & Final (I15) & 92 & 64 & 58 & 35 & 05 \\
\hline & \multicolumn{6}{|c|}{ CE50 = 41,21 $(18,18-93,38)$} \\
\hline \multirow{4}{*}{$\curvearrowleft$} & Leitura & Controle & $20,7 \%$ & $31,6 \%$ & $46,6 \%$ & $70 \%$ \\
\hline & Inicial (I0) & 91 & 85 & 91 & 94 & 83 \\
\hline & Final (I15) & 88 & 67 & 61 & 44 & 02 \\
\hline & \multicolumn{6}{|c|}{ CE50 = 40,78 $(13,42-123,92)$} \\
\hline \multirow{4}{*}{$\stackrel{0}{2}$} & Leitura & Controle & $20,7 \%$ & $31,6 \%$ & $46,6 \%$ & $70 \%$ \\
\hline & Inicial (I0) & 93 & 84 & 82 & 90 & 71 \\
\hline & Final (I15) & 93 & 72 & 61 & 45 & 01 \\
\hline & \multicolumn{6}{|c|}{$\mathrm{CE50}=41,41(11,01-155,75)$} \\
\hline
\end{tabular}

Tabela 8 - Dados brutos dos ensaios de toxicidade utilizando Vibrio fischeri das análises das águas superficiais do Rio Cubatão e seus contribuintes (afluentes) - $4^{\mathrm{a}}$ campanha.

\begin{tabular}{|c|c|c|c|c|c|c|}
\hline \multicolumn{7}{|c|}{$4^{\text {a }}$ Campanha } \\
\hline \multicolumn{7}{|c|}{ Data dos ensaios: Lote da bactéria: } \\
\hline \multirow{4}{*}{ 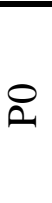 } & Leitura & Controle & $13,80 \%$ & $20,7 \%$ & $31,10 \%$ & $46,6 \%$ \\
\hline & Inicial (I0) & 93 & 89 & 87 & 85 & 92 \\
\hline & Final (I15) & 72 & 57 & 51 & 43 & 15 \\
\hline & \multicolumn{6}{|c|}{$\mathrm{CE}=47,58(26,60-85,12)$} \\
\hline \multirow{4}{*}{$\bar{a}$} & Leitura & Controle & $13,80 \%$ & $20,7 \%$ & $31,10 \%$ & $46,6 \%$ \\
\hline & Inicial (I0) & 93 & 79 & 82 & 80 & 88 \\
\hline & Final (I15) & 77 & 58 & 55 & 43 & 38 \\
\hline & \multicolumn{6}{|c|}{ CE50 $=47,80(43,74-52,24)$} \\
\hline \multirow{4}{*}{$\Sigma$} & Leitura & Controle & $13,80 \%$ & $20,7 \%$ & $31,10 \%$ & $46,6 \%$ \\
\hline & Inicial (I0) & 94 & 79 & 81 & 93 & 102 \\
\hline & Final (I15) & 78 & 55 & 51 & 56 & 44 \\
\hline & \multicolumn{6}{|c|}{ CE50 $=56,42(45,48-70,00)$} \\
\hline \multirow{4}{*}{$\tilde{\rho}$} & Leitura & Controle & $13,80 \%$ & $20,7 \%$ & $31,10 \%$ & $46,6 \%$ \\
\hline & Inicial (I0) & 113 & 102 & 95 & 89 & 93 \\
\hline & Final (I15) & 84 & 45 & 43 & 34 & 29 \\
\hline & \multicolumn{6}{|c|}{ CE50 = 31,77 $(26,72-37,78)$} \\
\hline \multirow{4}{*}{ s } & Leitura & Controle & $13,80 \%$ & $20,7 \%$ & $31,10 \%$ & $46,6 \%$ \\
\hline & Inicial (I0) & 96 & 89 & 104 & 99 & 98 \\
\hline & Final (I15) & 80 & 62 & 71 & 52 & 38 \\
\hline & \multicolumn{6}{|c|}{ CE50 $=44,93(34,32-58,84)$} \\
\hline \multirow{4}{*}{$\curvearrowleft$} & Leitura & Controle & $13,80 \%$ & $20,7 \%$ & $31,10 \%$ & $46,6 \%$ \\
\hline & Inicial (I0) & 93 & 96 & 105 & 82 & 93 \\
\hline & Final (I15) & 80 & 69 & 74 & 54 & 41 \\
\hline & \multicolumn{6}{|c|}{$\mathrm{CE50}=61,00(42,00-88,57)$} \\
\hline
\end{tabular}




\begin{tabular}{|c|c|c|c|c|c|c|}
\hline \multirow{4}{*}{ ڤ } & Leitura & Controle & $13,80 \%$ & $20,7 \%$ & $31,10 \%$ & $46,6 \%$ \\
\hline & Inicial (I0) & 94 & 97 & 85 & 82 & 77 \\
\hline & Final (I15) & 60 & 51 & 39 & 29 & 14 \\
\hline & \multicolumn{6}{|c|}{ CE50 = 31,26 $(21,93-44,57)$} \\
\hline \multirow{4}{*}{$\overline{\mathbf{a}}$} & Leitura & Controle & $13,80 \%$ & $20,7 \%$ & $31,10 \%$ & $46,6 \%$ \\
\hline & Inicial (I0) & 93 & 96 & 91 & 93 & 82 \\
\hline & Final (I15) & 79 & 74 & 62 & 55 & 34 \\
\hline & \multicolumn{6}{|c|}{ CE50 = 27,77 $(24,71-31,10)$} \\
\hline \multirow{4}{*}{$\frac{1}{2}$} & Leitura & Controle & $13,80 \%$ & $20,7 \%$ & $31,10 \%$ & $46,6 \%$ \\
\hline & Inicial (I0) & 96 & 101 & 108 & 97 & 89 \\
\hline & Final (I15) & 61 & 53 & 55 & 37 & 18 \\
\hline & \multicolumn{6}{|c|}{ CE50 = 35,37 $(24,41-51,26)$} \\
\hline
\end{tabular}

Tabela 9 - Dados brutos dos ensaios de toxicidade utilizando Vibrio fischeri das análises das águas superficiais do Rio Cubatão e seus contribuintes (afluentes) - $5^{\text {a }}$ campanha.

\begin{tabular}{|c|c|c|c|c|c|c|}
\hline \multicolumn{7}{|c|}{$5^{\text {a }}$ Campanha } \\
\hline \multicolumn{7}{|c|}{ Data dos ensaios: 14/02/2011 Lote da bactéria: 65 Ly005 } \\
\hline \multirow{4}{*}{ 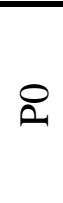 } & Leitura & Controle & $20,7 \%$ & $31,6 \%$ & $46,6 \%$ & $70 \%$ \\
\hline & Inicial (I0) & 92 & 109 & 91 & 86 & 87 \\
\hline & Final (I15) & 115 & 101 & 75 & 50 & 12 \\
\hline & \multicolumn{6}{|c|}{ CE50 = 36,33 $(20,47-64,48)$} \\
\hline \multirow{4}{*}{$\bar{a}$} & Leitura & Controle & $20,7 \%$ & $31,6 \%$ & $46,6 \%$ & $70 \%$ \\
\hline & Inicial (I0) & 107 & 105 & 95 & 104 & 95 \\
\hline & Final (I15) & 122 & 86 & 67 & 65 & 17 \\
\hline & \multicolumn{6}{|c|}{ CE50 = 37,90 $(21,28-67,51)$} \\
\hline \multirow{4}{*}{$\mathfrak{L}$} & Leitura & Controle & $20,7 \%$ & $31,6 \%$ & $46,6 \%$ & $70 \%$ \\
\hline & Inicial (I0) & 95 & 88 & 83 & 97 & 76 \\
\hline & Final (I15) & 104 & 76 & 66 & 64 & 17 \\
\hline & \multicolumn{6}{|c|}{ CE50 $=45,08(25,81-78,73)$} \\
\hline \multirow{4}{*}{ 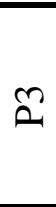 } & Leitura & Controle & $20,7 \%$ & $31,6 \%$ & $46,6 \%$ & $70 \%$ \\
\hline & Inicial (I0) & 83 & 65 & 66 & 88 & 67 \\
\hline & Final (I15) & 91 & 52 & 48 & 45 & 15 \\
\hline & \multicolumn{6}{|c|}{$\mathrm{CE50}=39,11(27,97-54,68)$} \\
\hline \multirow{4}{*}{ L } & Leitura & Controle & $20,7 \%$ & $31,6 \%$ & $46,6 \%$ & $70 \%$ \\
\hline & Inicial (I0) & 93 & 102 & 91 & 88 & 67 \\
\hline & Final (I15) & 107 & 88 & 68 & 45 & 15 \\
\hline & \multicolumn{6}{|c|}{ CE50 = 35,66 $(18,46-68,87)$} \\
\hline \multirow{4}{*}{$\check{n}$} & Leitura & Controle & $20,7 \%$ & $31,6 \%$ & $46,6 \%$ & $70 \%$ \\
\hline & Inicial (I0) & 94 & 93 & 94 & 91 & 98 \\
\hline & Final (I15) & 106 & 80 & 69 & 32 & 16 \\
\hline & \multicolumn{6}{|c|}{ CE50 $=35,40(26,68-46,97)$} \\
\hline \multirow{4}{*}{$\stackrel{0}{2}$} & Leitura & Controle & $20,7 \%$ & $31,6 \%$ & $46,6 \%$ & $70 \%$ \\
\hline & Inicial (I0) & 91 & 71 & 117 & 81 & 76 \\
\hline & Final (I15) & 104 & 69 & 66 & 38 & 05 \\
\hline & \multicolumn{6}{|c|}{ CE50 = 34,43 $(19,08-62,10)$} \\
\hline
\end{tabular}




\begin{tabular}{|c|c|c|c|c|c|c|}
\hline \multirow{4}{*}{$\bar{a}$} & Leitura & Controle & $20,7 \%$ & $31,6 \%$ & $46,6 \%$ & $70 \%$ \\
\hline & Inicial (I0) & 90 & 94 & 105 & 92 & 96 \\
\hline & Final (I15) & 110 & 88 & 84 & 54 & 08 \\
\hline & \multicolumn{6}{|c|}{ CE50 = 36,73 $(20,39-66,14)$} \\
\hline \multirow{4}{*}{ 壳 } & Leitura & Controle & $20,7 \%$ & $31,6 \%$ & $46,6 \%$ & $70 \%$ \\
\hline & Inicial (I0) & 97 & 94 & 86 & 91 & 84 \\
\hline & Final (I15) & 116 & 83 & 63 & 48 & 03 \\
\hline & \multicolumn{6}{|c|}{ CE50 = 32,64 $(11,67-91,24)$} \\
\hline
\end{tabular}

